Florida International University FIU Digital Commons

3-23-2009

\title{
The Experiences of Cuban American Women Attending a Hispanic Serving Institution and the Influences on Identity Development
}

Veronica Lynn Owles

Florida International University, owlesv@hotmail.com

DOI: $10.25148 /$ etd.FI10022538

Follow this and additional works at: https://digitalcommons.fiu.edu/etd

\section{Recommended Citation}

Owles, Veronica Lynn, "The Experiences of Cuban American Women Attending a Hispanic Serving Institution and the Influences on Identity Development" (2009). FIU Electronic Theses and Dissertations. 209.

https://digitalcommons.fiu.edu/etd/209 


\section{FLORIDA INTERNATIONAL UNIVERSITY}

Miami, Florida

THE EXPERIENCES OF CUBAN AMERICAN WOMEN ATTENDING A HISPANIC SERVING INSTITUTION AND THE INFLUENCES ON IDENTITY

DEVELOPMENT

A dissertation submitted in partial fulfillment of the

requirements for the degree of

DOCTOR OF EDUCATION

in

HIGHER EDUCATION

by

Veronica Owles

2009 
To: Interim Dean Kingsley Banya

College of Education

This dissertation, written by Veronica Owles, and entitled The Experiences of Cuban American Women Attending a Hispanic Serving Institution and the Influences on Identity Development, having been approved in respect to style and intellectual content, is referred to you for judgment.

We have read this dissertation and recommend that it be approved.

Roger Geertz-Gonzalez

Aurora Morcillo

Janice Sandiford

Glenda Droogsma Musoba, Major Professor

Date of Defense: March 23, 2009

The dissertation of Veronica Owles is approved.

$\begin{array}{r}\hline \begin{array}{r}\text { Interim Dean Kingsley Banya } \\ \text { College of Education }\end{array} \\ \hline \begin{array}{r}\text { Dean George Walker } \\ \text { University Graduate School }\end{array}\end{array}$

Florida International University, 2009 
(C) Copyright 2009 by Veronica Owles

All rights reserved. 


\section{DEDICATION}

Dedicated to my mother, Cheryl Decker and my father, Bob Owles, both who believed in my dreams and always inspired me to be the best person I can be. Thank you for your love and support. I love you both very much. 


\section{ACKNOWLEDGMENTS}

Far away in the sunshine are my highest aspirations. I may not reach them, but I can look up and see their beauty, believe in them, and try to follow where they lead. - Louisa May Alcott

Years ago, when I first embarked on this journey, I put that quote on my graduate school application as part of my personal statement. Now, I would like to thank all those who helped me reach my goal on this journey. I would like to first thank my wonderful faculty committee who guided and supported me throughout this process: my major professor Glenda Droogsma Musoba, and committee members Janice Sandiford, Roger

Geertz Gonzalez, and Aurora Morcillo. A special thank you to Dr. Musoba for your time, expertise, support, and amazing feedback, but most of all for your sense of humor and knowing just what to say, which always helped me refocus and see that an end was in sight. I will always be grateful for our chance meeting that introduced us. Dr. Sandiford, thank you for your guidance and support starting from my early days in your class. Dr. Gonzalez, thank you for always sharing your expertise about Cuban students with me. Dr. Morcillo, thank you for sharing your wonderful insights about gender studies, it only strengthened my commitment to do the best study.

I would also want to thank my supervisors, Craig Cunningham and Dr. Cathy Akens for supporting my academic endeavors and allowing me the time to complete this task. To Dr. Jones and Dr. Ellison, a special thank you for always encouraging me and checking in on my progress. To my friend Suzanne Onorato, thank you for being my Peer Reviewer. I can think of no one else that I would have asked to help me achieve this goal. A special thank you to my Student and Academic Affairs family from the beautiful 
Biscayne Bay Campus and University Park, as well as my many students and my lifelong friends; there were so many of you that invested interest in my progress and encouraged me during the long days and nights of the writing process. Thank you all for those kind words, phone calls, emails, and Facebook messages of support that motivated me to completion.

To the women who served as participants in this study, thank you for sharing your time and your stories. Your words inspired me and your stories moved me. You all are amazing women and it was truly my pleasure to meet you and begin to understand what it means to be a Cuban American woman.

Finally, I would like to thank my parents, who are and always will be my biggest cheerleaders. Thank you for your support and your love. From Eat, Pray, Love by Elizabeth Gilbert,

"In the end, though, maybe we must give up trying to pay back the people in this world who sustain our lives. In the end, maybe it's wiser to surrender before the miraculous scope of human generosity and to just keep saying thank you, forever and sincerely, for as long as we have voices." 


\section{ABSTRACT OF THE DISSERTATION \\ THE EXPERIENCES OF CUBAN AMERICAN WOMEN ATTENDING A HISPANIC SERVING INSTITUTION AND THE INFLUENCES ON IDENTITY \\ DEVELOPMENT}

by

Veronica Owles

Florida International University, 2009

Miami, Florida

\section{Professor Glenda Droogsma Musoba, Major Professor}

The purpose of this study was to gain an understanding and gather insight into the experiences of Cuban American women attending a 4-year, public, Hispanic Serving Institution and how those experiences influenced their identity development. This was accomplished by conducting in-depth interviews and focus groups with 12 self-identified Cuban American women who were classified as sophomores, juniors, seniors, or graduate students. All of the participants had attended Florida International University for at least 1 year. The women had varying degrees of on and off campus academic and campus involvement activities.

Participants were asked about six topics: (a) family, (b) cultural influences, (c) gender, (d) ethical and moral development, (e) education, and (f) ethnic identity. Based on the coding of the data provided by the participants, several interconnected themes emerged including the importance of family, familial support, cultural pride, expected gender roles, core values, decision making, biculturalism, and the value of attending a 
Hispanic Serving Institution. These themes were found to be all related to the identity development of the participants.

It was found that looking at identity through a multidimensional lens is essential. Looking at personal growth and development through anthropological, sociological, and psychosocial lenses gave greater insight to a population of students who have been largely underrepresented in the literature. The findings of this case study are that culture is contextual and identity development is complex for first and second generation Cuban American women attending a Hispanic Serving Institution in a majority minority city. It was found that several factors, including the importance of family and gender roles, were not found to be more important than one another; rather they supported each other in regards to the participants' identity development. The notion of biculturalism as it has been presented in the literature was challenged in this study as it was found that the participants' experiences living and attending a school in a majority minority city presented a new way of understanding what it might mean to be bicultural. For professionals in the field, the findings of this study may lead to a broader understanding of nuances within the Hispanic community and a better understanding of the distinctiveness of what it means to be a Cuban American woman. 


\section{TABLE OF CONTENTS}

\section{CHAPTER}

I. INTRODUCTION 1

Purpose of the Study and Research Questions 4

Rationale/Contributions to Theory and Practice 5

Women and Diversity in Higher Education $\quad 6$

Latinas in Higher Education $\quad 7$

Theoretical Framework and Delimitations $\quad 13$

$\begin{array}{ll}\text { Definitions } & 14\end{array}$

$\begin{array}{ll}\text { Organization of the Manuscript } & 17\end{array}$

II. $\quad$ REVIEW OF THE LITERATURE 19

Cubans in Miami: An Overview of Cuban Migration and Demographics 20

Theories of Student Development and Racial, Ethnic, and Gender Identity

Development 25

Tanaka: Intercultural Theory $\quad 27$

Gender Identity and Moral Development of Women 29

Josselson: Women's Identity Development Theory 29

Gilligan: Psychological and Moral Development Theory 31

Jones: Multiple Dimension of Identity Development Model 32

Racial and Ethnic Identity Development and Hispanic Students 34

Ferdman and Gallegos: Latino and Latina Racial Identity Orientation

Model 36

Keefe and Padilla: Mexican American Ethnic Orientation Model 37

Torres: Bicultural Model 39

Racial Composition on Campus and Identity Development 42

Ethnicity and Identity Development of Cuban American College Students

Attending a Hispanic Serving Institution $\quad 46$

Critique and Conclusions $\quad 49$

III. METHODS 52

Qualitative Inquiry $\quad 53$

The Case Study Method 53

Rationale for Using Qualitative Inquiry $\quad 54$

Role of the Researcher $\quad 55$

Pilot Study $\quad 57$

Data Collection $\quad 59$

Participants $\quad 59$

$\begin{array}{ll}\text { Procedure } & 60\end{array}$

Interviews $\quad 64$

$\begin{array}{ll}\text { Data Analysis } & 68\end{array}$ 
$\begin{array}{lll}\text { IV. PRESENTATION OF THE DATA } & 73\end{array}$

$\begin{array}{ll}\text { The Setting } & 73\end{array}$

$\begin{array}{ll}\text { Participants } & 74\end{array}$

$\begin{array}{ll}\text { Blair } & 74\end{array}$

$\begin{array}{ll}\text { Carmen } & 76\end{array}$

$\begin{array}{ll}\text { Carolina } & 78\end{array}$

$\begin{array}{ll}\text { Isabella } & 79\end{array}$

$\begin{array}{lr}\text { Jacqui } & 81\end{array}$

$\begin{array}{ll}\text { Luz } & 83\end{array}$

Michelle $\quad 85$

Miette $\quad 86$

$\begin{array}{lr}\text { Natalie } & 88\end{array}$

Sarah $\quad 89$

$\begin{array}{lr}\text { Sofia } & 91\end{array}$

Tiffany 93

$\begin{array}{lr}\text { Themes } & 95\end{array}$

Family 100

Cultural Influences 107

Ethical and Moral Development 131

Gender 142

Education $\quad 160$

Ethnic Identity 178

$\begin{array}{lr}\text { Summary } & 190\end{array}$

V. $\quad$ FINDINGS AND RECOMMENDATIONS 193

Summary of the Study 193

Research Questions $\quad 195$

$\begin{array}{ll}\text { Conclusions } & 210\end{array}$

$\begin{array}{ll}\text { Recommendations } & 216\end{array}$

Recommendations for Research 216

Recommendations for Practice 218

$\begin{array}{ll}\text { REFERENCES } & 221\end{array}$

$\begin{array}{ll}\text { APPENDICES } & 227\end{array}$

$\begin{array}{lr}\text { VITA } & 232\end{array}$ 


\section{CHAPTER I}

\section{INTRODUCTION}

Diversity at colleges and universities is the fundamental factor practitioners in higher education must be willing to understand in order for students of color to be successful in college. For many years, diversity has been a buzzword. Diversity training, seminars, lectures, and resources have all become a standard way of learning about our underrepresented students. Receiving the most recognition as underrepresented groups in higher education in the United States are African American, Native American, and Hispanic students (Komives \& Woodward, 2003). By the year 2010, students of color will make up $24 \%$ of the under-18 population in the United States (Hurtado, Milem, Clayton-Pederson, \& Allen, 1999). In states such as California, Florida, and New York, this number may be as high as 50\%. According to Komives and Woodward (2003), enrollment has increased for these groups from 2.1 million in 1982 to 4 million in 1999. In spite of this growing diversity much of our understanding of students' identity development is grounded in psychologically based and predominantly White identity models. Although much progress has been made, a more critical lens is needed to understand diverse student population.

Hispanic students, as it has been documented by the 1999 U.S. Census Bureau, are the largest and fastest growing minority population in the United States, constituting $11.5 \%$ of the population and one third of the minority population in the U.S. (Santos, 2004; Wijeyesinghe \& Jackson, 2001). This growing population of students will constitute $15.4 \%$ of the college population by the year 2015 . If current enrollment patterns continue, community colleges will feel the impact and presence of this minority 
group on their college campuses around the country. Enrollment of minority students since 1960 has greatly increased, and issues of cultural diversity came to the forefront in the community college. According to Castellanos and Jones (1997), enrollment for Latinos in college has more than doubled in the past 20 years. In the late 80 s and early 90s enrollment of students of color increased over $35 \%$ at community colleges as compared to their 4-year college counterparts at 29\% (Laden, 1998). The issue is not only about enrollment but also the low rates of degree attainment, which are not in accordance with the numbers (Bliss \& Sandiford, 2003). Hispanic students are not completing college at rates similar to majority students. According to the U.S. Department of Commerce, only $11 \%$ of Latinos earned a bachelor's degree as compared to $27.8 \%$ of all adults ages 25 to 29 (Castellanos \& Jones, 2003).

There are currently 203 Hispanic Serving Institutions (HSI) located in 12 states and Puerto Rico that serve over $46 \%$ of the Hispanic (full time equivalent) population currently attending college (Komives \& Woodward, 2003). According to these authors, HSIs are not only motivated by a guiding mission similar to the Historically Black Colleges and Universities (HBCU) but also by student enrollments. By definition, an HSI is characterized by at least $25 \%$ of the enrollment being students of Hispanic or Latin ethnicity (Gardner \& Sandra, 2003; Wolf-Wendel, 1998). Hispanic enrollment accounted for $42 \%$ of the total enrollment in HSIs in 2003, up from 29\% in 1990 (National Center for Educational Statistics, 2006; Wolf-Wendel, 1998).

Frequently students attending an HSI are first generation students living in urban settings and are from low-income households (Hamrick, Evans, \& Schuh, 2002). The majority of these HSI institutions, $68 \%$, are public. These institutions have had a steady 
increase in overall enrollment, and the increase in enrollment of Hispanic students has grown along with it (Rendón \& Hope, 1996). With over 5,000 colleges and universities and the anticipation that this subpopulation will soon constitute $15 \%$ of the college and university population in the United States, little attention has been paid to this quickly growing population as it relates to the HSI. It is important to understand the role HSIs play in student development because it can serve to help students develop and mature at that institution.

It is important to note that while this study is being conducted at an HSI, it is not the HSI that is being examined. This study focuses on the experiences of Cuban American Women at an HSI and the influences on their identity development. Their attendance at an HSI is just one aspect of their identity development that is being examined. It is one intention of this study to find out whether or not the role of the HSI is a factor and to what degree, but the focus is on the experiences of these women and not the particular setting in which the study takes place.

The classification Hispanic includes people with a shared language but fails to recognize the diversity of cultures, values, experiences, and incomes. The lack of understanding of the ethnic, racial, and cultural diversity among Hispanics tends to exclude or bury the Cuban American population who constitute 4\% of all Hispanic students (Torres, 2004b). This void is particularly true of Cuban American women. Several of the more recent higher education studies have looked at Latino populations but more work needs to be done. For instance, Ceja (2004) considered the academic success of a group of Chicana students and Geertz Gonzalez (2008) specifically examined civic engagement of Cuban American and non-Hispanic White students at an HSI. 
Additionally, Geertz Gonzalez (2007a, 2007b) did two follow up studies respectively examining the ethnic identity and spiritual beliefs of Cuban American students and nonHispanic Whites attending that same HSI using an anthropological and sociological lens. These subgroup specific studies clearly suggest differences among Latinos based on national origin. Taking into consideration the distinctive experiences of Cuban Americans in the United States, more research is needed, including gender, which considers the subpopulations distinctively.

Purpose of the Study and Research Questions

The primary purpose of this research was to develop an understanding of the unique experiences of Cuban American women attending a 4-year HSI and the influences of these experiences on their identity development. By examining several current racial, ethnic, and gender identity models, my intention through a qualitative case study was to determine whether or not these models are applicable to Cuban American women students at an HSI. Through the use of semi-structured interviews, students were asked to describe their personal experiences, thoughts, and attitudes about being Cuban American women students at an HSI.

Several questions guided this research: (a) What are the personal narratives of Cuban American women as they describe their identity development while attending a 4year HSI? (b) Do the women speak of cultural influences or personal factors as important to their identity development? (c) Do Torres's (1999) bicultural or Josselson's (1987) gender identity models adequately summarize the complexity of these women's experiences or is a multidimensional model more appropriate? 


\section{Rationale/Contributions to Theory and Practice}

One of the greatest limitations and problems faced when exploring the identity issues relating to minority populations is the lack of research information. Alexander Astin (1978), a well-respected author and researcher in the field of student affairs, has spent the last 30 years of his career collecting data to better understand how college affects students. Astin has collected longitudinal data from over 200,000 college students in 30 institutions covering such factors as attitudes, values, self-concepts, behavior, competency, achievement, career development, and satisfaction in college. The data represent large, small, public, private, selective, nonselective, 2-year, 4-year, single sex, coeducational, predominantly White, historically Black, religious, secular, residential, and commuter institutions. Missing from this equation is identified research on the HSIs.

As the face of higher education changes, it is imperative that colleges and universities begin to assess the services and support systems that are in place to ensure success of minority students in their psychosocial and intellectual development (Akens, 2001). For faculty and staff to have a true understanding of this connectedness of how behavior is shaped by outside influences, it is important to have an understanding of the racial and identity development models of those considered non majority (Torres, Howard-Hamilton, \& Cooper, 2003). This requires a recognition that identity development models currently accepted by practitioners be examined critically to assess whether they are applicable to minority students. It is evident that research theories and identity development models have been geared toward majority students. In addition, much of the research on minority students appears to chronicle the experiences of 
minority students at predominantly majority institutions (i.e., predominantly White institutions), as will be discussed in the subsequent section.

There is very little information on college students attending an HSI. As a student affairs practitioner working at an HSI, I am often concerned with the lack of overall research and interest in the fastest growing population in the United States, Latinos/as. This study provides insights and meaning about the college experiences of this understudied population. Examining the factors of identity development of Cuban Americans women attending an HSI is important because there is little research with this focus. By obscuring the differences among Hispanics, administrators are left treating all Hispanics the same. In the U.S., according to Wijeyesinghe and Jackson (2001), the subgroups of Latinos that were classified by the U.S. Census Bureau (1998) are Mexican Americans (63.3\%), Puerto Ricans (10.6\%), Cubans (4.2\%), Central and South Americans (14.4\%), and other Hispanics (7.4\%). Researchers have spent more time examining identity development of the Hispanic population as a whole, primarily with Mexican American and Puerto Rican groups, with justifiable reason since together they constitute over $73 \%$ of the Latino population in the U.S. (Torres, 2004a).

\section{Women and Diversity in Higher Education}

Women, in general, are more likely to persist to graduation with a baccalaureate degree than their male counterparts. According to the National Center for Education Statistics (2006), women earned more than half of the bachelor's degree awarded in 2001. Proportionally, Black and Hispanic women earned $66 \%$ and $60 \%$ respectively of the degrees awarded to members of their ethnic and racial groups, which was higher statistically than the proportion among Whites. Wolf-Wendel (1998) examined what 
made each of these groups of women successful based on race/ethnicity and type of institution each group attended. Additionally, the Wolf-Wendel wanted to know what institutional factors were associated with their success. It is not the results of the study that were as interesting as the implications stated by the author.

It was clear Wolf-Wendel (1998) believed separate analyses needed to be done by racial/ethnic makeup because of the number of European American women involved in the study. Wolf-Wendel also stated there was a clear benefit to each of these ethnic groups from attending institutions with others of like background. This is based on the premise that students flourish in environments where they feel supported and welcomed. In a different study, Poindexter-Cameron and Robinson (1997) state this is not to say that a Predominantly White Institution (PWI) cannot provide this; however, special focus environments/institutions provide a place where emphasis is placed on attaining educational achievements and the women reported there were academic support, social activities, faculty support, extracurricular activities, and social networks, which fostered growth.

\section{Latinas in Higher Education}

By all accounts, the literature and research about Hispanic students is limited. Additionally, research has focused primarily on the Mexican American and Puerto Rican college student population, with little mention of Cuban American students. Even less has been focused on female Hispanic students, with gender differences having been largely ignored in the literature, leading to a lack of understanding and knowledge (Rodriguez, Guido-DiBrito, \& Torres, 2000). The purpose of this section is to examine those factors that are unique to Latina students and set the stage for a better understanding of those 
factors that are similar and those that are different for Cuban American women's college student experiences. An examination by Rodriguez et al. (2000) of Latina college students focused on areas that helped fill the void of understanding for this much understudied group of students. The findings emphasized the lack of knowledge on the experiences of Latina students by assessing the issues of the lack of research in the student affairs literature and the difficulty of understanding the cultural differences of ethnic populations. Additionally, Rodriguez et al. examined common barriers that Latina college students experience in higher education settings as well as strategies and ways to promote the success of this particular population.

Although the findings suggest that there are common threads of the information, such as biculturalism and bilingualism, presented about other underrepresented groups, the focus of Rodriguez et al. (2000) was Mexican American and Chicana that comprise 64.3\% of the entire Latino population. Despite the lack of research on women, one thing is clear about this population. The issue of labeling is a sensitive area when the discussion of cultural identity is presented but it must be addressed. Researchers in general have chosen to use the term Hispanic to describe most students in the literature, avoiding labels such as Chicano/a. Hispanic is not the word of choice for all groups; consequently, the term Latina was used by Rodriquez et al. because the study was based on the level of acceptability to the group being discussed. Confusing as it may appear, issues such as labeling have a profound effect on those being discussed.

According to Rodriquez et al. (2000), although the issue of labeling is disturbing, equally problematic is the fact that most research about Hispanic students can be found not in primary and commonly used student affairs journals but in counseling journals. 
This fact wrongly legitimizes the idea that Latina students are mainly dealing with psychological or emotional issues or that Latina identity is a problem that needs to be addressed. The importance of this issue was examined as part of my research.

What does it mean to be a Cuban American woman and is there importance to that in relation to the identity development of the women being interviewed for the study? The term Hispanic is general and envelopes many cultures, so I sought to make a distinction of what it means to be a Cuban female residing in Miami and attending an HSI.

The more pressing and real issues for Chicano/a students related to their enrollment and persistence are concerned with four main types of stress: familial obligations and expectations, lack of financial support, academic issues, and gender-role stereotyping (Dayton, Gonzalez-Vasquez, \& Martinez, 2004; Rodriguez et al., 2000). In addition to complexities within the educational setting, many Latina students experience even more within the family units. Latina women, according to Rodriguez et al. (2000), attend college more than Latino men; however, fewer Latina women attend college than women from other ethnic and racial groups. They also report that there are two main factors: the decision to attend or not attend college and whether or not the Latina student is expected to stay close to home.

Stress levels of Latina students, like of most college students, are exacerbated by financial concerns; however, the financial need may be greater because of the lack of family financial support that jeopardizes academic persistence (Rodriguez et al., 2000). Chicano students rarely expect family financial contributions as families struggle in everyday life. This stress is even greater for Chicana students as they also struggle with 
insecure feelings of academic preparation. Some parents are ambivalent about their children's academic goals, which often lead to conflicts. Female students are left with feelings of confusion about reaching educational goals versus meeting family expectations (Rodriguez et al., 2000). Educational aspirations can also be jeopardized, especially for first generation students, if their families expect them to live at or close to home. Latina students, unlike their male counterparts, are also expected to engage in helping their families with household obligations. All of this has an impact on their program progress (Rodriguez et al., 2000).

Cultural stereotyping of Mexican American females, due to their often low socioeconomic status, brings about assertions around the idea of cultural capital. Cultural capital, while much broader, does include a societal belief system with attitudes and perceptions towards education (Lozano, 2000). Lozano believes that working class Latino youth attending predominantly White schools have the intellectual capacity, yet they receive mixed messages within the school system about their ability to succeed and persist. This, in turn, leads to the valuing of the students' abilities yet devaluing their cultural knowledge. In essence, students who demonstrate "appropriate" cultural capital are promoted within the school system perpetuating social inequality (Rodriguez et al., 2000). The valued cultural capital is usually associated with being White and wealthy, and these values may conflict with the values of Latino families.

Educational aspirations tend to take a back seat to family obligations. Historically, some Latino families believe that women should be more focused on marrying and raising families (Dayton, 2004; Gonzalez, Jovel, \& Stoner, 2004). Lozano (2000) asserts this cultural belief is at odds with female students' degree attainment. In particular, first 
generation college students, especially females living at home (or close to home), are constantly challenged to find the balance between familial obligations and schoolwork. Often times, parents are very supportive of their children's academic endeavors, but not at the expense of familial obligations. The lack of understanding of academic expectations and university culture from the family may compromise academic achievements with this particular population (Dayton et al., 2004; Rodriguez et al., 2000).

As the presence of Latinas in higher education continues to grow, it is important to understand the dynamic of what happens to the student who challenges the family culture and leaves home to attend a college or university. Gonzalez, Jovel, and Stoner (2004) examined the challenges and sacrifices of Latina (Mexican) students who chose to leave home for the opportunity to seek a degree. The women were from low to middle socioeconomic status families and came from working class homes in California. The researchers interviewed two different groups of women: (a) 12 who were given the opportunity to attend two highly selective national universities and (b) 10 who were attending a local community college but later transferred to a national university.

Although these women's challenges and sacrifices were extensive, Gonzalez, et al. (2004) focused on the challenges the women faced after being admitted. Admittedly, the biggest hurdle for these women attending the selective university was defying the family expectation to live at home and attend college. Obtaining a certain sense of independence was important to these women, yet most were aware of the contradictory feelings their parents had. The students agreed that their parents understood that the opportunities were much better for them on campus; however, it was the parental concern 
for their welfare that worried them the most. Not being married, not living at home, and not being taken care of by family, parents, or spouse made parents apprehensive at best.

The only way for these women to leave home unmarried was to attend college, and even this caused discomfort to the families (Gonzalez et al., 2004). Many of the women shared these sentiments as well as some emotional guilt about their decisions. Three of the participants had older siblings who had attended college and who were able to serve as their advocates reassuring the parents on their welfare. One of the few things that seemed to ease the apprehensions of the parents was the knowledge that there was a support network of other Latinas on campus.

Ironically, this new found independence came with bouts of homesickness (Gonzalez et al., 2004). For some of the students, leaving home was not as difficult as staying away. Familial bonds, cultural ties, losing contacts with immediate family members, and homesickness challenged these women throughout their academic career. Most students stated an expectation from their parents to return home after they graduated; however, if they decided not to, they felt their parents would be supportive regardless.

On the contrary, some Latina students face familial barriers because they chose to live at home. While the parents and custodians are supportive, there are still expectations that children should contribute to the family financially. Often Latina students also have the expectation that they will live at home until they are married and help with family obligations such as raising younger siblings (McGlynn \& Provitera, 2003). In regards to Latina students' persistence, it is important to keep in mind that as these students progress through college, they may be experiencing some constant discontent. 
This study is important to understanding the basic premise of personal development. Because there is a break with cultural tradition if a Latina chooses to leave home, understanding the challenges that such a student faces is important. Understanding the motivations of these students and their reasons for attending college is important to their academic success (McGlynn \& Provitera, 2003; Santos, 2004).

McGlynn and Provitera (2003) attempted to understand what these challenges were through interviews. The key limitation of the study is the lack of women who claim their ethnicity as Hispanic from backgrounds other than Mexican. As the number of Latinas increase, this investigational study provides future researchers with a good basis for studying different groups of women. By doing that, there could be a broader understanding of whether these issues of persistence and personal development cross subgroup backgrounds among young female Hispanic students.

\section{Theoretical Framework and Delimitations}

This study examined ethnic identity and gender identity development models and whether they accurately describe the experiences of Cuban American women college students attending an HSI. Much of higher education research focuses on minority students" experiences as the "other" at predominantly White institutions. This study examines the experience of Cuban women in a context where their culture is prevalent, even if not necessarily dominant. Although much of this same rationale would be true of Cuban American men, they are outside the scope of this study. Further delimitations of this study are that this is a bounded case study conducted at an HSI in Miami, Florida, with women who self-identified themselves as Cuban American. 
Most research on Hispanic populations reflects a co-educational voice. Looking at gender as a component adds to the value of the study due to a distinction between the cultural treatment of Hispanic men and women and due to many stereotypes about gender roles among Hispanics that may or may not be true of Cuban women (A. Morcillo, personal communication, November 5, 2007).

I provide an understanding from Cuban female students' perspectives, which are missing in the research. As student affairs practitioners and other members of academia continue to develop a better understanding of diverse student populations, developing an understanding of this perspective from several theoretical lenses including, psychological, sociological, and anthropological, becomes important for a comprehensive picture to be painted of this particular group of students. This study was designated to provide a better appreciation of students' experiences at a majority minority institution, such as an HSI. This study moves beyond the traditional models and theories of identity development reviewed in chapter 2 that tend to categorize identity by gender, ethnicity, and cultural as single dimensions. The purpose is to see if there is a more reflective way of better understanding of this population of students from a core identity development that share multiple dimensions.

\section{Definitions}

For the purposes of this study and to accurately reflect the research as it was presented, I decided to quote the authors as they used the terms Hispanic, Latino/a, and Chicano throughout the review of the literature. There is perplexity about the terms, as often times the terms Latino/a and Hispanic are used interchangeably, both with the research participants and with the current literature on this population of students. 
Catellanos and Jones (2003) have provided historical definitions that can help the reader discern the difference in the terms as they are generally used in society today and throughout this research study. The literature review reflects various terms as the participants were labeled; however, for my reporting, I chose to use the term Hispanic to reflect the participants and their voices. When I am specifically speaking of Cuban students, then I identify them by their subgroup.

Hispanic. Introduced by the Office of Budget Management in 1978, the term Hispanic was created as an ethnic category that included persons of Mexican, Puerto Rican, Cuban, Central American, South American, or other Spanish origins (Castellanos \& Jones, 2003). This label refers to, ...various populations that are bound by a common ancestral language and cultural characteristics but that are vastly different in immigrant history and settlement in the United States. (p. xx)

Latino/a. The term Latino was introduced in 1987 by Hayes-Bautista and Chapa to identify persons residing in the United States whose ancestors are from Latin American countries in the Western Hemisphere. Included are persons from Latin America who do not necessarily share the Spanish language e.g., those of Brazilian ancestry (Castellanos \& Jones, 2003).

Chicano/a: This term, meant for Mexican Americans, reflects the dual heritage and mixed culture. According to Castellanos and Jones (2003),

The term emphasizes the importance of equal American rights, and some Mexican Americans used the word to relate their cultural and political struggles. From a historical perspective, this term also recognizes the struggle of the Mexican Aztecs' quest to survive during the Spanish conquest. (p. xx) 
Mexican American: Based on personal communication with Geertz Gonzalez (2008), "Chicana/o emerged out of the 60s whereby Americans of Mexican descent started to acknowledge their indigenous heritage/background and rejected the term Mexican American. For example, in New Mexico, Americans of Mexican descent acknowledge themselves as direct ancestors of the Conquistadors and thus rejects both Mexican American and most definitely Chicana/o; they call themselves Hispanos and form a part of the elite in New Mexico." Gloria Anzaldúa, a feminist and gender theorist has challenged anthropologists to reconsider the conceptual boundaries by which they classify humans by what she calls a hybrid consciousness (Grant, 2008). While some anthropologists have examined how the border defines the human relationship, Anzaldua "metaphorically associated the border with the internal and interpersonal boundaries of race, language, and gender" (p.12) and claims those who colonized straddle multiple identities to survive.

Hispanic and Latino are controversial terms in the context that they are used. As stated earlier, both terms are used interchangeably by some, yet many groups or individuals reject the term Hispanic because it is too broad, and many Latinos feel that is was applied to them without consent. Castellanos and Jones (2003) discuss the cultural perspective giving some explanation as to the differences,

...many have argued in history that the term Hispanic does not acknowledge the heterogeneity in the Latino group. On the other hand, in certain regions, you will find Latinos who prefer the term Latino over Hispanic indicating that Latino is even more sensitive to people with mestizo background and not Spanish heritage. The term most often used by government agencies and the media is Hispanic. (p. $\mathrm{xx})$ 
Acculturation: As defined by Walker et al. (2008), acculturation is, "a complex, psychosocial phenomenon that involves individual and group-level changes in cultural patterns for ethnic minorities as a consequence of contact with the ethnic majority. (p.72)" Defining and understanding the meaning of acculturation helps to understand the complexities of discussing issues of biculturalism with these participants.

Identity development: As defined by clinical psychologist, Erik Erikson, identity development is "the internal relationship we have with ourselves as well as the external relationship we have with others" (Evans, Forney, \&Guido-Dibrito, p.56). Erikson describes identity as ever changing from birth to death; a series of crisis that when successfully resolved help to form an established identity. Other developmental theorists have expanded on the work of Erikson to explore various aspects of identity including psychosocial, cognitive, gender, and racial/ethnic. For the purposes of this paper, I have included language such as cultural influences and personal factors which I allowed the participants to define. As they discussed identity through their narratives, cultural influences and personal factors were defined as family, religion, gender, race/ethnicity, ethical/moral development, and education.

\section{Organization of the Manuscript}

In summary, because identity development models were developed within a social context that privileges being male and White and most theories are situated within a psychosocial framework, a study that examined the relationship between gender, ethnicity, and identity development in a critical sociological and psychosocial lens is important. This is particularly interesting in a majority minority context like Miami and Florida International University. The next chapter lays out the research on identity 
development theory with a special emphasis on theories that examine minority and female students. The third chapter introduces the context and methodology for the current study. In the fourth chapter, I introduce the women who participated in this study as well as the overarching themes that emerged in their interviews; and in the final chapter, I explore the implications of this for identity development theory, recommend further research, and make recommendations for professional practice in higher education. 


\section{CHAPTER II}

\section{REVIEW OF THE LITERATURE}

Literature was examined about Hispanic students ranging from the very broad, for which there is a significant amount of research, to the very specific, of which there is very little. For the purpose of this study, several types of search engines, including ERIC dissertation abstracts, Wilson Web, and Omni Pro Quest, for example, were utilized. A list of key words such as Hispanic, college student, student success, identity development, student development, gender identity, racial identity, Cuban, Cuban American women, minority serving institution, and Hispanic serving institution were used in part and in combination as a part of this search for information for this study. The next sections summarize the following: There is research suggesting that the experiences of minority students vary depending on multiple variables, including the type of institution attended and self-identification in racial identity models. There is also research discussing the differences between men and women concerning cognitive outcomes during the college years. Furthermore, there is research that discusses the experiences of African American students attending Historically Black Colleges and Universities (HBCU) and studies examining the experience of minority students at majority institutions. It was my intention to demonstrate through the literature review the deficiencies in the literature as it pertains to Cuban American (Hispanic) women. This review revealed several studies that, if replicated with a student sample more inclusive of Hispanics, including Cuban Americans, would prove to be very informative and useful to student affairs practitioners and other members of the university. 
Several different key studies reviewed in this chapter demonstrate various aspects of the college experience of minority students, including psychosocial development, racial identity development, student involvement, intellectual development, and gender specific issues. This review discusses the studies and research about being Cuban American in Miami and identifies the challenges facing female and Hispanic students.

Cubans in Miami: An Overview of Cuban Migration and Demographics

It is important to understand the complexities and the diversity of Cuban Americans in the United States. Often times, Hispanics are grouped into one category, mostly because of the common language. Yet, even within national sub-groups, there are differences. This is demonstrated through a brief description of Cubans in Miami. Cuban Americans' arrival to the cultural landscape of the United States started in large numbers in 1959. Political and economic reasons, it was said, explained why residents fled from their mother country (Stepick, 2003). It is agreed by most historians that the Cuban migration to the United States occurred in four different waves between 1959 to the present day. The first wave brought to the U.S. the upper and middle class Cubans escaping the rise in power of Fidel Castro. In the second wave from 1969 to 1974, freedom flights were arranged by the Cuban and U.S. governments to bring working class to individuals the U.S. In the 1980s, the third wave of Cubans called "Marielitos" consisted of all segments of Cuban society, including the poorest members. From 1989 to the present, because of strict political sanctions and the plight of people under Communism, Cubans continue to seek refuge in the U.S. via boats and rafts (Pew Historic Center, 2006). Through legislation that applies to only Cuban immigrants, they are able to acquire legal status in the United States relatively easily. This migration to the 
United States and path to citizenship are key factors that separate the Cuban population from other Hispanic groups.

While the Cubans who settled in Miami eventually came into local political and economic power, a shift was occurring. Cubans were reaping the benefits of power and embracing a community that had openly welcomed them, yet they had not assimilated into the majority White culture, and this caused some ambivalence with most nonHispanic groups (Portes \& Stepick, 1993; Stepick, Grenier, Castro, \& Dunn, 2003). Other minority groups including other Latinos were disgruntled as they were not welcomed in the same manner and were not recognized in this shift of power. Cuban Americans living in the United States in Miami have recognizably benefited from their unique immigration to the United States as they have a higher median income than most Hispanics, tend to have a higher education level, and have a higher rate of home ownership (Pew Hispanic Center, 2006).

According to the 2004 Census data, there are currently 1.5 million Cuban Americans living in the United States (Pew Hispanic Center, 2006). As a part of the 40 million Hispanics living in the U.S., Cubans comprise $4 \%$ of that population. An estimated $68 \%$ of these Cubans, or 990,000, are currently living in Florida. New Jersey $(81,000)$, New York $(78,000)$, California, $(74,000)$, and Texas $(34,000)$ are the geographic locations with high populations of Cubans outside of Florida. A significant finding from the census data was that $86 \%$ of Cubans when asked about race identified themselves as White. This is distinctly different from other Hispanic groups such as Mexicans, Puerto Ricans, and Central and South Americans. 
In an attempt to understand the complexities of the changing relations between newcomers to the United States and established residents, an anthropological examination project sponsored by the Ford Foundation was conducted between 1992 and 1994 (Stepick et al., 2003). The larger project was conducted in six major cities, including Philadelphia, Chicago, Monterey Park (California), Houston, Garden City (Kansas), as well as Miami. The cities that were chosen were to represent different configurations of newcomer and resident relations. The underlying premise or motivation of this project was to examine the claims of cultural conflict created by immigrant groups and grassroots organizations. However, there were contrary reports that claimed immigrants and Americans were exhibiting positive relationships. Miami, as described by the researchers, was unique because it was difficult to find a neighborhood where significant newcomer-established resident relations occurred due to the economic and residential segregation of the city.

The methodology used primarily as a part of the Stepick et al. (2003) research project was based on day to day observation and in-depth interviewing. In the Miami study, the business community, work sites, and a high school were selected as the venues in which the study was conducted. One limitation to the study was that participant observation was limited among the highest levels of the business elite; attempts were made to also observe slightly lower levels of those businesses. Information gathered from the high school site also proved to be informative as some inconsistencies arose between interview data and observations between school administration. Administrators viewed the relationships as harmonious, and teachers and students who revealed strong negative stereotypes of other groups. 
The Stepick et al. (2003) project/study is important to my study as it presents an anthropological lens needed to understand the unique relationship Cuban Americans have with pre-existing residents in Miami. The interview data revealed that there were also inconsistencies with how immigrants viewed issues of becoming American. Interview data produced common recitations of "freedom, liberty, and the land of opportunity" ( $p$. 161); however, observations and reflections revealed that many aspects of American identity were uncovered. Some of these cultural aspects included rules for behavior and interactions. Findings also suggest that different groups can "dominate or at least exercise significant influence" within and across different arenas. In what Stepick et al. (2003) coined as transculturation, there was a shift in power that occurred in Miami when Miami Cubans did not assimilate to the disappointment of many Miami Americans. Reverse acculturation occurred when Miami Americans began to adapt to the ways of the new immigrants. Transculturation, however, referred to the notion that newcomer immigrants and established residents were learning to adapt to each other. This is an important concept when understanding the Latino influence and the powerful interactions in Miami among newcomers and established residents in regards to issues of social class and conflict.

In a series of three decade long ethnographic studies conducted by Portes and Rumbaut (2006) following a group of immigrant children from two regions of the U.S., Southern California and South Florida, the culminating results were reported in the Children of Immigrants Longitudinal Studies III (CILS-III) document. In the original study, with two field teams located in each region, participants $(n=55)$ were tracked and interviewed in-depth. The sample was diversified by age, nationality, and socioeconomic 
status. The Southern California respondents $(\mathrm{n}=135)$ were also tracked and interviewed; however, limited information was given about the sample. In the prior original 1992 study, 5,262 students were surveyed with the criteria that the student must be born in the U.S. and one or both parents must be foreign born. In a second study conducted in 1995, 4,288 ( $81 \%$ return rate) were contacted and interviewed again. Although this study is important in understanding issues of immigrants to the United States, one of the biggest limitations was that the subjects were not just Cuban Americans, but it included immigrants from Jamaican, Chinese, Mexican, Cambodian, and Laotian decent. Additionally, the participants were all younger and in high school, which could have influenced the maturity of the earlier responses. Despite this limitation, the strength of the study was the discussion of issues relating to Cuban Americans in Miami and the unique circumstances that surround this community both economically and politically. Portes and Rubaut are a few of the selected researchers who have examined Cuban culture as it relates to the second generation immigrants.

Understanding some of these issues is important to my study as most of the participants were second generation Cuban American women. Along with the issues relating to immigrant children, Portes and Rumbaut also agree with the findings of Stepick et al. (2003) that the Cubans in Miami instead of complaining, laid claim to the city through the political system. Established Anglo leaders in the community were being replaced by former Cuban exiles. This shift in Miami, according to Portes and Rumbaut (2006) has had an effect on ethnic formation of both the first and second generation Latino community. In the results of the larger study, Portes and Rumbaut report the parents rarely confuse their ethnicity with their race. This is contrary to what $93 \%$ of first 
generation Cubans reported, as they identify themselves as "white" racially. This, according to the researchers, is because the term "Hispanic" has taken a racial designation in the recent past.

Another important finding by Portes and Rubaut (2006) that was relevant in framing my study is the notion of selective and dissonant acculturation. Selective acculturation describes a second-generation child and the ability to acculturate to American ways without abandoning the parents' language and culture. This provides parents an easier time to help the child succeed academically and socially. Common characteristics in selective acculturation are displayed through stable families and cohesive communities. Dissonant acculturation, while not necessarily describing a downward assimilation, does describe a situation in which the child abandons the parents' culture and language. This type of acculturation does put the child at risk against external forces and a weakening of parental support.

\section{Theories of Student Development}

and Racial, Ethnic, and Gender Identity Development

The use of student developmental theories were a result of the 1925 Student Personnel Point of View, a document that encouraged student affairs practitioners to educate the whole student and help students maximize their full potential and become good community citizens (Evans, Forney, \& Guido-DiBrito, 1996). During the 1960s several "student development" theories emerged within a cognitive and psychosocial development framework as well as several typology theories. In texts such as Student Services: A Handbook for the Profession (Komives \& Woodward, 2003) and Foundations of Student Affairs Practice (Hamrick, 2002), there is little mention of 
Hispanic/Latino students' development. The focus of historical philosophies, theories, models, and research about college students appears to primarily focus on White students and to a lesser extent to students of color who are classified as African American, Asian, and other.

There are racial/minority identity development models in various texts that are commonly used by higher education practitioners, such as Student Development in College: Theory, Research, and Practice (Evans et al., 1996). Most of the work by Chickering and his seven vectors of developmental tasks (psychosocial development), whose work is based on the theories of Erik Erikson, influenced the birth of racial/ethnic identity development and gender identity development models used today (Evans et al., 1996). However, neither Erickson's nor Chickering's theories of identity development account for racial, ethnic, or gender identity development issues.

In the early 1990s, the emergence of racial identity development models was a welcome compliment to common student development theories. More recently theories focused on women and other populations of students evolved. Foundational theorists who helped to shape the road of minority identity development include: Marcia's model of ego identity; Josselon's work with women's identity; Cross's model of African American identity; Helm's model of white identity; D'Augelli's and Cass's work with models of homosexuality identity; Phinney's model of ethnic identity; and Atkinson, Morton and Sue's minority identity development model (as cited in Evans et al., 1996; Torres et al., 2003). Several minority identity developmental models, including the work of Vasti Torres's (1999) bicultural model of orientation, are examined in further detail as they 
frame the developmental theory landscape for this study. Torres specifically examined Latino students.

\section{Tanaka: Intercultural Theory}

A postmodern researcher, Greg Tanaka (2002), sought to rethink the work of student engagement theorists such as Tieney, Tinto, Astin, and Pace. Tanaka does not seek to change the existing theories; he only suggests that the works of these theorists need to be "rearticulated" in such a way that they reflect the complexities of colleges and universities. For him, if there were one goal in mind, it would be to integrate social theory into current methods used by practitioners in student affairs. Tanaka argues that current student development theories need to be examined and revised as they are ethnocentric in nature and their authors have not attempted to make connections between culture, power, and knowledge. He articulates that all modern theorists have some things in common such as an interest in measuring the impact of student involvement on a college campus and the tendency to disregard certain underrepresented subcultures at their respective institution. Tanaka argues that assessment tools currently used have measures to examine cognitive development, social involvement, critical skills, and institutional characteristics; however, not one of the tools measures the impact on student development from racial demographic shifts, power shifts, or cultural norms at many colleges and universities today. Tanaka suggests that there needs to be a shift in thought towards a more "intercultural" theory of student development. Intercultural as defined by Tanaka is a step beyond multiculturalism. Interculturalism he says is "a process of learning and sharing across difference where no one culture dominates" (p. 282). He suggests that there are three interpretations to this new method of thinking: "hybridity 
analysis", which looks at how researchers examine points of contact as cultures interact; "border theory", which examines the ethnocentric impact of two cultures that come into contact with each other, and "intersubjectivity", in which the emphasis is for each subject (student) to have a voice and place to tell his or her individual story. Intersubjectivity, according to Tanaka, tends to lead to a greater sense of interdependence and a great sense of identity and belonging. Intersubjectivity also tends to create a more positive experience as it evaluates the meaning rather than power in relation to the social identifiers such as gender, ethnicity, and sexual orientation.

Tanaka (2002) suggests that there are ways to build upon and integrate this idea of interculturalism within current student development ideologies and instruments such as the Cooperative Institutional Research Program survey and the College Student Experiences Questionnaire (CSEQ). Asking questions that deconstruct power and focus more on cognitive and affective development by redesigning the questions that are currently used is the key to new ways of thinking. Future implications, he states, are to challenge those in higher education to rethink these current assessments to reflect the ever-changing face of higher education. As I examine the experiences of Cuban American women college students, Tanaka's theory of interculturalism is important to the discussion. His theory is a reminder that current student development theories can be enhanced by adding a social theory component to them. This is very important because I examined the experiences of a particular sub population at an HSI, which is considered a majority minority institution. Additionally it is where they are a part of the majority and focusing on meaning and power is something to keep in mind as the study progressed, 
especially because there are cultural differences among the Hispanic population at this institution.

\section{Gender Identity and Moral Development of Women}

There are three key women's identity development theorists that need to be considered. Josselson and Gilligan were early leaders in exploring gender and identity development while Jones' work is more recent.

\section{Josselson: Women's Identity Development Theory}

Important to this study is the understanding of gender identity and moral development of women, which has only been addressed by a few researchers in the recent history of student development. Based on the psychosocial theory of Erikson and Marcia's model of ego identity, Josselson (1987) sought to understand the complexities and the developmental roots of identity formation in women. Her work stemmed from Erikson's Stage 5, identity versus identity diffusion, which is the developmental stage that describes the transition between childhood and adulthood. Her work also borrowed from Marcia's ego identity development model, which helps to explain why some people are able to resolve their identity crisis and other fail to in this stage.

Based on her longitudinal studies conducted between 1971 and 1973, Josselson interviewed 60 randomly selected college women (Josselson, 1987). These women were seniors selected from four colleges and universities. Of the original women who participated, 34 women were contacted and interviewed again to understand the developmental changes that occurred from their adolescent identity formation to their adult lives. Josselson concluded that there were four, non linear stages of development of women. Women described as "foreclosures" did not experience much in the way of an 
identity crisis. They were likely not to risk the disapproval of their parents; therefore, many are hesitant when making decisions and base their choices on childhood messages and assumptions. "Identity achievement" can best be described as the stage where a woman takes a critical examination of her childhood and makes a decision to break from the psychological ties of her parents and form a distinct identity. Although very challenging, it means letting go of what is comforting and familiar, but it allows them to define who they want to be in the future. Women who are in the third stage, "moratorium", often find themselves in an unstable state and discover and experiment that there is more than one right way and that identity is a continuous process. The final stage, "identity diffusion", can best be described as a lack of crisis and commitment. These women tend to have difficulty establishing relationships, have high anxiety, and a tendency to withdraw at times.

Josselson's (1987) work is important to understanding the complexities of women's identity development as it was one of the first bodies of research that only examined women as subjects for examination. Josselson says:

We have long taken it for granted that men differ from each other and in important ways worthy of careful study and understanding. But we rather assume that all women are fundamentally alike. In our understanding of women's development we have lacked perspective on the different pathways to development of women, the different roads a girl may travel on the way to womanhood....What we need are meaningful ways to compare women with each other. Yet we are not sure which are the centrally important dimensions, especially with a culture that is so uncertain about these matters. (p. 5)

She continues on to say that there is limited research on dimensions or "parts" of a women such as those between homemakers and career women, lesbians and heterosexual women, and feminists and non-feminists. Little research has been conducted on how 
those parts are connected to make a meaningful whole (Josselson, 1987). It was my hope to bring forward to the research on women's identity development the missing piece of culture and ethnicity, which is missing from Josselson's work.

\section{Gilligan: Psychological and Moral Development Theory}

From a historical perspective, human development theorists often excluded women's participation in psychological studies as they were not viewed as worthy participants (Evans, Forney, \& Guido-Dibrito,1998). One theory of moral development is attributed to cognitive psychologist Lawrence Kholberg. As a student of Kholberg, Carol Gilligan (1982) challenged the notion that moral development was different for women and believed Kholberg's work was comprised of generalizations grounded in a patriarchal hegemony based on lack of awareness of how women make decisions. She challenged the work of her mentor, whose research was conducted with 29 adolescent boys. Her research led to a broader theory of moral development that included women's voice.

Based on three separate longitudinal studies, each examining different aspects of moral development, Gilligan (1982) began to challenge the existing ways that women had been portrayed in research in human development. In her study of college women, Gilligan set out to examine identity and moral development in early adult years. More specifically she wanted to explore the relationship between views of how one thinks about morality to the experiences and choices one makes. She selected at random 25 sophomore students who had taken a course on moral and political choice. These students were again interviewed during their senior year. It was her abortion decision study (Gilligan, 1982), however, that led to her findings on women's moral development. The 
participants for this study included 29 women from diverse backgrounds, aged 15 to 33 . These women were interviewed in their first trimester of pregnancy during a time when they were contemplating an abortion. Gilligan was exploring the relationship between experience and thought and the role of conflict in development.

Gilligan demonstrated that the themes of care and responsibility comprised what women believed to be their moral compass, which contradicts Kholberg's idea that the most developed individual functioned from strictly universal principles. Gilligan's theory of moral development is a developmental sequence with three levels that include:

Orientation to Individual Survival (Level 1); Goodness as Self-Sacrifice (Level 2); and the Morality of Nonviolence (Level 3). As with the work of Josselson, Gilligan also began to examine those differences that set women apart from men. However, like Josselson, Gilligan fails to examine culture and ethnicity as a part of her research. To date, Gilligan is still the leading researcher on the experiences of women's moral development. By examining the Cuban American women, the voice of another dimension of differences among women will be added to the literature.

\section{Jones: Multiple Dimension of Identity Development Model}

In a qualitative study, Jones (1997) attempted to examine the multiple dimensions of identity development based on the premise that theories of identity development are often contextualized by race and/or gender and have not been integrated. Jones argues that theories of racial and gender development have failed to include other identity dimensions. The purpose of Jones' study was to examine the multiple dimensions of identity as told by the women in their own terms based on the students' understanding 
and descriptions of their own identity. Ten women from diverse backgrounds in terms of race, religion, and culture were chosen by purposive sampling to participate in this study.

The participants were 20-24 years old, were mostly upper class status, varied by academic majors, and were from a large East Coast university. Jones conducted and analyzed three in-depth interviews with each woman. Ten key categories emerged: (a) relative salience of identity dimensions in relation to difference, (b) the multiple ways in which race matters, (c) multiple layers of identity, (d) the braiding of gender with other dimensions, (e) the importance of cultural identifications and cultural values, (f) the influence of family and background experiences, (g) current experiences and situational factors, (h) relational, inclusive values and guiding personal beliefs; (i) career decisions and future planning, and (j) the search for identity. Her findings suggest the key categories themselves are not independent of each other and there is a connectedness and a relationship among them. For example, the category of "influence of family" was prevalent throughout the data and influenced other key categories.

The participants in Jones' (1997) study articulated identity as an evolving concept that blended fluidly "meaningful contexts of race, culture, gender, sexual orientation, family, relationships, religion, experience, and personal attributes" (p. 9). One of the important findings about identity development in this study stresses the further need to examine the complexities of identity development within multiple dimensions. Jones suggests the experience of difference shaped identity with these participants. This is important to note because when the women felt different, they experienced more intense connections to a dimension of identity. The stories of these women clearly suggest the importance of outside influences such as family, society, and peers. 
Jones' (1997) work of all the researchers examining women's identity is the most contemporary as it brings to the literature a cultural dimension that has long been missing. Her work is different from Josselson and Gilligan as it does not solely rely on one dimension or a specific lens when trying to identify the complexities of women's development. Her research does not contradict the work of Josselson or Gilligan; rather it is complementary to both of their bodies of work. Jones' concept of multidimensional identity development is what can be considered to be the most thorough examination of identity that has occurred in recent years. Some critiques of her work is that like most research on diverse populations, the work occurred at a PWI in the northeast. The women in the study who were of diverse backgrounds were truly in a minority situation.

Additionally, it has not been fully developed and replicated. However, this study was important to my research because it provided a basis to examine identity development from multiple perspectives. The implications of this study served as a backdrop to my examination of Cuban American female college students.

Racial and Ethic Identity Development and Hispanic Students

More than 39 million Americans identify themselves as Hispanic. We call ourselves by that name, check that box. Why do we feel the kinship? Why do we believe we share a theme? We are not a seamlessly uniform people. We do not necessarily share a culture or a common history. We are South Americans, Central Americans, Mexicans, Caribbeans, scrambled and sliced in different ways. We are jungle people, mountain people, coastal people, desert people, island people, urban people. We have-even as Latinos-a melting pot all of our own. (Arana, 2001, p.8)

The complexity and diversity within the Latino community unquestionably adds to the difficulty central to understanding this group. Heterogeneity among Latinos in the social science literature often disregards or ignores those things that distinguish many of the Latino subgroups (Ferdman \& Gallegos, 2001). Often the term Latino/a (also referred 
to as Hispanic or Hispanic American) student is a broad umbrella term that disregards the geographic distribution, political affiliation, socioeconomic status, language use, and other cultural features based on the subgroups of national origin (Ferdman \& Gallegos, 2001; Wijeyesinghe \& Jackson, 2001). The Latino identity, regardless of the heterogeneity within the group, share a cultural "groupness" based on a unique historical and sociological history in the United States. These commonalities, which unite Latinos from across groups, include the use of Spanish as a language, the appreciation of similar yet varied cultural values, religious traditions, and a focus on family. However, according to Wijeyesinghe and Jackson, Latinos feel connected to each other based on this identification as a group and due to the external treatment by others. Ferdman and Gallegos (2001) argue that overlooking the identification based on national origin can be challenging mostly because the social processes and the Latino experience differ systematically across subgroups. Often times, they state, most Latinos have not adopted this primary label without some reference specific to their national origin or subgroup. Torres (2004) stresses the importance of examining these within group differences and how they affect the college experience of students from different countries. She states that even with the shared commonalities, often overlooked is an examination of immigration patterns, generational status, and varying ethnic experiences in the United States, which are particular for each ethnic group.

As with any model of identity development, it is difficult to generalize the complicated nature of characteristics that are shared within a group of people. The following three models are the most progressive in understanding the nature of Latino identity development. These models offer explanations focused less on traditional stage 
development (linear model) and more on the idea of orientation or how individuals within the Latino culture view themselves (individually or within the group), how Whites are viewed, and how race is defined.

\section{Ferdman and Gallegos: Latino and Latina Racial Identity Orientation Model}

Ferdman and Gallegos (2001) developed what they hesitantly refer to as a model not based on stages of development but rather observations they have made as they researched Latino racial identity constructs. Despite an agreement on many factors that influence Latino identity, Ferdman and Gallegos present a model of orientations through which individuals move depending on the factors involved. They say some individuals may maintain one orientation throughout their lives. The key classification in Ferdman and Gallegos' Latino identity development orientation model follows. Latino-integrated individuals understand the full complexity of the Latino identity and see other and their own subgroups, including Whites, positively. Latino-identified individuals identify with the term Latino broadly but do not subscribe to the U.S. racial constructs placed on the group by majority Whites. Subgroup identified people identify primary within their own ethnic/racial group and view Whites as barriers to their societal inclusion. Latino as "other" individuals may view themselves as a minority but resist the term. They are not very aware of their own specific background, history, or culture and view themselves as "not White". Undifferentiated individuals are oblivious to racial differences, do not focus on racial categorization, and may view themselves as "just people". White-identified individuals are assimilated into the White culture, view the world through White-tinted lens, are more likely to view themselves as racially White, or may view themselves as bicultural - preferring the White culture over Latino culture. 
Arguably, the biggest critique of their work is that although it provides insights to the Latino culture, it was created based on the researchers' observations. As a limitation to their findings, no more rigorous research supports their ideas. They are clear that it is not a model but a way of describing various possible orientations within this community. Ideally, there would be concrete research to support their observations. However, it would be remiss to not mention them as part of the literature review because Ferdman and Gallegos (2000) are part of the small company of researchers who have studied the Hispanic population. What is important to their observations is that this is not a linear model of identity development; rather it is a way for an individual to define his/her orientation. The model provides a lens for individuals to identify themselves within the Latino and White community and to explore how race fits into this equation. The model is important in the understanding of the Cuban American community as it speaks not to identity but more to the social constructs of being a Latino in American society and how individuals see themselves.

\section{Keefe and Padilla: Mexican American Ethnic Orientation Model}

According to Torres, Howard-Hamilton, and Cooper (2003), of the current theories that deal with Latino identity development, only Keefe and Padilla in 1987 studied a particular subset, Chicanos (Mexican American). They examined ethnicity by looking at three components: cultural awareness, ethnic loyalty, and ethnic social orientation. The component of cultural awareness related to an individual's awareness of Mexican people and culture. Ethnic loyalty included perceptions and preferences that an individual had developed about the Mexican culture. Ethnic social orientation included 
how an individual integrates the Mexican culture by demonstrating preference for ethnic food and interacting with others of Mexican decent.

Keefe and Padilla (1987) conducted a quantitative survey to attempt to explain the change in cultural ethnicity in relation to changing demographics in the United States. A stratified sample of Mexican American ( $n=860)$ and Anglo American $(n=776)$ households in three neighboring cities (Santa Barbara, Santa Paula, and Oxnard) in California was utilized. This study was conducted in three different phases over a span of 28 months. During each of the phases, a smaller subsample of the prior phase was chosen as the interviews became more in depth. The questionnaires were administered by local university students and targeted male heads of households. The female heads of households were utilized when the males were unavailable. The fact that men were targeted is a considerable limitation to the study. It does not share a complete story of cultural ethnicity from a balanced gender perspective. The most notable strength to the study is that it examined changing demographics in the United States and discussed the changes in cultural attitudes and beliefs among familial generations.

Keefe and Padilla (1987) found a significant decrease in cultural awareness between the first and second generation persons. This decrease in cultural awareness continued through the fourth generation. Ethnic loyalty only showed a slight decrease between the first and second generations on through to the fourth generation. The significance of these findings is that despite a lack of historical knowledge, participants continued to demonstrate positive feelings towards their cultural group. In regards to the ethnic social orientation, a similar pattern was found, indicating that after a span of several generations these students continued to socialize with members of their cultural 
group (Torres, Howard-Hamilton, \& Cooper, 2003). Keefe and Padilla (1987) developed the Mexican American Ethnic Orientation model from the findings of their study. There are five types of orientations ranging from Type I (unacculturated and self identify as Mexican) to Type V (having very little knowledge and identity with Mexican culture). The types that fall in the middle are harder to distinguish; however, it is noted that most participants fell in a Type III category. Type III can be most closely associated with a bicultural identity model: a balance between two cultures. Although this model only focuses on Chicano participants, it is important to my study because it embraced the notion of biculturalism and established the precedence for looking at one distinct subgroup of Latinos.

The notion of biculturalism as presented by Keefe and Padilla (1987) is important to the study of Cuban American college students as it serves as a model to refer to when discussing how students may identify themselves. This study focused on Mexican Americans and that does have some significance as there are very few models of biculturalism used as reference points. The importance is that there is literature that supports the idea that a person can struggle with identity when living between two distinct cultures as well as generational differences. These are points that should be considered when examining the Cuban American population to decide if there are more similarities than differences.

\section{Torres: Bicultural Model}

The work of Torres (1999, 2003a, 2003b, 2004a, 2004b, 2004c) has brought a positive heightened awareness to the issues of identity development to the field of student affairs. Her work (Torres, 1999, 2003, 2004; Torres \& Baxter Magolda, 2004), however, 
appears to be geared toward cognitive development and other influences on cultural identity. Torres et al. (2003) found three factors influencing student identity during the first year of college: (a) environment in which the student grew up, (b) familial influences, and (c) self perception of status in society. Based theoretically on the foundation of ethnic identity and biculturalism, Torres's (1999) Bicultural Model of Orientation for Hispanic Students was based on the student responses in her qualitative research.

Few studies have been dedicated solely to the Cuban American college student. In 1980, Szapocznik and Kurtines examined the notion of biculturalism in one of the few known studies of undergraduate Cuban American students' experience. Their findings suggest that the more bicultural the students were, the higher the adjustment score they would receive by the instructor. Maladjustment, they stated, occurs when a bicultural student is placed in a monocultural environment. In 1997, Torres and Phelps introduced the Bicultural Model of Orientation (BMO) as a pilot study set to examine the intersection of acculturation and ethnic identity. The validation of the BMO (Torres, 1999) verified what Torres and Phelps had identified earlier as four cultural orientation quadrants used as a tool for identifying the cultural orientation of Hispanic college students. This study surveyed 372 Hispanic college students from four institutions (two comprehensive universities and two community colleges) in three different states (Texas, Georgia, and Florida). Based on 1,359 surveys that were sent to students, 372 were returned ( $n=60$ from Georgia, $n=120$ from Florida, $n=129$ from Texas) with a 27\% return rate. Based on the demographics of the students that returned the surveys, the largest percentage students came from Mexico $(n=119)$, Central and South America $(n=80)$, 
Cuba ( $n=71)$, Puerto Rico ( $n=11)$, Spain $(n=11)$, and Caribbean $(n=6)$. Most of the students were between the ages of 17-25 and considered second generation Hispanic Americans. The questionnaire used in this study consisted of a demographic section and three scales (Short Acculturation Scale for Hispanics, Multigroup Ethnic Identity Measure, and the Bicultural/Multicultural Experience Inventory-B/MEI). Data analysis was conducted by utilizing various methods including cross tab analysis, multivariate analysis, and a univariate analysis of the B/MEI.

Torres (1999) validated the earlier pilot study findings that students could be categorized into one of four cultural orientation quadrants: bicultural orientation, Latino orientation, Anglo orientation, or marginal orientation (see Appendix E). Like the work of Keefe and Padilla, this model also disproved the notion of a linear acculturation model. Torres's (1999) study findings indicated that there are students who do not find themselves advantaged to be in one quadrant over another; however, they do seem to maintain their ethnic identity even when they are more Anglo oriented and can be considered bicultural in their orientation. There are limitations to this model including the fact that most of her work has been conducted at predominantly White institutions (majority institutions) and very little has been connected with Cuban American students. Torres's work, which has been connected with some Cuban American, both male and female, students, like other similar studies involving Hispanic students, is limited in participants and neglects to look at the differences within the Hispanic community. This examination of Hispanic students as a whole neglect to allow for sociological constructs such as immigration but helps in understanding issues of acculturation and cultural ethnicity. In terms of ethnicity, Torres's body of research adds to the literature as she is 
one of the few practitioners that has a developed a model that allows for a student to examine themselves in this way. However, it tends to confine identity to one of four quadrants that fails to examine fully all the elements and complexities of ethnicity as a part identity development. Some researchers would argue that identity development models are useful but fail to take into consideration that identity is not constant and, therefore, more fluid in context.

It is for these reasons that for the purposes of my research study, I used the work of Torres (Torres, 1999, 2003, 2004; Torres \& Baxter Magolda, 2004). Overall, I believe that her model of Latino Identity Development is the most researched and well developed of the Latino identity models; however, there has not been a study dedicated to Cuban American women college students. Her work has been primarily performed at predominantly White institutions with a mixed group (male and female) of Hispanic students that come from a variety of cultural and ethnic backgrounds. I consider her work to be the most relevant ethnic identity model to my research, as I know the issue of biculturalism is as important to this study as the telling of the stories of the Cuban American women college students that I interviewed.

\section{Racial Composition on Campus and Identity Development}

With limited research being conducted on the cognitive and intellectual effects and identity development of Hispanic students attending HSIs, it is important to look at other established minority based institutions for support in understanding issues pertaining to minority students in higher education. There is research on the experience of Black students attending predominantly White institutions that find that Black students find such environments more alienating (DeSousa \& Kuh, 1996). Based on the theoretical 
frameworks of Astin, Pascarella, and Terezini, Kuh and DeSousa (1996) examined factors that influenced the educational gains of Black students at HBCU and at PWI. Kuh and DeSousa set to determine if the amount of effort in various activities influenced these students' development and if there were differences reported in educational gains (critical thinking and writing skills) by the students attending each institutional type. As in prior studies mentioned, the College Student Experiences Questionnaire (CSEQ) was used as the data collection instrument for this study. This commonly used instrument in colleges and universities includes 191 items that measure various aspects of a student's experience including 14 scales measuring the quality of effort put toward certain activities. The method for data collection included a mailing to a random sample of students $(n=1200$ : 600 students from a HBCU and 600 from a PWI) in the spring of 1993. The universities chosen were both in the mid Atlantic part of the country situated approximately eight miles from each other. In total, after final reminders were sent to students, the response rate was $40 \%$ ( $n=481) ; 305$ respondents were from the $\mathrm{HBCU}$ and 176 were from the PWI. Due to the significant number of variables on the CSEQ, a factor analysis was performed to identify clusters of variables more closely related to each other. The clusters included (a) involvement in academic activities, (b) involvement in social and interpersonal networks, (c) personal and social development, (d) critical thinking and science/technology, (e) vocational and career skills, (f) history and cultural awareness, and $(\mathrm{g})$ arts/literature.

The most significant finding offered by this study suggests the following: Black students attending a HBCU reported greater educational gains than those who attended a PWI; Black students at the HBCU devoted more time and effort to academic and 
extracurricular activities than their counterparts at a PWI (which may be due to the perceived institutional barriers of racism, isolation, and alienation at PWIs); and the experiences outside the classroom and peer interactions were important to the personal development of Black students independent of the composition of the university.

One of the strengths of this study was the CSEQ instrument. Used by over 300 colleges and universities, this instrument has faced rigorous challenges of reliability and validity and established itself as a trustworthy instrument. The instrument, however, does not take into account socioeconomic background information or community based activities, both aspects that may affect the Black student experience (DeSousa \& Kuh, 1996). One additional significant limitation of this study was the number of participants and limitation to only two campuses. The number was relatively low for a quantitative study and does not present a clear enough picture of the important issues the researchers were attempting to ascertain.

Research needs to recognize the variables affecting the college experience, especially at HSIs and HBCUs. Underestimating the value of a welcoming environment is only ignoring a problem often disregarded at a majority institution, yet the ones who feel the effects of this environment are our minority students. How important is the concept of social support networks to the identity development of minority students? Despite very limited information about the importance of social support, it is widely accepted that a social support network is especially important to our racially diverse student populations on majority campuses (Kenny \& Stryker, 1996).

In a qualitative study conducted at a large PWI located in the mid-Atlantic United States, Hernandez (2002) examined the experiences of a purposive sample of 10 Latino 
first year college students. All were full time students between the ages of 18 and 20 . They were both male and female participants representing Central America, South America, and Puerto Rico. None of the students in this study self-identified as Cuban.

Hernandez (2002) identified four themes based on the experiences of these participants: (a) academic and social adjustments, (b) family support and encouragement, (c) involvement opportunities, and (d) ethnic and cultural identity. Most of the participants reported they had difficulty in adjusting academically. This was compounded by the fact that they felt ill prepared for college level work, challenges of time management, lack of on-campus community support, and pressure to excel academically. The participants agreed that they all received a great deal of familial support and encouragement. One of the reasons for going to college was to graduate and be able to offer financial assistance to their families. There were plenty of opportunities to get involved, they agreed; however, few did. The focus on achieving academically was more important to the participants. Interestingly, the students studied shared a variety of experiences about culture and ethnicity based on each of their life circumstances. Several of the participants commented on the additional challenges that this presented. One participant commented that she believed she was facing "gradual assimilation" and feared "a loss of her culture" in her current environment. A few of the participants who went to predominantly White high schools did not seem bothered by the culture shock of attending this university; however, for some the challenge was to balance life in two cultures by "negotiating parental expectations with their own definition of what it meant to be Latino". Hernandez makes the point that most of these students did seek out other Latino students. 
Despite the limited in scope, the study does offer some insights about minority students attending a majority institution. They were challenged to do well academically and persist to graduation, while trying to remain culturally connected to who they were within the context of a PWI. More importantly, it helps to shows the experience of students who are attending a majority minority institution, like an HSI.

Ethnicity and Identity Development of Cuban American College Students Attending a Hispanic Serving Institution

Identity development of Hispanics in the college setting in the United States is greatly impacted by the historical/social context and the diversity from which they come. Educators should try to understand the nature of these students as the diversity of the group is dependent on so many variables including generational status and country of origin. There is very little information on college students attending HSIs. In particular, there is very little research on Cuban American students attending intuitions of higher learning (PWI or HSI), as they do not represent the largest population of Latinos in the U.S. Additionally, there is confusion about the definition of what it means to be Hispanic in the U.S. today. By default, Hispanic in educational research is most often categorized as Mexican American or Puerto Rican. If Cuban American students are included in a study, participation ranges from $0 \%$ to $5 \%$ of the study sample.

While the research on Cuban American college students is limited, Geertz Gonzalez (2007a, 2007b, 2008) has examined various aspects including civic engagement practices, ethnic identity, and spirituality of Cuban American students as compared to Non Hispanic White students attending an HSI. In his study examining civic engagement, Geertz Gonzalez (2008) questioned whether there are differences between civic 
engagement practices of Cuban American students and Non Hispanic White students at an HSI. Based on his interviews with 14 Cuban American (6 females and 8 males) and 15 Non Hispanic White (9 females and 6 males) students, the findings suggest that both groups were engaged in similar activities regardless of their backgrounds. That study was conducted over a 2-year period at an HSI in Miami, Florida. Given the unique sociopolitical issues surrounding Miami as a city, that bounded case study has implications important to understanding issues of ethnic identity and Cuban Americans. What Geertz Gonzalez found more interesting, and not part of the original research question, was that there were issues of how these students defined their own ethnic identity and how they saw themselves compared to other ethnic groups. Findings of a later follow-up study utilizing the same participants (Geertz Gonzalez, 2007a) suggest that students identify themselves with four themes, including celebrations and food, cultural conflict, language, and racism, which help them shape their ethnic identity.

These findings were consistent with the work on Cuban American graduate students studying at an HSI done by Alvarez, Bliss, and Vigil (2001). The authors stated that the students spoke of food, music, and familial emphasis on having a strong achievement drive as important to their ethnic identity. While adding to the body of research on Cuban American college students, some major limitations of this study were the scope of the study, the limited number of participants, and the applicability to the larger population of Hispanics attending institutions of higher learning. The relevance to the present study is that there are similar themes that the graduate students share with the women in this study. 
In his latest examination of Cuban American and Non Hispanic Whites, Geertz Gonzalez (2007b) examined the attitudes about spirituality with the same 14 participants from the larger study on civic engagement. Geertz Gonzalez conducted a study to compare and contrast the attitudes, thoughts, and beliefs of spirituality of Cuban American and non-Hispanic Whites attending an HSI and the extent to which the experience was shared. His findings suggest no conclusive answer to whether or not attending an HSI had a major effect on these students in terms of their spirituality; however, all of these students showed a strong belief system. Furthermore, all Cuban American participants stated that attending church was not as important as having faith or being spiritual.

As a result of these studies examining civic engagement, ethnic identity, and spirituality, Geertz Gonzalez (2007a, 2007b) recommends further consideration in the area of research not only for Cuban Americans but for researchers interested in delving into areas of Hispanic research. He challenges researchers to look past the traditional college student development theories and to examine issues about Hispanic college students from a sociological and cultural lens. His research is some of the only work being conducted in the area of Cuban American college students. What is missing is the female voice. His research provides a solid understanding for studies examining the Cuban American female perspective in higher education; however, more can be done to see if there are differences in this community by examining identity development with gender as a main component. 


\section{Critique and Conclusions}

The importance of understanding the issue of identity development of Cuban American women as it relates to the participants in my research study is that there were some participants that were living on campus and some that were living at home. Cuban American women college student participating in this study, like the students in prior research studies, could have similar issues with parental control and/or support. Additionally, these may affect identity development and are rarely considered in the traditional psychological models. The importance of these studies is that they do examine some of the cultural issues that the Cuban students may be exhibiting; however, the research does not address Cuban American students. My findings could add to the research in this area.

Similarly, in much of the research on Latino students, ethnic issues and financial issues can be convoluted. In many studies, issues of family socio-economic status are mixed with issues of ethnic patterns. In the case of Latinos, family financial challenges have been seen as family cultural challenges. Obviously, a Latino student would not need to contribute to family finances if family finances were abundant. Because Cubans as a group generally are wealthier than the other national subgroups of Latinos, the discourse around financial stress in Latino literature may be less relevant (Pew Hispanic Center, 2008).

Research that has been conducted has usually been done at PWIs and often on the general Hispanic student population (predominantly Mexican). The research has been geared towards Hispanic students attending 2-year community colleges or focused on 
persistence rather than identity development. Despite that fact, neither research about HSIs or the PWIs has minimally addressed gender specific issues.

And of biggest casualties is the lack of research being conducted to examine the gender specifics issues of Hispanic women. It is because of my concern and discontentment about the lack of research (and understanding) that I have chosen to examine more closely female Cuban American college students. More specifically, it is for all of these reasons that more research needs to be conducted concerning Cuban American females attending an HSI. While there are several ways a researcher could inform the academic and student affairs community about specific issues affecting a specific and often neglected subset of the Hispanic community, my study examined the factors, including psychosocial, intellectual, cultural, spiritual, and student involvement, that affect Cuban American women attending an HSI.

In particular, Torres's bicultural model of Latino Identity Development, Josseson's study of women's identity development, and Jones' model of multidimensional identity development informed the study. Torres's work has been groundbreaking in working to help understand the general Hispanic population as it relates to identity development as is Josselson's work with women's gender identity development. Jones (1997) is the latest researcher to examine identity through multiple lens examining the interconnectedness of ethnicity, gender, religion, race as well as contextual influences such as family on identity development. Approaching my study from a multi dimensional perspective provides the most thorough analysis. I focused strictly on the experiences of Cuban American female college students attending an HSI. This is where the research has not attempted to go as yet. What is missing is a focus on 
this particular subpopulation and the following questions guided this research study: (a) What are the personal narratives of Cuban American women as they describe their identity development while attending a 4-year HSI? (b) Do the women speak of cultural influences or personal factors as important to their identity development? (c) Do Torres's (1999) bicultural or Josselon's (1987) gender identity models adequately summarize the complexity of these women's experiences or is a multidimensional model more appropriate? 


\section{CHAPTER III}

\section{METHODS}

The previous chapters provided the theories and the review of research that outline the framework for the study. The purpose of this study was to examine the experiences of Cuban American women attending a Hispanic Serving Institution (HSI) and the influences and factors affecting their identity development. This qualitative research study was conducted with 12 Cuban American women participants who attended Florida International University (FIU) and were classified as juniors, seniors, or graduate students at the time of the study. By utilizing a three interview process (two semistructured and one focus group), each participant was given an opportunity to describe her experiences of life growing up as a Cuban female in a predominantly Hispanic city and being a full-time college student at an HSI. I sought to gain an understanding how these experiences pertained to their personal growth and identity, not only as women, but as Cuban American women.

The questions that guided this research were: (a) What are the personal narratives of Cuban American women as they describe their identity development while attending a four-year Hispanic Serving Institution? (b) Do the women speak of cultural influences or personal factors as important to their identity development? (c) Do Torres's (1999) bicultural or Josselon's (1987) gender identity models adequately summarize the complexity of these women's experiences or is a multidimensional model more appropriate? 


\section{Qualitative Inquiry}

This study utilized qualitative inquiry methods. Bogdan and Biklen (1992) define qualitative research by four characteristics: the natural setting is the direct source of data and the researcher is the main instrument; the research is descriptive; researchers most often analyze their data inductively, and qualitative researchers are more concerned with process versus outcomes and products. Qualitative inquiry allowed me as a researcher to gain an understanding of the experiences of these women. The use of semi-structured interviews and focus groups and an examination of their thoughts, beliefs, attitudes, and perceptions of their own identity development allowed for a story to be told and for interpretations and meaning to be drawn. Creswell (1998) states, "qualitative researchers study things in their natural settings, attempting to make sense of, or interpret phenomena in terms of the meanings people bring to them" (p.15). In this case, working with the participants allowed for insights into their personal journey of growth and development, not only as women but as Cuban American women attending college.

\section{The Case Study Method}

This research study utilized the case study method. Stakes (1998) states that a case study "is not a methodological choice, but a choice of object to be studied" (as cited in Denzin \& Licoln, p .86). There are three types of case studies according to these researchers: intrinsic, instrumental, and collective. The intrinsic case study is used to gain a better understanding of a particular case. The purpose is not to build theory but rather to simply examine a case that raises a particular interest. Instrumental case studies are designed to provide insight into an issue or examine refinement of a theory. The case itself is of secondary issue. This study, however, used a bounded case study 
methodology. In this study, the case is constructed of Cuban American women attending an HSI, that Creswell (1998) would argue are a part of a bounded system. Creswell (1998) defines a case study as an exploration of a bounded system over time through detailed, in-depth data collection involving multiple sources of information rich in context. A case, whether a program, event, activity, or individual, is bounded by time and place. This bounded case study of Cuban American women attending a 4-year HSI, as defined by both Crewell (1998) and Denzin and Lincoln (1998), meet the description and is appropriately used for this study of the issues and factors that influence the identity development of this particular cultural group.

\section{Rationale for Using Qualitative Inquiry}

Creswell (1998) suggests four possible reasons to engage in qualitative research: (a) the nature of the research question, (b) the need to explore the topic,(c) the need to present a detailed view of the topic, and (d) the need to study individuals in their natural setting. Examining the experiences of Cuban Americans females attending an HSI is very much suited for a qualitative study. The nature of my research questions was to find out the how, the what, and the why that was occurring within this cultural group, specifically from their own perceptions. The experiences of this group can best be interpreted for meaning by using a qualitative method of inquiry.

A campus like Florida International University (FIU) truly lends itself to this type of study with this particular student group. I have been working at FIU for 8 years, and in that time I have had the opportunity to understand what it means to be a member of such a diverse community. Most research on Hispanics has been done at 2-year community colleges (e.g., Bliss \& Sandiford, 2003) and PWIs (Torres, 1999, 2003, 2004a; Torres \& 
Baxter Magolda, 2004), and research focusing specifically on Cuban American women college students is almost non-existent. Because FIU is located in Miami, Florida, this also lends itself to be a unique environment based on the political and cultural climate of the city. Most prior research is based on more traditional immigrant cities and states such as Texas, New York, and California, with the exception of the work by Stepick, Portes, and Rumbaut. South Florida is an area that needs to be explored as very few have an understanding of the distinctiveness of FIU. This dearth of research makes setting up a qualitative case study the best and preferred method to present a detailed point of view of the participants. These women offer a rich start because prior research did not give them voice.

\section{Role of the Researcher}

I believe my skills as an interviewer enabled me to ascertain information and articulate the findings so that members of student affairs and academia alike have a better understanding of this special demographic. I am certain that my training as a counselor and as a researcher assisted me in my interviewing process. I obtained a Master's degree in Counseling and Development in Higher Education from George Mason University and spent my career working in a higher education setting within the realms of student affairs. This extensive training in interviewing techniques and listening skills along with 18 years of experience working with and advising college students served as my greatest asset in this process. Confident in my abilities to conduct thorough and informative interviews, my hope was to gain a rich description of the experiences of these women, and the meaning they make of these experiences could not be easily gathered through quantitative methods. 
My lack of membership in the Cuban American community could be seen as a concern for some and an asset by others. There has been debate on whether one must be an insider to truly understand, just as there has been debate whether one needs to be an outsider to avoid personally biasing the data or to elicit "honest" responses from participants. I believe that my years of professional experience at FIU, my research setting, gave me the experience to straddle the line between insider and outsider. Also, by engaging in member checking and peer review, I did my best to assure that I accurately reflected the women's voices in my study.

My peer reviewer was also not Cuban American but had an extensive experience in the Miami context and was a trained administrator and researcher. With over 13 years of experience in student affairs, my peer reviewer examined the transcripts that did not contain comments I made during data analysis. Based on her experience in the field of student affairs and education, her opinions and conclusions were helpful to me as I analyzed and interpreted the data. The consistency between our interpretations lent credibility to the findings.

The second potential concern for some could be my dual role as a researcher and an administrator. Because I performed my administrative role in Campus Life and Orientation primarily prior to matriculation, I did not have any relationship with the students. Therefore, I could not utilize my administrative power, threaten, or offer benefits to the participants to influence their responses. This, along with my introduction to the interview, assured them that my dual role functions were viewed as a strength in this study rather than a hindrance. I hope my research brings a new understanding to my peers and colleagues working in student affairs and the academy. I am not Cuban. I am 
not a Latina or Hispanic woman. I am a woman of European descent. I choose to identify myself as a White, woman from Italian descent. Though I have mixed ancestry, Italian is just one part of my identity; I also share English, Polish, and German roots. More importantly, I am a student affairs professional and scholar who has a passion for sharing knowledge with others. When I speak of my research topic to my students, I always get nods of approval. I am telling a story that needs to be told.

\section{Pilot Study}

In the initial stages of this research study, fall of 2007, a pilot study was conducted to help define and adjust the questions used in the individual interviews and hone my interview skills as well as search for potential themes or other topics for questioning. The pilot study was conducted at FIU before the actual collection stage began. Two participants were identified in the same manner that the actual research participants were chosen. I interviewed and followed up with each of them if I had additional questions. The information ascertained from these participants was included in the actual research. This pilot study was limited in scope, but it helped clarify the interview questions and add certain topics that I did not initially identify based on the literature.

As indicated, each pilot participant was selected based on the same criteria as other study participants. Both were current FIU students, between the ages of 18-25, had attended FIU for at least one year, and identified themselves as Cuban American. Two semi-structured interviews were completed with each woman to gather data that would be helpful before commencing with the other participants. In fact, there were several things that occurred that were helpful in regards to the study as well. Themes emerged that 
helped to guide future questions. First, I discovered that one of my pilot study

participants was from a self identified multi - racial household. Her father was Cuban and her mother was Jamaican. This in fact made a difference in her responses of understanding the complexities of the bicultural model that I discussed with her during the second interview. It became clear that to gain a complete understanding of the uniqueness of the students' Cuban experience, I had to ensure that both parents of participants were of Cuban descent. This did not discredit her experience; her story as well as those of the other participant did help me to clarify the nature of the questions for the other participants. The pilot participants reflected on their life experiences, thoughts, and beliefs and were able to articulate what it meant to be a Cuban American college student and the struggles and the successes that come with that. As a result of these interviews, I recognized that I was challenged in my discussions with them about their identity development as it pertained to Torres's Bicultural Orientation Model (1999). As a result of the pilot study, I shared a handout that described and defined each of the four quadrants in the Bicultural Orientation Model for each future participant to have during interviews (Appendix E). The handout facilitated the discussion and helped avoid a complicated explanation of the Model. I used this handout toward the end of the other interviews.

The pilot study prepared me better for the line of questions I had developed. I became more confident in exploring different areas in the lives of these women. Because the themes of family, gender, religion, education, core values, and moral development emerged, I was better focused on these areas as well as the implications of their cultural identity development. The pilot study enabled me to shape the interview questions to 
explore the complexities and uniqueness of Cuban American women attending an HSI through many lenses, including gender, culture, and psychosocial development.

\section{Data Collection}

\section{Participants}

My research study examined of Cuban American women attending an HSI located in South Florida. Florida International University is a 4-year public HSI located in Miami, Florida. Established in 1965, there are currently 38,000 students enrolled at the time of the study. According to the FIU Office of Planning and Institutional Research website (Fall 2005 fact sheet profile), the university classifies 55.7\% of its students as Hispanic.

Research participants consisted of 12 self-identified Cuban American women, traditionally aged (18-25), with at least 1 year at FIU. I purposefully wanted the participants to have at least one year at FIU in order for them to articulate their experiences that I felt a first year student would not have been able to articulate. Further, in order to explore if the HSI was a salient characteristic of their development, they needed to have been enrolled at the HSI for duration of time.

The sample size was chosen with the composition of the focus group interview in mind. The size of a focus group should be small enough to be manageable but large enough to provide opportunities to elicit in-depth individual responses and to facilitate a vivid discussion among the participants (Merton, Fiske, \& Kendall, 1990). These researchers consider a group size of 10 to 12 as adequate and sufficient for a focus group. Seidman (1991) suggests that there is no agreement about the number of participants for individual interviews; however, to establish the number of participants, a researcher 
should take into consideration the issue of sufficiency and saturation. He continues by stating that sufficient numbers of participants in a study should reflect the number of individuals in the population.

As the group was already ethnically homogeneous in nature, I attempted to account for some individual differences and diversity within the group. By advertising for participants in various locations on campus and by conducting a screening meeting prior to the initial interviews, I was able to diversify my sample to include various residential living situations, majors, academic years, and involvement on campus. This allowed for a variety within the sample; however, the small number did not allow for saturated representation within every sub-category.

\section{Procedure}

After obtaining the required permission through the Institutional Review Board (IRB) Office for use of human subjects at FIU, I contacted various integral Student Affairs and Academic Affairs offices, such as Campus Life and Orientation, Office of Multicultural Programs and Services, The Women's Center, Office of Sorority and Fraternity Life, and Residence Life that had daily contact with students, to gather names of possible participants. I also generated an advertisement flyer seeking participants for this study that I placed on Facebook (see Appendix A). I targeted student groups and individual students that I have known in my position as the Associate Director of Campus Life and Orientation. As potential participants were identified, either by colleagues' nomination or recommendation or by the participants themselves contacting me, I contacted each woman by phone or via email to assess her interest in participation in the study and for initial screening. 
By utilizing both purposive and snowball sampling techniques, I was able to find the candidates for interviewing. As defined:

Purposive sampling is a nonrandom sampling technique in which the researcher solicits persons with specific characteristics to participate in a research study. In purposive sampling, the researcher specifies the characteristics of a population of interest and then tries to locate individuals who have those characteristics. (Johnson \& Christensen, 2004, p. 215)

Bogdan and Bilken (1992) support this by adding that purposive sampling enables a researcher to choose particular subjects that the researcher feels would "facilitate the expansion of the developing theory" (p. 71). I chose purposive sampling because I was intentionally targeting a specific population, Cuban American female college students of traditional age. The strength in choosing this sampling technique was that I was able to solicit the university community through a variety of methods that ensured a wellrounded group of students that represent a variety of life experiences. The weakness in this approach may be that I am a university administrator, and this may have inadvertently influenced some participants if they knew who I was. I intentionally targeted students from the other campus of FIU where I do not work to avoid this.

The use of the snowball sampling technique was helpful in this situation. Based on the stated criteria, I asked each of the participants to help identify any other women that they felt may be qualified and/or interested in participating in this study. While snowball sampling is considered a form of purposive sampling, it is often useful when trying to find representatives from a population that is hard to identify (Johnson \& Christensen, 2004). Indentifying and locating Cuban American women for this study was more challenging than I originally anticipated, but persistence and follow up with all leads resulted in a diverse group of participants. While Cuban Americans were plentiful 
on this campus, I based their participation on whether they self-identified as such, fit the age and class status, had a variety of living situations and involvement activities, and were willing to participate. One strength of snowball sampling is the common interests of participants who recommend someone, as it is human nature to associate with people that share common interests. I do not believe that the challenge in recruiting participants biased my sample.

As women for the study were identified, I sent each a copy of the advertisement (Appendix A), a detailed letter explaining the research study in full (see Appendix B), and a copy of the informed consent form (Appendix C), which they were asked to read over and not sign until the first meeting/interview. Participants were asked to participate in two individual interviews and one of the two follow up focus groups. All interviewees participated in all three interviews with the exception of two women who were unable to participate in the focus groups; however, transcripts were analyzed even if a participant failed to follow through on their her commitment to the focus group. I minimally compensated each of the participants for their time in the study by providing them with food vouchers to be used in the dining facilities on campus. In total, each participant spent approximately 3 to 5 hours interviewing within the duration of study.

This research study was designed to take place over a 2-semester period of time. During the fall of 2007, proper contacts and permission to proceed were established at the institution, including IRB permission. In addition, the pilot study was conducted before I began the initial stages of research during the latter part of the semester.

I began the initial interview process during the latter part of the fall 2007 semester and completed the interviews in the beginning of the spring 2008 semester after the 
women returned from winter break. I wanted to give each of the women time to reflect on her first interview experience before engaging them all in the second interview and the final focus group. During the initial interview, I openly and thoroughly explained to them the purpose of the research study, issues of confidentiality, and the commitment of time that the study required. This was in addition to the initial email that I sent to them explaining the process before the study started. If the participants agreed, the consent forms were signed. All participants were told that the interviews would be tape recorded for accuracy. Each participant granted permission to be taped. Seidman (1991) also recommends that participants have the right to withhold any part of the interview data they choose, and I followed this recommendation. I informed them that they would each receive a copy of their transcriptions for review. This process of member checking provided them an opportunity to read over what was said in both individual interviews and focus group discussions for accuracy. All participants were told that they could inform me if there was anything in the transcriptions that they did not want to be published in the findings or that was inaccurate. In order to maintain the highest level of confidentiality and to help establish rapport and trustworthiness between myself and the participant, each woman created a pseudonym for the purposes of the research. Some of the women who were student leaders on campus used vague descriptions of their experiences in order to protect their identity during this research project.

Keeping a research journal and field notes was also an important part of the process as it helped me to reflect on the experiences, non-verbal behavior, and initial interpretations during the meetings with the students. I wanted to make sure the key information that was coming from the interviews was recorded as it was happening. I 
found keeping a tape recorder more helpful than the actual journal process. I was able to have more of a free flow thought process. Later, it also allowed me to hear the emotion in my and their voices as I was going through the interview process.

\section{Interviews}

I chose to use several different approaches to data collection as it provided me with the most well rounded perspective and helped me draw conclusions that were personal, factual, and useful to the field of higher education. The initial interviews were semi-structured individual interviews that provided substantial data and revealed areas of exploration to follow up on with the focus groups. A set of predetermined questions was used as a base guide; however, I had the latitude to ask supplemental or follow up questions as the interview progressed. The set of questions purposefully asked the participants about specific topics including their families, values, education, cultural influences, gender, and ethnic identity. Semi-structured individual interviews gathered individual stories/experiences of these participants that were not affected by a group process or the opinions of others. Siedman (1991) suggests using an interview guide but advises caution because the guide may manipulate participant responses. He also warns that interviewers working with an interview guide "must allow for the possibility that what may interest them or other participants may be of little interest to the person being interviewed" (p. 70).

In order to provide an in-depth interview structure, I decided to model, with a slight modification, my interview process after the "three -interview series" approach (Seidman, 1991). Designed by Dolbeare and Schuman (1982), the three-interview series allows the interviewer (i.e., the researcher) and the participant to go in depth into the 
experience and situate the experience into a significant context. According to Dolbeare and Schulman, the first interview should focus on the life history and reconstructing as much as possible the participant's experiences. The second interview focuses on the details of the participant's experiences in the social setting that is being researched. The final interview should be a reflection on the meaning of the experience. I utilized this model with a modification of the final interview. I conducted two focus group interviews instead of a third individual interview, and I included questions in the second interview asking the women to reflect on the meaning of the experiences.

After the process of the first interview was completed, it was my intention to use the second round of interviews as a way to review and explore in greater depth potential themes and to follow up on any questions that were not answered during our first meeting. By utilizing a three-interview approach, the second round also allowed the students to respond in greater depth. Following the interviews, each of the participants was given an opportunity to review the transcripts for accuracy and to expand on or retract statements. None of the women requested any changes, revisions, or offered any expansions to their transcriptions.

After the completion of the individual interviews, two focus groups were established from the students who participated in the individual interviews. Merton, Fiske, and Kendall (1990) state the following advantages of focus group interviewing: (a) releasing inhibitions, (b) widening the range of responses, and (c) activating forgotten details. They assert that these benefits offset the disadvantages. They report that a group interview will produce a more diverse compilation of responses from the participants. 
Montell (1999) notes that group interviews allow for more interaction between the participants resulting in new and important data not necessarily found in other types of data collection. As illustrated in several articles about this topic, researchers reported focus groups were helpful when representing "invisible groups" such as Latina women (Madriz, 2003). Focus groups are particularly useful when trying to gain information on a particular subject while trying to understand it from multiple perspectives. According to Bogdan and Bilken (2003), women have the ability to confirm and recognize common patterns and experiences in their everyday lives. Montell (1999) writes that researchers noted the use of focus groups, versus individual interviews, provides a better forum because the goal is to elicit a conversation providing a more comfortable atmosphere for the participants.

Focus group interviews can produce a wealth of information in a short period of time (Hatch, 2002). Although the focus groups do not have to be homogeneous, segmenting by age, race, gender, class, and socioeconomic status can prove extremely helpful in ascertaining information about a particular group (Hatch, 2002). Madriz (2003) states it is best to connect the participants to each other in some capacity forming a group based on a common point or points. However diverse the group is, "educational homogeneity" outranks all other kinds in making for an effective interview with groups (Merton, Fiske, \& Kendall, 1990, p. 138). This segregation was present in my focus group because I used Cuban female college students of traditional age.

A consideration, not just with the use of focus groups, but also with interviewing individual participants in general, is the relationship that is formed between the researcher and the participant (Kirsch, 1999). According to Kirsch (1999), in focus 
groups issues of confidential revelations, value conflicts, unrealistic expectations, and diverging commitment levels and diverging interests may all lead to an inhibition of information or a hindrance to the relationship that was forming between the participant and the researcher. In the present study, potential focus group questions covered the same topics as the individual interviews with an emphasis on themes that emerged. Asking similar questions gave the participants an opportunity to elaborate on questions they answered in the individual interviews and to respond to the comments of their peers. The time between the individual and focus group interviews allowed the participants to reflect on the individual interview questions prior to the focus group. Again, the focus group allowed individuals to partake in, listen to others, and provide feedback to the group based on shared experiences. It was the goal of the focus group to bring the group together and share some of the preliminary results (themes) that were brought up by the participating members. By utilizing the focus group method, it was my intention for the group to accept or negate themes that I may have developed and allow them to respond to my preliminary analysis. This also allowed the group an opportunity to meet each other and to hear what other members shared and confirm or counter their statements. I had the latitude to use my judgment, focus on a line of questions, and moderate the group as necessary. The focus group added to the developing themes. The focus group encouraged more open participation by the students as they discussed issues of identity development that relate to the students' college experience.

As a form of internal validity and triangulation of data, two focus groups were formed instead of one. It was thought that by having two smaller groups, a comparison between group responses could be used as another form of member checking. It also was 
useful in helping to structure the questioning for the second group interview. Of the 12 participants in the study, Group A consisted of 4 members and Group B consisted of 5 members. One member was out of the city and two members were not able to attend because of class conflicts. Even though three women were unable to participate in the group interview, the data from their individual interviews were considered. Seidman (1991) says it best, "Remember it is not a perfect world. It is almost always better to conduct an interview under less than ideal conditions than to not conduct one at all" ( $p$. 15). Both of the focus groups were recorded with a tape recorder. Notes were taken on where each of the participants was sitting during the group interview for transcribing purposes. I was able to transcribe easily because of voice recognition from the individual interviews.

Interestingly, conducting the two focus groups did in fact validate each other and reiterated some of the themes that emerged from the individual interviews. From an observational standpoint, the women were actively engaged with each other in the focus groups. They had not met each other prior to the group interview, and I was surprised at how quickly they engaged each other in the dialogue. In both groups, they often affirmed each other in a positive light and readily agreed that they all had many things in common with regards to their family and school lives.

\section{Data Analysis}

As for the analysis of a case study, Creswell (1999) suggests the researcher form the initial codes: describe the setting of the case (paint a picture of the setting, the subjects, and the events); analyze the data for themes and patterns; interpret the findings and make sense of them; and present the narrative of the findings (supplemented by 
tables and figures). I began my coding with an informal review of the materials. Creswell (1999) suggests that data analysis, whatever the research tradition one uses, begins with a general review of the information collected, including notes, journals, and transcriptions. This is to ensure that the researcher develops a general sense and feeling of what information has been collected.

Bogdan and Bilken (1992) offer suggestions in terms of how to use coding when first disseminating information, including classifications of codes: setting and context codes, definition of situation codes, particpants ways of thinking about people and objects, process codes, event codes, strategy codes, relationship and social structure codes, and method codes. This system helps in separating the massive amounts of information into a more manageable set.

Creswell (1999) offers suggestions on how to do this if it is the researcher's choice. More specifically, Creswell recommends a general review of all the collected materials. This provides an opportunity to make notes in the margins of observations made during the interviews or from the field notes. He also suggests writing a summary of the field notes, if taken. Following this, Creswell advises to seek for participant feedback, also known as member checking, which I solicited from all of my participants. Each participant had the opportunity to review the transcriptions of all her individual and group interviews. They were also given the opportunity to read the final draft for accuracy of content and reflective meaning. Creswell encourages a close look at words that were used, including the use of metaphors by the participants, and states that utilization of charts, tables, or diagrams may be useful to visualize the material. The next step, as recommended by Creswell, is to develop a short list of tentative codes or 
categories. This enables the researcher to expand the categories as the reviews (and rereviews continue). The ultimate goal is to collect, describe, classify, and interpret the information in such a way that is logical and clear. Lincoln and Guba (1985) refer to this inductive data analysis process as "unitizing" and "categorizing." Unitizing can be accomplished by reviewing observational notes, documents and records, and notations made about the behaviors of the participants. The units that represent the raw field data should be transferred onto index cards. The authors suggest that there are two criteria for unitizing data: (a) it must be heuristic in nature and (b) it must be able to stand by itself. In other words, the information must be interpretable without any additional information in the broader understanding of the context. Categorization of the information after it has been put in units is the next step in the data analysis process. Simplified, categorization entails placing the units into categories based on the content of the cards. After categorization of the units is complete, the pile is labeled. A review is conducted to make sure there is no overlap of information. The categories are reviewed for possible relationships among each other. Decisions can be made at that point to combine categories or subdivide them. Lincoln and Guba (1985) suggest that there are rules to guide a researcher on when to stop collecting and processing: When there is an exhaustion of sources; when there is a saturation of categories; when there is an emergence of regularities; and finally, when there is overextension of data, meaning no new information is being brought that would contribute to the categories.

Several authors suggest that cross-case analysis or cross-case causal networking is a form of analysis that helps a researcher examine more than one case by completing a comparative analysis of all the cases in a sample. (Creswell,1988; Huberman \& Miles; 
1994; Lincoln \& Guba, 1985). Creswell (1988) defines it as the step that typically follows the within-case analysis. Huberman and Miles (1994) suggest examining the streams of variables that come from the outcomes that were measured and finding those that are similar or identical across the cases.

As a part of my data analysis of the information gathered in this research project, I went to many lengths to ensure that I took the steps noted by well documented researchers in the field. I carefully read and reviewed the transcriptions of the interviews I conducted for my initial reactions to the content of what was said and made notes summarizing in a word or two the content of a particular paragraph. Instead of highlighting, I assigned each woman's transcript a color so that when cut and placed into categories, they could be easily identified. This allowed me, at a glance, to see how many women had similar thoughts, beliefs, or experiences. I carefully sorted these into categories that emerged. After completing that task, I began to categorize the data. I developed an organizational chart of the information and began the process of data reduction and reorganization that enabled me to begin to find the developing themes in my research. I continued to move the categories around into placements on the chart that would make the most sense relationally, although it was clear that many of the categories were intersecting with other categories. This allowed me to explore the relationship between the categories, which are explained further in chapter 4 . I also developed different charts based on different lenses that were based more on conceptual thoughts of what the categories represented within a larger scheme.

To minimize bias in my interpretation, I used member checking and the peer review process. A selected colleague was asked to serve as a peer reviewer. My peer 
reviewer was a fellow doctoral candidate and student affairs professional with over 13 years of experience working in higher education. I asked her to serve in this role because of her work at FIU and her expertise in student development. She was provided with a copy of all of the transcriptions. She was able to provide a second opinion about the merging themes. My peer reviewed material helped check for bias and elicit different explanations or interpretations of the potential emerging themes.

Keeping a research journal and field notes during the process helped me to reflect on the experiences, non-verbal behavior, and initial interpretations during the meetings with the students. I wanted to make sure the key information that was coming from the interviews was recorded as it was happening. I found keeping a tape recorder more helpful than the actual journal process. I was able to have more of a free flow thought process. Later, it also allowed me to hear the emotion in my voice as I was going through the interview process.

Triangulation is an attempt to gather data from different sources using a variety of data collection strategies to look for consistency and divergent views (Newman \& Benz, 1998). Triangulation was accomplished through individual interviews, two focus groups, member checking, and the peer reviewing process. Newman and Benz also support these processes of member checking and peer reviewing and suggest other ways to enhance trustworthiness, including prolonged engagement on site and peer debriefing. I included these measures in the study. The methods described in this chapter helped me to provide a comprehensive data analysis, which is presented in chapter 4. 


\section{CHAPTER IV}

\section{PRESENTATION OF THE DATA}

The purpose of this chapter is to present the data and results of the study about Cuban American women attending a Hispanic Serving Institution (HSI). Prior to the findings, an individual profile of each of the 12 research participants is presented as a way of introducing and giving a glimpse to the reader about the unique personal characteristics each of these women. Additionally, a description of the setting is also shared to demonstrate the contextual setting of the study, as it will be helpful to understand more about the place where these women spent a substantial amount of their time. Finally, the themes that emerged from the data as a result of the narrative interviews with these participants are presented and discussed.

\section{The Setting}

Florida International University (FIU), located in Miami, Florida was founded in 1965 and opened its doors to the Miami community in September 1972. According the FIU website, FIU began with 5,667 students and was Miami Dade County's first public university boasting the largest opening day attendance of any university in the United States. Considered a 4-year public HSI, FIU is classified by the Carnegie Foundation for the Advancement of Teaching as a High Research Activity University (www.fiu.edu). With current enrollment at approximately 38,000 students, FIU hosts students from all over the world; however, $52 \%$ of the student body is of Hispanic decent. FIU is currently one of the $25^{\text {th }}$ largest universities in the United States. Among the 100 top degree producing colleges and universities, FIU ranked $3^{\text {rd }}$ in granting bachelors and $9^{\text {th }}$ in granting masters degrees to minority students (www.fiu.edu). 


\section{Participants}

Twelve self-identified Cuban American women aged 18-25 participated in this research study. All of the women were current junior, senior, and graduate students at the time of the research project. All had attended FIU for at least a year prior to the study; these criteria were used to ensure that each had a good understanding of the possible impact (or perceived impact) their college experience had on their identity formation. For reasons of confidentiality and anonymity, each woman was asked to select a pseudonym by which she wished to be identified. Personal information about each woman was gathered before the first onset of interview and recorded on a data sheet. Table 1 is a summary of demographic information about each participant and is provided here as a way to gather a comprehensive look at the participants. A brief description of each woman, in the alphabetical order of their pseudonyms, follows.

\section{Blair}

Blair was a 22 year old senior, majoring in Occupational Therapy, born in Miami. Blair's parents were born in Cuba and both received a high school education. Her favorite story told to her by her parents was how they met at a bus stop in Cuba. Her dad pulled a hair ribbon from her mother's hair. He asked her to meet him later; however, her mother rebuffed the advances and told him that he would have to come to her house if he wanted to see her. Traditions and stories like this one stayed with her, and she would like to pass them down to her family someday. Her decision to attend FIU was based on a decision to stay local. She says, "It was really weird for me to leave my family and they didn't want me to leave..." When asked about her overall college experience, she said that she was not that involved her first 2 years, but all that changed when she moved on campus. She 
Table 1

Summary of Participant Information and Basic Demographics

\begin{tabular}{lllll}
\hline Name & Age & Major & Classification & Country of Birth \\
\hline Blair & 22 & Psychology & Graduate & United States \\
Carmen & 21 & Education & Senior & United States \\
Carolina & 23 & Spanish & Senior & United States \\
Isabella & 20 & Public Administration & Graduate & United States \\
Jacqui & 20 & Journalism & Junior & United States \\
Luz & 20 & International Relations & Junior & Cuba \\
Michelle & 22 & Psychology & Junior & Cuba \\
Miette & 21 & English & Junior & Cuba \\
Natalie & 21 & Political Science & Senior & United States \\
Sarah & 20 & Nursing & Junior & United States \\
Sofia & 23 & Psychology & Graduate & Cuba \\
Tiffany & 20 & English & Junior & United States \\
\hline
\end{tabular}

joined a sorority and became involved in other campus activities. In hindsight, she wishes she had joined a sorority her freshman year because of all the things that it offered to her. She commented on how her confidence level, ability to balance her life, and socialization skills improved and how she became more refined and diplomatic when dealing with people. She feels that all the good that she put into relationships, her community, and her family would come back to her. As she said it, "I am who I am right now." 
Although she embraced many of her Cuban American cultural influences about

being, she has mixed feelings and frustrations about the concepts of race and ethnicity.

She remarked:

...I was born here. I don't really want to be like considered like, Cuban. Yes, I am, like culturally that but you know, at some point every American was British or Irish or you know, like nobody, nobody's really like American except the Native Americans... and I'm just like you know, I'm American that's my culture. I'm an American like, yes, I have Cuban descent but I mean: don't the Germans, don't the Italian Caucasians...don't they keep the traditions? Like why am I, like, just because I'm, you know why am I...fine..., you guys beat me here by like hundreds of years, but still I eventually want to integrate into the American culture because that's who I am and I've always wanted to...

She described herself as blunt and honest. As she made decisions about her future, she said she always wanted to move away, that Miami was not the place for her. Now that she had experienced living on campus, she felt that she was more comfortable with herself and that she had gained a sense of independence about who she was. As for her thoughts on her peers

...I have so much faith in my generation, like particularly in my peers, my Cuban American peers at this age. I see, I see them. I see what we're doing, and I have so much faith in us. And I hope that we are the generation that paves the way for our children and really like helps our culture like be really accepted and be considered Americans.

\section{Carmen}

Carmen was a 21 year old, senior, Education major. Born in Miami, she was the youngest in her family with five half brothers, something she said worked to her advantage growing up. Her parents were both born in Cuba. Her father, who had since passed away, was a medical doctor in Cuba, and she considered him to be her best friend. After he moved to the United States, he received certification to practice family medicine. His professional experiences had a profoundly positive influence on Carmen. 
She commented on how she shared many of his personality traits, including being nurturing and caring. She described him as outgoing, giving, and adventurous, as well as being someone that she strived to be like; "I want to immortalize him in that sense by doing all the good I can.” Although many of her family members thought she should pursue medicine, her dream was to be an elementary education teacher.

She was also very close to her mom and grandmother. She lived at home with her mother and her grandmother lived down the street. Her mom was very supportive of her education and Carmen was not expected to work during the school year. Her choice to come to FIU was based on several things. She felt that she wanted to stay close to her mom, but mostly it was to alleviate the financial burden on her family, even though she received scholarships to go out of state. She did pause and reflect as she thought about what it would have been like leaving and the impact it could have had on her sense of independence. She attended private, Catholic school from pre-K through high school, and she wanted to lessen that burden on her family. Her relationship with Catholicism played an important part in her life. She found practicing her religion comforting during the difficult times, and felt that "God is always there."

Carmen also spoke of how she felt "at home" and about the "fit" she had at FIU. Since attending FIU, Carmen commented that some of the changes she had seen in herself were her increased self confidence and becoming more open minded to different things. When she came to the university, she decided that she wanted to become involved in campus activities and found some organizations that became a part of her overall experience. This also included a study abroad program: 
....and then in the Free Cuba Foundation, it was interesting. I got the opportunity to meet other students, who like myself were at the university level and were very passionate about Cuba, so that was exciting. Then with the Catholic Student Union, it kinda made me feel like at home, because I've gone to Catholic school all my life and it was my first time attending an institution that wasn't Catholic..so it was...it was a continuation.

Her passion and understanding of her Cuban culture and politics stemmed from early childhood memories. Both her mother and father were involved in politics. Her father was a politician in Cuba. She remembered listening to the local Cuban radio station in the morning and discussing the political situation in Cuba, as well as reciting Jose Marti poetry in elementary school. When I asked her what it meant to be Cuban American, Carmen said:

Well I'm American because I was born in the United States and I am proud to have been but at the same time it's acknowledging that you have those Cuban roots. By identifying yourself as Cuban American...those roots have made me who I am. They, they're in the way I talk and the way I speak and what I eat ... in everything.

It disappointed her to some degree that her peers were not so engaged in social causes about Cuba, "where we come from makes us who we are today and also who we will be tomorrow."

\section{Carolina}

Carolina was a 23 year old senior, majoring in Spanish. With aspirations to work in international relations, she said she would possibly like to represent the United States by living in another country or working with embassies and consulates some day. She was the oldest child of her Cuban born parents. Born in Miami, Carolina also had a younger brother and sister. Both of her parents attended college and she described the relationship with them as close and supportive: 
I think that family is pretty much like one of the most important things. I think that without family, I don't think I would have too much direction. I wouldn't have a support system. They're always there for me.

She made a decision to move out of her house so that she could live on campus; however, there still was a latent desire from her parents to have her live at home. Academically, Carolina had changed her major four or five times, but despite that, her parents supported her educational goals. She had been actively involved on campus including being a member of sorority, Dance Marathon (charity fundraiser), Relay for Life, and some academic honors societies. Carolina attended private, Catholic school all of her life and did not consider herself overly religious; but religion had played a large role in her life. Carolina contended that because she attended an all girls Catholic school, she wanted to join an organization that would expose her to different people, other cultures, and people who did not have her same upbringing. She said that she "has loved her time at FIU" as she reflected on all of these experiences.

When asked who she was and what she believed in, Carolina responded:

I would say I am an ambitious girl that is getting educated to do the things she wants to do. I would definitely mention that I am Cuban American but I think that's a big part of who I am. I would mention how I am very close to my family and how I would just want to make them proud and other people proud. Determined to do what I want to do and to realize my dreams

\section{Isabella}

Isabella was a 20 year old graduate student who was getting her Masters degree in Public Administration. She graduated from FIU with a Bachelors degree in International Relations. She was born in Miami and at the time of the study lived at home with her younger sister, mom, and dad. Both of her parents were born in Cuba. While her mother never made it past sixth grade, her father finished high school and attended some college. 
She described her parents as hardworking, entrepreneurial business types with a solid work ethic. She said they had worked very hard for the successes the family had achieved. She described the family struggles that her grandparents (on both sides) went through to get where the family was and survive, including her grandfather spending a year in prison to buy freedom for his family. The importance of family, being successful, and obtaining an education was an ingrained value that Isabella described:

You know, if you live a sufficient life did you fulfill these goals; did you fulfill your career dreams? Did you give enough to leave some for your grandchildren and your children? Success for them is did you do something for your children and grandchildren. That is how they measure themselves.

Living in a traditional Cuban household, she said, was very challenging while going to school full time. The expectations placed on her, from her point of view, were to go to school, hold down a part time job at the university, help out at home by doing household work, attend to her younger sister, and work at the family business doing secretarial work. Gender roles and cultural expectations for her were clearly delineated and expressed growing up. Her father was the head of household; her mother was the caretaker of the house and children, and she was not to leave home before she was married.

Even though Isabella worked very hard through a specialized program to obtain enough credits for an Associate's degree before she even started college by participating in a dual enrollment program, her intent was to go away to school. She applied to several schools, including one in Washington, DC, despite the fact that she received scholarships to some Florida schools. The family business was struggling, so the answer was no. With her full time work schedule, Isabella was taking six classes a semester, so there was little 
time for socializing. However, while in graduate school she did start a club, the Modern Language Graduate Student Organization.

She described herself as determined and hardworking and as she said, "I really see myself as someone who has a lot of goals and a lot of hopes and I don't see a margin for failure." She attributed her believes, morals, and values to her parents, "My family has taught me how to be me." Her father was one of the most influential people in her life. He advised her and taught her how to take care of herself; he told her not to get discouraged, to never take no for an answer, and to never accept failure. As she spoke, Isabella described her struggles with the issues of culture and how Cuban Americans were perceived by others. She wanted to leave Miami someday, when she was financially able, to "test the waters and make a way for herself." Isabella would like her parents' support but she knows that may not happen.

Jacqui

Jacqui was a 20 year old sophomore, majoring in Broadcast Journalism. As the youngest of three siblings, she lived at home with her parents, older brother, and sister. Despite her parents' hope that she would attend law school when she completed her degree, Jacqui wanted to be the first Hispanic female news anchor on Good Morning America. She was born in Miami and both of her parents were born in Cuba; she "feels" the struggle that her parents endured created an important sense of family for her. As she described it:

As I got older, I started to realize the importance of family. I really understand that concept of blood is thicker than water. In the end no matter where you go or what you become, you always have your family. It's interesting because my past is always going to be a part of me. My father's past, my mother's, my grandparents' past is always in a way a part of me. I feel like I carry on some of 
the things they had to go through and the experiences and the struggles. So even though I never had to struggle, I feel like there's a part of me that carries that with me because it has made me who I am.

The importance of education was stressed by all members of her family, including her grandparents. Jacqui's grandparents were college educated with careers established in Cuba but were unable to get jobs in the United States due to language barriers. Both of her parents obtained Associate degrees and felt very strongly that education was a way to a better future. She said that both she and her sister took education very seriously. Jacqui originally made a decision to attend a PWI in central Florida because she wanted to move away from home. She found herself transferring to FIU after only attending one semester. She described this experience as

... I think when I went to college and spent some time away from home, I really started to miss my family...don't tell them, I would never admit it...I really started to miss my family. Miss a sense of culture because I was in Orlando. There wasn't a big Hispanic population, and so I kind of missed that feeling of being welcome and seeing people that looked like you, act like you, and you really can connect with. That's really when I started to get close to my family.

During that time away from her family, she commented about how much she learned about herself and how much she grew up. Since her time at FIU, Jacqui had been involved in several campus activities, primarily in Dance Marathon (charity fundraiser), student government, and the Peer Advisor Orientation team, which she described as "awesome." All of these combined experiences she said "have made me more of a leader" and given her a sense of independence, despite the fact that she lived at home.

When asked about challenges and decision making, Jacqui said she relied on her experiences to help her, which she said was a culmination of family and religion. Jacqui attended Catholic schools all her life and said despite what her friends were doing in 
college, religion to her was "what keeps you grounded" and acted as "this sort of conscience.” As for Jacqui's future, she stated that she hoped that she was independent and had her life together, and that she would accomplish everything she sets out to do. She said it best when she said that she made a "great decision coming here" and that for her "everything is just gonna flourish because of my experiences here, so no regrets and I'm very happy with where I am, very happy being Hispanic and all that good stuff." Luz

Luz was a 20 year old junior, majoring in International Relations. She was born in Havana, Cuba, and immigrated to the United States when she was almost 8 years old. Her family was selected in the lottery system allowing them to leave Cuba. She remembered her transition as challenging, but it was her first night in Miami that was most memorable to her. She remembered her great aunt driving her family to a famous statue of the Virgin Mary near a hospital in south Miami. She recollected:

It is kind of a tradition when someone comes from Cuba they go there. Apparently it is something that most Cubans do because she looks over all the refugees and things like that. So we went over to the church and I just remember looking at all the lights and all the buildings and my mother reminds me of it. She said that I kept saying that this is like a dream because I feel like I am not here. That is about all I remember of the first days.

Because she was the only child, both of her parents, according to her, were overprotective. However, they are very proud of her academic achievements, as neither of them had a college degree. She was the first in her family to achieve this. Because of the sacrifices her parents made for her, she felt pressure to succeed and knew that she would accomplish this goal. To her, family was everything. She said, “...you have to stay 
close to your family, and you have to defend them because it is all you can really count on."

Eager to experience something different, Luz made a decision to go away for school. However, she did not feel like her mom was ready to let her go, so she made the decision to come to FIU for a semester and ended up enjoying the experience so much that she decided not to transfer. Due to her erratic schedule, she made the decision to move on campus, which was still a challenge for her mom who felt she was "so far away." She enjoyed school, but her life on campus had been her best experience. At the time, Luz served as a Resident Assistant in campus housing. While she had also been involved with the College Democrats, Amnesty International, and various community service projects, being a Resident Assistant had been the most meaningful experience for her. She enjoyed helping her resident students and always tried to ensure that they were doing well socially and academically. When asked how she had changed since being at FIU and in this position, she said:

I am definitely a lot more open. I use to be more shy... and the more I get involved in things the more I want to get involved, which is kinda bad because then I have a very tight schedule, but I just keep wanting to do things that I always thought I wanted to do, but never really got the courage to go up and just try to do them. So now I'm definitely more involved and not afraid to get involved in different things and apply for different things.

This sense of independence was supported and encouraged by her mom, who stressed the importance that one day she should be able to be stable and live her life comfortably, but to remember the family in the process. Luz also said, "I'm more self confident, more ambitious, and I know more of what I want to do....” Her future aspirations, while not 
concrete, may include law school. What she did know was that whatever she chooses would involve helping people.

Michelle

Michelle was a 22 year old junior, majoring in Psychology. She was born in Cuba and moved here with her entire family via the lottery system. During the focus group interview, she shared that she was about to take the test to become a U.S. citizen and she seemed excited and touched by the process. In Cuba, her father was an architect and her mother received a degree in French. While her family was not excited about her moving out of the home, they were supportive. She knew getting her degree and having a career was her ultimate goal, but she struggled with the fact that she had little time for activities and family. Michelle was going to school full time and working part time. She commented that while her parents tried to help with tuition and her car payments, their moral and emotional support was the most valuable. She was a self proclaimed Catholic who did not go to church regularly but did believe in one God. Michelle said she was raised to keep family values close; be nice to people; have good manners; and act accordingly to what her parents would expect.

When she reflected on her home experiences, Michelle was very observant to the differences in gender treatment between her and her brother growing up. Her brother, who was 3 years older, was treated differently from her by having more privileges. This self proclaimed tomboy was criticized for playing sports like hockey, riding her bike, and playing tennis, and for always wearing pants in Cuba. Her thoughts on gender equality are the following: 
I really thought women and men should be treated equally. We have the same brain cells so we should know better. I have always been a rebel because when they tell me, "No, women should do this. Men should do that," I feel like why? I always questioned. Like I am female but I like to do those things. I do them because I like to do them and that is it. I don't care if they are gender role based. If I feel like doing it, I will do it. I don't care about what other people think.

As a transfer student from a local community college, Michelle said, "I love FIU.

I love the culture. I love the environment basically." However, it was her love of her

Cuban heritage that she spoke proudly about:

Being Cuban in this society has been a great experience. I guess it has been better. I don't think it would be the same if I was born here because I wouldn't have had those roots like the way I was raised in Cuba. There is a huge difference. I thank God for me being born there cause I have a choice of both cultures and I guess I have that feeling of what it is to not be American. The feeling to come here and being a Cuban and being able to have the two experiences and it helps me a lot to be bilingual and it helps me a lot to be Cuban in Miami.... I thought it was really amazing like, if I wasn't Cuban-American I wouldn't have the things I have now. I am bilingual. I have the two perspectives so I am more like a full person.

\section{Miette}

Miette was a 21 year old junior, majoring in English. Born in Cuba, she left when she was 8 years old. In 1994, her mother came to the United States alone on a visa. The difficult and emotional decision to leave Miette behind was very hard on her mother. Miette and her father left Cuba shortly thereafter and lived together in Nicaragua for 5 years until the paper work finally went through and the family could be reunited in the United States. This separation proved to be emotionally challenging on a couple of levels. Her mother's visits to Nicaragua during this time were emotionally charged, now Miette realized the sacrifices her mother had been making for her.

While Miette's parents made a decision to divorce after the family reunited, one of the greater family conflicts was how Miette was raised. Her mother felt that her father 
was not protective enough of her while she lived with him in Nicaragua and that he had not placed enough limitations on her, in regards to things she was exposed to there. At the time of the study, Miette lived with her mother while she was attending school. She said that she was happy to be with her mom and felt that she and her mom had grown closer. Both of her parents were college educated, as well as both of her grandmothers. All of her family was very supportive of her getting a degree. A message that Miette heard often growing up was the value of education and independence, “... become educated, be able to support yourself, be independent." She said her family would define success as:

Getting the job that I want and being able to support myself and being happy with what I'm doing. Being with something that I'm happy with that I find worthwhile.

Her original intent before coming to FIU was to attend art school. Miette was a dual enrollment student in high school, and once she realized that the art school was limited in the curriculum, she decided to explore FIU. While she initially thought attending FIU was her "default" school, it was a school that she had good experiences with, including with her teachers. She did make time for campus involvement but it was not the focus of her time on campus. She was taking 15 credits a semester which left little time for involvement, but she had participated in the Honors College, the Student Programming Council, and intramurals throughout various semesters.

Her study abroad experience to Spain sparked her interest in living and working abroad in the future. Not long before participating in this study, Miette applied to a program that would allow her to teach English as a second language. The issues of identity were very personal to her as her upbringing was diverse, living in Cuba and Nicaragua. The awareness of her ethnicity and racial relations in Miami became apparent 
to her after she moved to Miami. As issues of ethnic and cultural identity were explored during the interviews, it became clear that Miette would like to leave Miami, she said:

I think I want to immigrate again and marry a foreign man and honestly why do I want to do this? Yes, it is because I want to get far away from this. I don't not like all this awareness of Hispanic versus Anglo and I do feel like I will be able to be isolated from it. Even though I will be an immigrant again, since I won't have the Cubans around me to remind me of it...you know, if I'm just by myself and people are reminding me of it. I think I definitely can get away from it and lead a more relaxed existence.

Natalie

Natalie was a 21 year old senior, majoring in Political Science with aspirations of attending law school upon graduation. Born in Miami, she was the only daughter of her two, hardworking Cuban parents. Neither of her parents went to college; however, both immigrated from Cuba and owned a successful business together. She recognized and appreciated the struggles they had endured to ensure her successes in life and education. Natalie will be the first one in her family to graduate from college, which she found very exciting. She described living at home and being very involved on campus as challenging because her parents were very overprotective and traditional in the sense that she was a young single female who should be at home attending to the family. Since her freshman year, Natalie had been involved in student government, Peer Advising Orientation team, and a sorority along with many other clubs and activities. She said that her experiences in the sorority were the most meaningful as they gave her the encouragement and boost in self esteem to try and do everything that she wanted to accomplish in college.

To her, family "is a big deal" and many of her conflicts had been from helping her parents to understand her many roles at the university. Despite that she was about to graduate, her parents still had expectations that she would help with the family business 
on weekends, an idea she supported. She was also very moved as she spoke about her grandfather who recently passed away and the care of her ailing grandmother, who lived nearby. Even with all her responsibilities at school, she commented,

My Mom's been taking care of my Grandma so I've recently been taking care of my Grandma as well. So it's kind of like making sure that I'm there for them at all times.

However, it was her grandfather with whom she shared a very special

relationship. She saw many of his qualities, especially his love and pride of Cuban culture and connections to the community. She saw these as the ties that bonded them and as something they shared. While she recognized the generational differences between her grandmother, her mother, and herself, she was determined to make a difference politically in her local community by going to law school and working to improve the educational system in Miami. She had no intention of leaving Miami, as she said laughing,

I like my bubble. ... In my political realm of what I want to do, I've realized I'm a lot more of a local person and I think maybe it's because I get to...I physically get to see what I please...like even DC to me seems like worlds away cause I don't feel like I get that connection and not because I want people to thank me. I could care less if they thank me, but I could see things with my eyes and I know what affects them personally because I live there and that's what I'm working for so to me it gives me. That's the kind of satisfaction that I think I like.

Sarah

Sarah was a 20 year old year old junior, majoring in Biology, who was studying to be a doctor. She was a full time student and single mother, raising her daughter with the help of her family. Soon after the second interview, Sarah left for basic training in the Army so that eventually she could go through the Army Nursing program to accomplish the goal of becoming a doctor. She would return to FIU before attending this program. 
Going into the Army, she said, would create the break from her family that she needed to gain a sense of independence and give her the job security for the future, for her and her young daughter. Sarah considered herself Cuban American, but also described herself as multi-racial, as her father was Cuban American and her mother was African American. She was the second oldest of seven siblings, three brothers, two sisters, and two step brothers.

Both of Sarah's parents, now divorced, were in the military when she was born in Germany. After her father left the military, he became a pastor and decided that he was going to home school the children to instill religious values. This had contributed to her strong sense of family and religion. Her father and mother only received their Associate's degree and were thrilled that she had surpassed their educational attainments.

As for being home schooled, Sarah felt that it gave her a different outlook on life. She shared:

I don't get as jilted as some people. Usually some people will freak me out when something bad happens. I just let it play out because I know that it happens for a reason. I am one of the people who believe that God has a reason for everything so everything happens for a reason. I get stressed but I don't get like overbearing stress about anything.

The curriculum was religious based, and Sarah recalled learning Bible verses and catechisms along with math, PE, and her other classes. She also stated that she felt home schooling gave her an advantage academically and, being from a large family, she did not feel that she missed out on social interaction.

In terms of her multi-racial identity, she "never felt $100 \%$ of anything." She described it as, 
I never felt distinctly $100 \%$ Cuban or $100 \%$ American. It was always when I was in one distinct element. I was kind of a little shifty when it came to that. I grew up and felt the progression and that's when I felt identifiable. Now that I have different friends; I have some Black friends and I have some White friends. Once I am in the Cuban-American element, I feel yes these are my people. This is my ethnicity. Then when I am with my Mom's family I feel American. This is what I identify with. So I guess it depends who I am with.

As for her experiences at FIU, Sarah had been focused on her academic

achievements and was very driven to succeed. She was originally going to attend another university but due to financial reasons and her pregnancy, she decided to attend FIU. She appreciated FIU for the diverse environment and for what she had gained from that. She commented on an experience that was memorable during her time at the university. She remembered seeing a mock shack, which represented all the homeless people in Miami. "It gets you thinking... I just start thinking of these new ideas, new things I might not have known prior about what is going on in the world. I realize that on campus." She further commented,

Because this is such a diverse college I do have that opportunity which is really very good because you get to see a lot of different points of views, different opinions and such.

Sofia

Sofia was a 23 year old graduate student obtaining her Master's in Psychology. Born in Havana, Cuba, she came to the United States when she was 12 years old. Both of her parents went to vocational technical school in Cuba. After a very long and arduous process, all of her family managed to leave Cuba in 1997 . Her father was very reticent to come to the United States to join other family members. The only way that he would come was for Sofia. He had no family in the U.S. but after the passing of his mother, he decided he would support the move. The transition period for her was one of the toughest 
times she ever experienced. She found the environment the U.S. to be something she never experienced. Her experiences the U.S. in grade school were very emotional. Despite the language barriers she faced, she excelled at school and worked very hard to prove herself. She described herself as shy and timid, but it was a very emotional time for her. Education had always played an important part of her life, and she was grateful for the opportunity to study the U.S. as she knew her life in Cuba would have been very different if she remained there.

In 2003, Sofia experienced the loss of her father and her grandfather within 6 months of each other. She was very close to her grandfather, and says that they shared the same caring personality. This was an especially difficult time for her, not only because she lost two influential people, but she also assumed some roles as the head of the household. When asked about the importance of family, "It is everything to me. I think it is when you are happy, when you are sad, and every moment....family comes before anything." Sofia was grateful for the spiritual and emotional support of her grandmother and her mother especially as she was about to finish her graduate degree. At the time of the interview, Sofia lived at home with her mom. Her grandmother lived very close by. She recognized that she needed independence but found it was hard, "I think part of it is I have always wanted to move away to school to try to see how I could do by myself and I never did because there was always something that would stop me.

When asked to describe herself, she admitted that she was often soft spoken but she offered this:

I have always been as labeled quiet, the good girl, always there when you need her, always quiet and calm and all that stuff. I have a very strong character. That is what I find interesting, that I come across that way but I hold a lot inside. I 
don't express it because I don't want other people to feel bad or I don't want them to change the perception of what they have of myself.

As for how she defined herself living in Miami:

Like since I came here I have always thought of myself as Cuban. Like even now, I don't call myself Cuban-American. I call myself Cuban and even as the time passes by I think I am Cuban and not American...there is the Cuban way and there is the American way and if you go too much into one of the two it is bad. So if I stay at times to my Cuban roots it is like I am not getting used to the American way. I can be singled out. The way we say it in our culture is like you just came from Cuba and you are not letting go to those old ways because that is seen as bad.

Her experiences at FIU had been very positive in all of her years attending this school. She felt that FIU offered her a place where she "fit" and she did not feel isolated. She said that since she started attending FIU, she got involved in various women's organizations and events on campus. All of these she said had made her less shy and more open to meeting other people. Sofia hoped to be a therapist when she graduates, but she said that she wanted to be successful at everything she were to do.

\section{Tiffany}

Tiffany was a 20 year old sophomore, majoring in English. Her career aspirations were to attend law school when she graduates. Tiffany was born in Miami while her parents were both born in Cuba. Her mother and father both came to the United States when they were just small children. While neither of her parents had a college education, both completed high school. Tiffany's mom had a vocational technical degree. At the time of the study, Tiffany lived at home and commuted to school. She had a younger brother who lived also at home.

Tiffany cited that the reason she lived at home was solely financial, though her mother did not really want her to leave home. Tiffany felt that her decision to live at 
home and save for law school was the right thing to do. She described the pressure she felt about being the first one in her family to graduate from college, a daughter, and what success meant for her family:

...I don't stop. I do everything and I have to do everything. I need to be there for them. I need to help them with their business. I help my mom at work. I'm her assistant. So I work for (her company) also. I'm my dad's secretary. I do his contracts. When he's short a man I get in the truck, I help him. I help my little brother. I come to school so I'm getting so emotional...so I'm like the guinea pig. I'm gonna cry. Just to always push not to stop to keep going so be there for mom, be there for dad, be there for brother...helping with school being the example. The first to go into...my parents always thought that education was number one. Without a degree unfortunately you can't get anywhere in life. They feel like everyone else is ahead being that we had to come to this country and start over. There's the pressure of not failing because you're the first. So you're the example and it's almost like you're the stepping stone for those behind you. So you have think of those coming behind you all the time.

Respectful of her parents, she strived for independence. Not wanting to ask them for money, she had a part time job that allowed her to have some spending money. This allowed her some freedom to buy things for herself. The double standard she perceived at home was frustrating to her. She clearly saw that her younger brother was allowed more privileges and could come and go as he pleased. This was not so for her. While she did not appreciate this traditional Cuban way of thinking, it was her reality. She was very proud to be Cuban and wanted to share with her future family the culture of where she came from, not only Cuba but Spain too.

Despite her busy schedule, Tiffany considered herself a practicing Catholic. The value of religion was not only instilled in her, it was what helped guide her every day. She said, "Religion is everything." Her beliefs had also made an impact on her as she valued community service and giving back to others. During her time at FIU, Tiffany had been very involved in several campus activities including student government, 
Homecoming, and a sorority. Her real passion was intramurals sports. She said joining a sorority was the perfect way to play intramurals and as a bonus she had enjoyed taking on other leadership opportunities within that organization.

\section{Summary}

While each of the women shared a relationship with the other women simply by identifying themselves as Cuban American, it was much richer than that. They shared many things including a family history of immigration, various familial struggles of acclimation to Miami, religious values, a drive for success, and a pride in their cultural ancestry. As each of the women told her stories, the themes began to emerge from their voices. The following is a presentation of those themes.

\section{Themes}

Information gathered from the pilot study was reintroduced in the study as I began to interview the remaining participants. As mentioned previously, some of the initial themes that emerged in the pilot study were (a) general differences in gender roles growing up, (b) the importance of religion, (c) the expectation of educational attainments, (d) the importance of family, not only in support, but in development of core personal values and moral development, and (e) the importance of having a cultural identity. As I began to code the data from the study, it became apparent that these themes were prevalent throughout the coding process. The complexity lies within presenting the data in a manner that is easy to understand. Identity development and formation is complicated, and there were themes that emerged from the data.

After creating a flowchart to begin to examine the major themes based on the participants' interviews, it was clear that many of the themes overlapped and that 
distilling the information was difficult. My peer reviewer offered some helpful words, which resulted in a breakdown of the themes even further. With her assistance, we identified those topics that were the most relevant to my study and the relationship each topic had with the other themes. Figure 1 presents the final coding of themes and in a chart. The themes were displayed by the different aspects the women discussed in their individual and group interviews. After reevaluating and reexamining the data, the flowchart presented is the best representation of the data, but it does not show the relationship to each other. Figure 2 allows the reader to visualize the relationship within each theme in terms of dependence and interdependence. As shown, family, gender, culture, and ethnicity are all interrelated to each other. All have a significant impact on identity formation and development but the theme of education was more closely related to the theme of family. Ethical and moral development was the theme that appeared to have a partial, yet important relationship to family and gender. It could be argued that the theme of culture could have an impact on ethical and moral development, but because family and culture were dependent, the relationship with ethical and moral development was seen as tertiary. Figure 3 represents the "lens" that the themes represent. Research on identity development is often presented from a singular lens, typically from a psychosocial, anthropological, or sociological view point. This will be discussed at length later in this chapter, but I suggest that looking at the findings from a multiple lens perspective gives the research on identity development more depth and breadth than when it is presented from a single lens perspective. It is not surprising that several of the themes overlap each other as identity development is not isolated by individual 


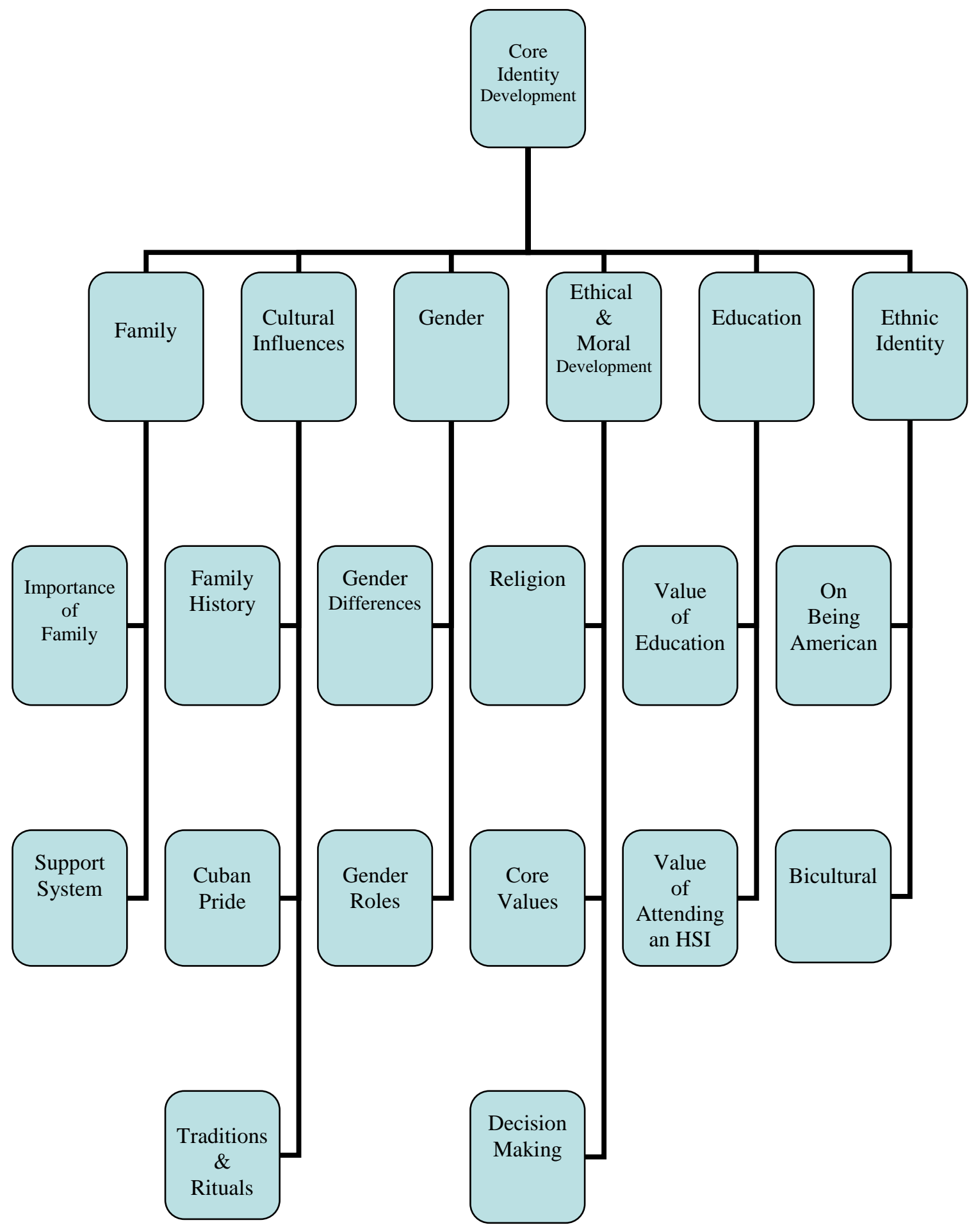

Figure 1. Final coding of themes of influences and factors affecting identity development of Cuban American women participants. 


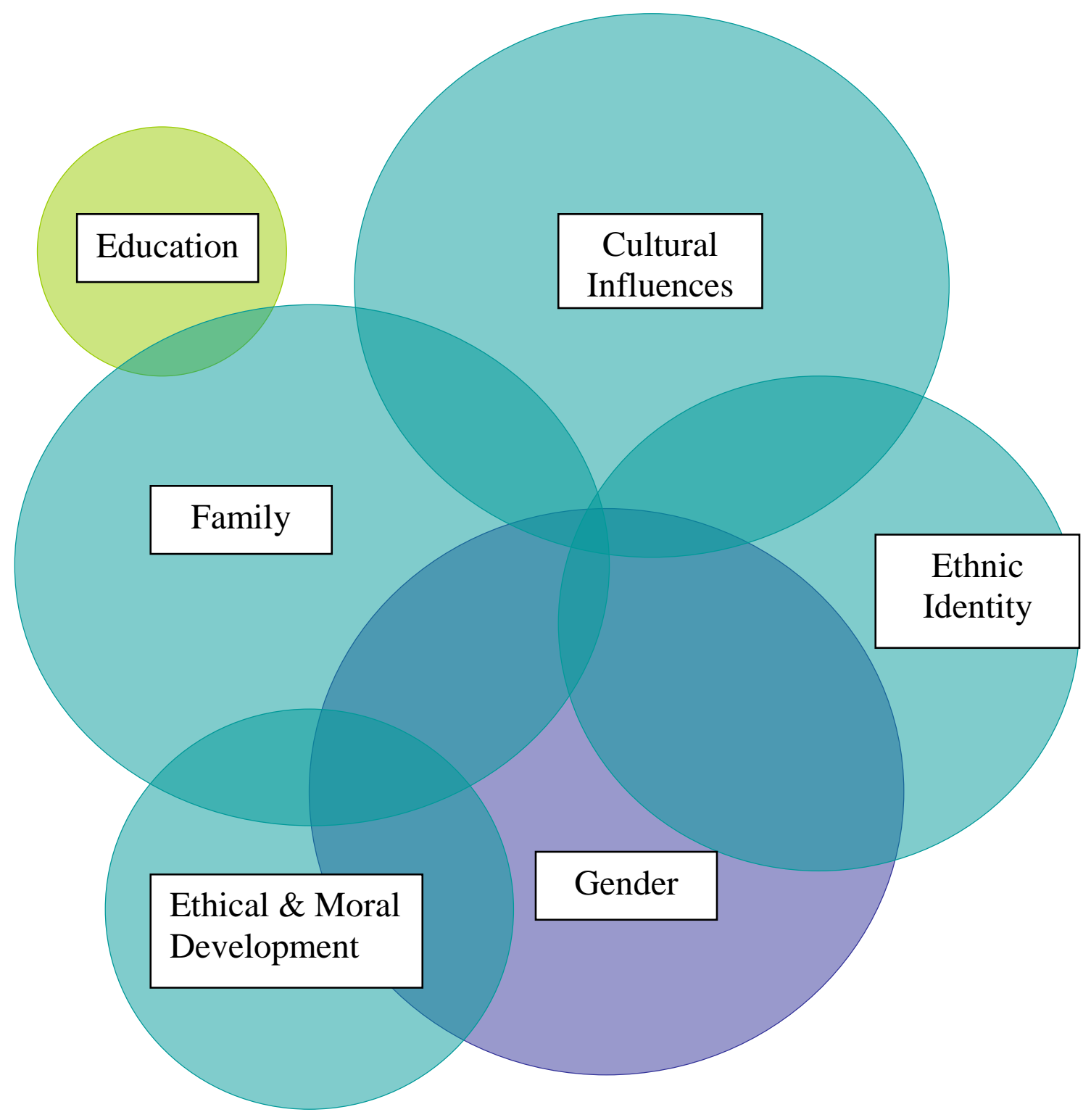

Figure 2. Relationship describing the concept of dependence and interdependence of themes relating to identity development of Cuban American women attending a Hispanic Serving Institution 


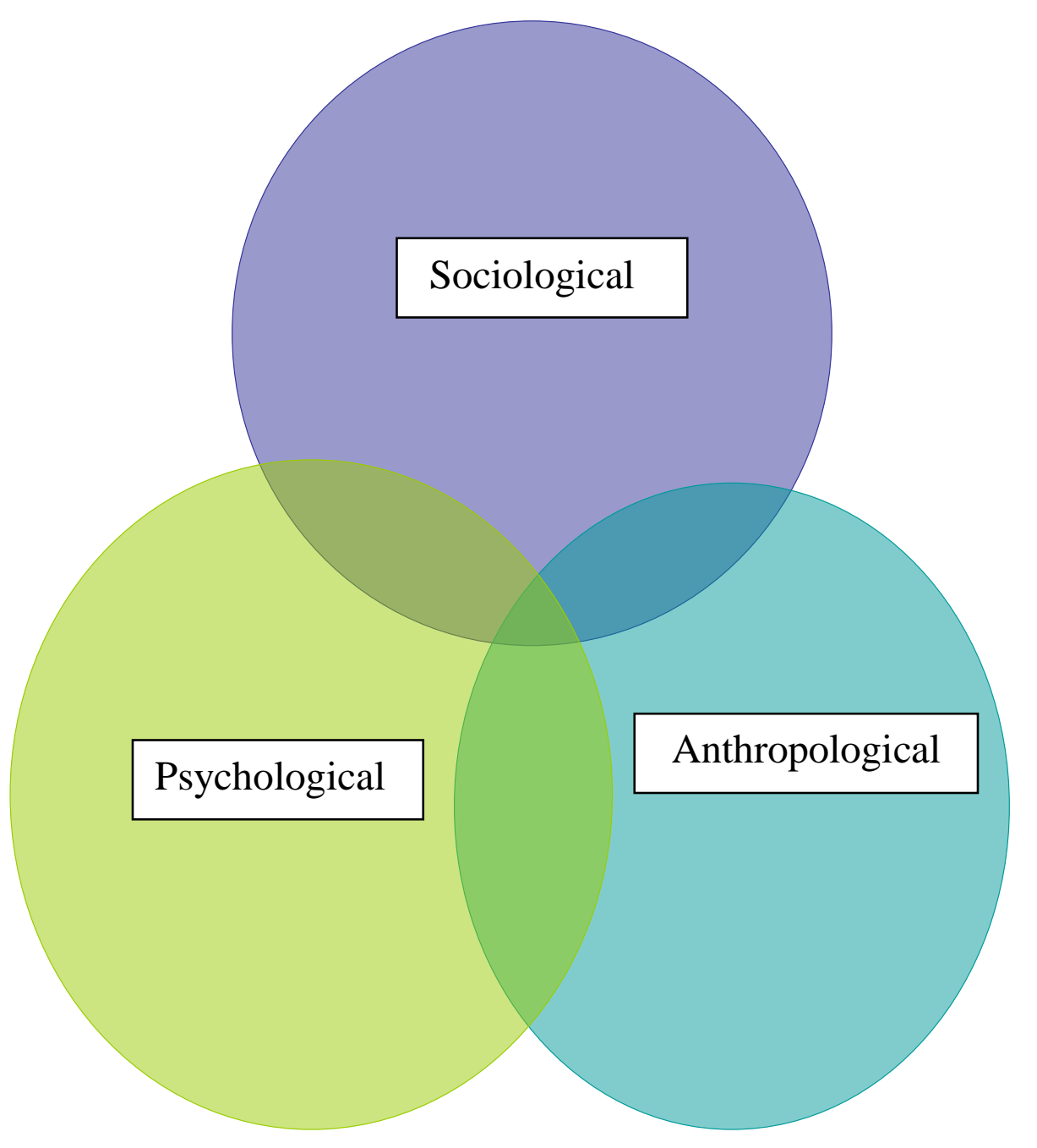

Figure 3. Theoretical framework lens examining identity development of Cuban American women attending a Hispanic Serving Institution. 
components but rather it is comprised of components that interact with each other as discussed in Jones’ Multidimensional Identity Development Model.

Some themes were interdependent (cultural and ethnicity) because they could not stand alone to paint the entire picture of these participants. However, the theme of education was not reliant or dependent on the other themes, but it was a significant influence on identity formation. The themes are not presented in any particular order of importance; rather they are presented in an order that builds a progressive story. Based on the data, the six topic areas are (a) family, (b) cultural influences, (c) gender, (d) ethical and moral development, (e) education, and (f) ethnicity. Within each of these areas are several themes.

\section{Family}

The topic of family is used to describe the significance family plays in the life of the participants in this study. It includes two themes (a) the importance of family and (b) the influence of familial support. It is not surprising the family theme is significant in the findings. As the literature states, family influence is a factor when examining ethnic identity of Latino students (Torres, 2003). However, there is no research that I have found that supports the idea that the role of the family and family history are important in the identity development of Cuban American college students. The women clearly articulated that they were in part who they were because of their relationships with their families and their family histories. Ethnic identity is just one facet of an individual's identity. The importance of family on identity development, as it is discussed here, is the cornerstone of the findings from which all the other themes stem and are related, including education. 
Importance of family. The first theme in the family is the importance of family (including non-familial members). This theme emerged early in the responses and is very closely linked with the other themes. The importance of family permeates throughout the findings in this chapter. The focus of this theme is to provide a context of the importance of family, culture, and other themes withstanding, and how important the concept of family was ingrained in the participants and to what degree it influenced their identity development.

The theme of family emerged early in the interviews. Developmental theorists such as Chickering, Josselson, and Gilligan, discuss the importance of maturation in terms of the interpersonal relationships, but not as it relates to women and the family in the younger formative years (as cited in Evans, Forney, \& Guido-DiBrito, 1998). There is no mention in the research literature of what the impact of the messages of family, whether verbal or non verbal, are on identity development and how it affects identity development.

All of the women who participated in this study spoke of the importance of family to them personally. Despite the closeness of the women to the family or the stress they felt at times with the family, the bonds were strong. Sophia, whose father and grandfather both passed away within 6 months of each other and who lived with her mother and grandmother described the importance of family as,

It is everything to me. I think it is when you are happy, when you are sad, and every moment. I mean I go home and I am surrounded by my family now, since I don't have those other people, is my mom, my uncle, my brother and my grandmother. It is a lot of work too. As I have a kind personality and I take the time to worry about them and stuff like that but it is everything I know and everything I think I will be learning later on. Always when I was young, sitting next to my grandmother learning how to cook...now a days, I come home and I 
don't do anything at home because my mom and my grandmother take care of it. So it is actually a luxury. It is not only the material things they can do for you but more like spiritual support. Like I was just going through finals and my grandmother asking me every 5 minutes "Are you okay?" "Are you eating?" This and that....and it is nice to have them around.

The importance of family as a unit was so integral to the lives of these women;

the reactions were at times very strong and emotionally charged as they spoke about their families. Many of the participants cried as they shared stories of their families. Jacqui was the only participant who originally went away to school and transferred back home and into the FIU. She realized just how important her family was to her after she was on her own. She recollected that time as challenging but integral to her identity formation:

Family's definitely important. I know when I was younger, I was rebellious. Not rebellious, like I did bad things but I didn't want to spend a lot of time with my family. I hated going to family functions and family parties. I was very into my friends and school and the activities I could do at school. As I got older, I started to realize the importance of family. I really understand that concept of blood is thicker than water. In the end no matter where you go or what you become. You always have your family... But I definitely think that family is extremely important and it's makes you who you are. It doesn't matter where you go and even if you don't get along with your family, you just can never run away from them.

Messages about family are not always explicit verbal messages; some of the messages are implicit. Sarah, who came from a military background and grew up in a large household with seven siblings, recollected her family time and the value she placed on that:

Both of my parents were family oriented especially my Dad. He was a real family man. We went out on outings on the weekends. During the week he would take us to the track and we would run. I remember Susie, she could run a mile at the age of five. He took us on bike rides. There were like eight of us. One time we were going through this neighborhood and there was this little kid who asked, Is this a bike race or something? We were always together. My parents since their divorce have always had the team mentalities. If one person can go, we all can go. 
Carolina, who was close to her family, was living off campus away from her family. She described the closeness with both of her parents in different ways. She said that her mom was someone she would go to for certain things, like personal issues, but her dad had been a good dad and "he's really been good providing everything for the family and a good supporter." This sentiment, the role of the mother and father in the family dynamic, was echoed by other participants as well but as Carolina said about her family:

I think that family is pretty much like one of the most important things. I think that without family I don't think I would have too much direction. I wouldn't have a support system. They're always there for me. We're really close. Not only within my nuclear family, my parents and my brother and my sister, but within my entire family.

Luz was another participant in the study that moved out of her house and into campus housing. During that time, she assumed a leadership position as a Resident Assistant. She was very close to her mom. She enjoyed her experience living in the residence halls and had created her own "family" community with her resident students based on learned behaviors from her mother. Luz told how her mom was supportive of her living away from home but was constantly reminding her of the importance of her family. Luz described it as:

Definitely that family is very important and you have to stay close to your family and you have to defend them and because it is all you can really count on. I see that it is true because like I mentioned with my father and how we don't talk for a while and then we just start talking again. It is just something that I see in the family. With friends it is very very rare that the same kind of argument arises and then you just start talking again. That is very very rare. Usually you have to adjust with it and talk about it. With family, it just kind of rolls off your back after a while. With family you just love each other and you accept it when bad things happen. 
On few occasions during the interviews, the women spoke of "members" of their families that were thought of as family members, but were not blood relatives. Carmen described this concept of family as:

Family means to me a group of individuals that they can be related by blood or not by blood, because there are friends of mine that I consider family. You know that you are there for each other.supporting each other in every possible dream. Even if that dream doesn't necessarily involve you. Like you know for example...my dream to become a teacher. I know I could count on my family. I say family, not only referring to my blood family but also those friends that I consider family.

This concept seemed to be common and accepted among the women. It was not surprising that the women referred to their friends as family because this was learned from behaviors exhibited by their families. Later Carmen commented:

Family is number one. You know, be a good person. Never forget where you come from. I think that's so important. I see people whose parents are Cubans and they're like I don't identify with all those Cuban Americans. Knowing where you come from. I'm trying to find the words. It's about having roots and knowing how to fly. You have to have one to have the other. You have to always have that place that you call home so I would definitely, stress that a lot. Just love for Cuba in general. You know like, I want to pass that on.

Family as a support system. The second theme is of the family as a support system. It is important to understand the support system dynamic within the family structure. This theme could have been placed with the section on cultural influences; however, I believe, is best suited in the family category because it exemplifies the importance of family support values shared by these women. Most of the participants described their home life as caring, loving, nurturing, and supportive. The support for these women spanned from emotional, financial, community, and familial support. Community support will be discussed later in the chapter; however, this section will provide an understanding to the complexities of the relationships these women had with 
immediate family members and the support they offered these women. The discussions with the women revealed they received support in various ways, whether it was a life decision, educational decision, or advice when needed. In the preceding section on family history, many of the participants described family struggle as the foundation to the family structure. Often times as described by the participants, the family support for the decisions of these women was so that they had a better life than those that came before them.

Natalie knew that her parents struggled a lot as they made their way in the United States. This was something that she thought about as she was the first one in her family to graduate from college. I asked her about the importance of this but her underlying message was about the support she received from her parents.

To them it's a big deal.... just think a lot because they haven't been able to obtain. They feel sometimes...I go to my parents job to pick up something and like there's kind of like a counter, so my parents' and employees are on one side and whoever comes in, come through there. So he'll be like "This is my daughter...all this is for her" and tap me in the shoulder... They've always taught me you need to not only love yourself and do what you want to do, especially in your education. Anything that involves that or what I want to do, they will give the world to me.

Later in the focus group she said:

....because even though they're my goals, I know in the end it's also my parent goals too. I think I've been fortunate because a lot of the times I hear parents forcing you to do anything and my parents have always been pretty open to me wanting to do whatever I wanted to do. ....Even though I know their highest goal would be for me to do the highest potential but at the same time, you know them having a chance not to have those goals, kind of pushes them to work for and be there for me.

Carmen, whose career aspirations had always been to be a teacher, said she felt pressure from other family members to be doctor like her father. She said: 
Well, I have to start off by saying that my family is very supportive of my dreams. They're like, whatever makes you happy and you're not doing harm to yourself or to others. That's what they've always told me.

After she told others that she did not want to be a doctor, her mom told her:

Ultimately, I will support you in whatever you decided, because it's your future and I want you to have all the opportunities I never had.

Carmen, who was living at home, said her mom insisted that she did not work so that she could focus on her educational attainments.

Luz had a very close relationship with her mom, who looked forward to Luz coming home whenever she could. Recognizing the sacrifices that her family was making in order to support her, Luz said:

She is very hard working. We don't make much money and she has other problems, and she always seems to take care of things. She does anything for the family. She is very overprotective. It is out of love.

Carolina, who made a decision to not live at home, said her mother, who was sending mixed messages, often remarked about her coming home after her lease is over. While Carolina has no intentions of doing that, she said her parents had been supportive of her living away or traveling because it was what she wanted to do. As she described her relationship with her parents, she shared some of the same sentiments as a few of the other participants:

My relationship with both...I'm very close to my parents. It's close in a different way because there are things that I talk to my mom about and things that I talk to my dad about, you know. Maybe more things having to do with guys or something like that. You know that I would probably go to my mom and my dad just because they have different opinions and different views about different things. My parents are also very into like helping me. They support me in everything as long as I'm happy...that's always what they say. 
Sarah also expressed this as a family philosophy:

I think one of the reasons I get along with my parents so well is that my parents don't really pressure me to do anything. As long as you are happy and as long as you do what you want and be productive at the same time, it is fine with them. They don't really push to be a lawyer or a doctor or you have to do this or do that. They just let us be.

Sophia, who was living with her mom and her grandmother, felt very fortunate to have them as a support system. She knew that living with them was a luxury because she did not have to worry about cooking or laundry because it was done for her before she got home from work and school. She said, "It is nice that I call my mom my best friend. We can talk about everything. She understands me a lot. She does a lot for me to be good and stuff like that."

\section{Cultural Influences}

The topic of cultural influences in this chapter describes the impact that culture plays in the formation of identity development of Cuban American women college students. It includes three themes of (a) family history/story; (b) pride in being Cuban, including issues of politics and immigration; and (c) traditions and rituals. The findings examine cultural influences from an anthropological and sociological perspective as these influences relate to the psychosocial development of the women in the study. Cultural influences, different from issues of ethnicity, examine the unique characteristics, values, and beliefs that are shared amongst Cuban Americans. This section gives an overview to the experiences of being a Cuban American. Issues of gender are discussed later as an individual theme.

Family history. The first theme in cultural influences is the role of family history in the identity development of the women who participated in the study. Initially, all the 
women were asked to voluntarily write down their family history in an essay form. None of the women partook in this activity, so I asked each of the participants in the study what they knew of their immediate family history or "story" including immigration issues, recollection of stories told to them, and educational attainments of their parents and grandparents. Most of the participants, with the exception of four, were first generation Cuban American, meaning their parents were born in Cuba and they were born in the United States. It was not surprising that each of them were able to tell me something about their families' lives in Cuba or their personal or family journey to the United States. Though it was surprising at the details and the extent of what these women knew about their families. As discussed in chapter 2, Cuban migration occurred in three distinct waves to the United States. Some of their parents and grandparents arrived via a lottery system, such as Luz and Michelle, or they were granted permission to leave with little issue. Michelle, born in Havana, was old enough to remember what was happening in her family. She recalled:

My mom didn't want me to go. She said like, no you are not going anywhere. You stay here with me. My dad of course wanted to come. He was the one who actually applied. There was a better future waiting for him here. Because there you go to school your whole life and you are nothing. You don't get anywhere. So my future would not be as bright as it could be coming here. Basically I could have gotten a degree. I wanted to be a veterinarian. With that I wouldn't be able to do anything. I would basically work for the government. And don't get paid anything. So that is what made my dad come over here. Because we didn't have much of a life there. My dad is an architect so he used to make good money. My mom never worked in her life. Here she sees that she has to work, but she finally agreed at the last moment

Other Cubans made decisions that resulted in family hardship and struggle during the second and third waves of Cuban migration to the U.S. This unique political migration issue created a social movement in Miami, which most of the participants were 
aware of via family history. The stories these women shared, whether they were about their maternal or paternal grandparents, aunts, uncles, cousins, or parents, seemed to have a direct impact in the value they placed on the importance of family and the appreciation for what they had. All of the participants had been affected by these experiences. The richness of all the stories is too great to discuss in depth here. The women provided insight on the emotional and psychological impact of their individual family history/story through their narratives, thus defining for them some aspects of their cultural identity as Cuban Americans.

When I asked Jacqui what she knew of her family history, she recalled a story of her grandfather's turmoil in Cuba:

I know that on my father's side they did the basic got on a plane and my dad was 10 years old. So he spent the most time in Cuba. Their journey to America was actually a very easy one, really wasn't that difficult. What was difficult was when they actually got here and they had to take on very random jobs and just kind of start over. What's interesting is my mother. She actually came with her family when she was a baby. She doesn't even really remember the trip but her father, my grandpa, was a member in the Army. When Castro came to power, he didn't really want to be a part of that Army. He didn't really agree with him as a President. So he was on a sniper list. And so one night, as the story goes, that my grandfather was carrying my mother in his arms and he was outside on the porch and there was a sniper hired to kill him. Once the sniper saw my mother, he was scared that if he shot my grandfather that he would fall and the baby would break her head or anything like that. So he actually emerged from the bushes, told him "Look, I was hired here to kill you. I couldn't do it when I saw you with the baby in your arms. I'm letting you know that if I'm not going to do it, somebody else is going to do it." My grandfather actually had to flee Cuba and he actually got on a raft, landed in Jamaica. Then from there went to Costa Rica. It took him a couple of years for him to actually meet up with my mother and her mother and my uncle.

Earlier when Jacqui reflected on the importance of family, she mentioned the idea of struggle. The idea of struggle was spoken about throughout the interviews by many of the 
participants in direct and indirect ways. It was a commonly shared thought among the participants. Jacqui said:

It's interesting because my past is always going to be a part of me. My father's past, my mother's, my grandparent's past is always in a way a part of me. I feel like I carry on some of the things they had to go through and the experiences and the struggles. So even though I never had to struggle, I feel like there's a part of me that carries that with me because it has made me who I am.

It became clearer that the importance of family had a direct link to family history/story of what happened in Cuba. Often times when these women shared their stories, whether it is of grandparents, cousins, parents or other family members, it was often associated with the feelings of struggle. As they spoke, it was as if they had this familial burden to bear, though most had never lived in Cuba. The impact of this burden permeated throughout the discussions of family and culture. Isabella recalled the stories of both her maternal and paternal grandparents with great detail, but understanding her parents' story and struggles gives great insight into the woman she was becoming. She recalled:

My father came here because my grandfather gave up a year of his life in prison under the regime of Fidel Castro to buy his freedom. That is how they got here. I would say my dad was 8 years old so that was 1970 exactly. That was right around Fidel Castro's time and my grandfather spent a year in prison and that brought my Dad, my aunt and my Uncle along with my grandmother over here. When they came here they had nowhere to go. The little savings they had to live very poorly. They didn't have shoes. They were working at farms during that time. They did what is called immigrant work for people which pretty much was immigrant work back in the 1970s. I know my grandfather he wasn't going to give my parents a home and my grandmother didn't want my mom to move back in with her because she was married with a husband. So they kind of just had to live in a little $10 \times 10$ and then they worked their way up without any money or anything.

When I asked a little further about the imprisonment of her grandfather, she spoke of both of her grandfathers adding insight to her views on family: 
My grandfather that was the journalist he put himself through college. He actually, for many years, worked really hard to save a lot of money and go ahead to allow my mother and my aunt and my grandmother to come to the United States and survive while they were in Spain. He was a lot older than my grandmother and he knew he was going to die. He had a heart attack but he worked until the very end. He was very hard working and he interviewed very famous people. There are many articles published by him.

My other grandfather he was not educated at all. He was my dad's father and he had something about him. He was never intelligent, book wise. He could not read but he did know one thing and that was family mattered to him a lot, and it was important to keep his family alive, healthy and safe. He would work very hard and eventually the Castro regime recognized who he was and they allowed him to basically imprison himself for one year to buy his freedom for him and his family.

Without any education and without any guidance from anyone he did that on his own. I think that both my grandfathers were very smart. One was book smart and one was street smart. And both of them did everything they could so that their wife and kids would have a better future. I don't think, I mean my mom's family was very rich in Cuba and my dad's family was very poor, but both of them had the same values. Family came first and work was essential.

Natalie shared the experiences of her family and in reflection understood and spoke about the sacrifices her family had made for her:

Just like the stories of my Dad. He was in Havana when the Marielas were going and someone told him if you leave now you could get in that boat and it was a boat of prisoners. He called my Grandmother and told her "I'm leaving." And so like my grandparents... he was the second oldest and everybody else was like little kids. So they were not happy about it at all. He left and he came and it was really bad because like a lot of people were telling my grandparents that he died or was never going to talk to him again. It was hard because you couldn't get any information. He had absolutely no one here. Not a single person here. So when he got here they sent him to Arkansas and he was over there at a Naval base and his stories are crazy because where he was by there was a lot of Klu Klux Klan and so they would come a lot of times and throw things at them until finally people that are considered family... it was one of my aunts that we don't talk to ex husband's family, like cousins and stuff were here and they were like "No, we'll take care of him".

They shipped my Dad from a Catholic church in Arkansas back to Miami. She was there waiting for them. They had no idea. My dad could have been anyone and they took them to their homes. With my mom too. Her story of coming over she was 12 and they had to wait in tents for days and days. They had to give 
everything away. Until whenever there number would be called. My aunt said there was just water and bread is what they had. Trying to get over here. Kind of like to me it's their start and to me because of their sacrifices, I owe everything to them. Because if not for what they've done is...I guess sometime...even though they've been strict with me. I do understand I guess in a way and through their sacrifices they been able to do all this to give me whatever I want.

For some of these women the sacrifices come at a very personal expense. Miette's family was forced to make some very challenging decisions about their departure from Cuba when Miette was a very small girl. It was a difficult and emotional story for Miette to tell but through the difficult times, she was eventually reunited with her mother after 5 years of separation. She recalled the story of her mother's departure from Cuba and the effects this had on her growing up:

She left in 1994. She came here. She was really lucky to actually get a visa to visit. And when she came here, she had family here which helped us a lot to be able to come here and when we got here, get started. So when my mom came here we were left in Cuba. It was not really decided that she was going to stay because she was really...she didn't want to leave me behind. She felt this is too risky. I might never see my daughter again. So when she came here, they were thinking this is our ticket to go, you know, this is a great opportunity. It was not really decided. My mom tells me that this is really a difficult decision for her to stay. But her family they were supporting her here, they wanted her to stay. They were giving her support. So eventually she decided "I'm going to stay." She stayed.

Once she decided to stay if was kind of all focused on how do we get you guys out of there. What happened was we were able to obtain a visa to go to Nicaragua, both of us [Miette and her dad]. So we went to Nicaragua. That was kind of like a year after, 1994? 1995? I'm not sure. Almost a year after my mom left to come here to the U.S., we left to go to Nicaragua. When we were there..what was the next step? We considered crossing the border because I was too young and her dad said, "I'm not going to put my daughter's life at risk." We were kind of just waiting for my mom to get completely legal. She got her residency and when she got her residency, she claimed us as her family.

Sophia also left Cuba when she was a young girl and described it as one of the toughest times she experienced. She told of the difficulties that she had once she arrived in the United States acclimating to the new environment. Additionally, she struggled in school 
because of not fully understanding the language. She told of how her father was hesitant to come to the United States and said that he would not come until his mother passed, which she did a month before Sophia came to the U.S. Reluctantly, her father wanted a better life for her and agreed to join them. She told the following story of what her family went through to stay together:

My uncle, the middle one, he left Cuba when the Mariel happened and he was here for 11 years without seeing any of my family, very little contact with letters, and then they allowed calls to be made. He then went to Cuba when I was 8 years old. That was when I first saw him...Then my uncle, it was in 1997, was when we came here, he asked for my grandmother. He was already a citizen so he asked for her to come. They approved her and so since we lived in the same household, she was allowed to ask for us to come also. It was something where you could reunify the family. But it was hard. It was a long process because my brother was also at the age where you had to go to the military and since it is mandatory and the only way you could pretty much get out is if you are sick or there is another problem where you are leaving the country. But if you are leaving the country it takes about 2 years or so.

So we had to get fake papers saying that he had this health condition. It was a matter of trying to buy the papers and that is how we ended getting his release and that was how we were able to get out in a year and a half. On my uncle's side, the older one, who was the one who was still in Cuba with us, he used to live in Havana and we used to live with him. It was like two different places. We had to fix all the papers. You have to have this little notebook where there is one section for groceries and one section for needs and this and that. We had to fake that. We had to fake his diploma from school. We had to pretty much buy all that stuff and pray that whenever we would go that it would be fine for him to get out because since he didn't live in the same household he wasn't going to be accepted. He went to the interview because you have to do an interview before you leave the country and that is where they tell you if you can leave or not. We were approved and they weren't. It was devastating because my grandmother who was already here, my grandfather had come to visit a sister so we were planning for it to be sad.

We would all come before my grandfather and my grandmother would stay definitely because if not we would not be able to see them. So my uncle tried again. He had to get other papers. I mean in every street there is a person that kind of oversees everything that happens. They watch every little move that you do. So we were fortunate that this person was willing to help us because we had been remaining in the same place for so many years. I was born in the same house that 
my mother was born. So they never said anything and they finally went again and they were approved. So they actually came before us because we had the problem with my brother who wasn't allowed to leave the country.

Cuban pride. The second theme is about cultural pride within the Cuban

American community. This theme is used to describe the pride that these women feel about being Cuban American and thoughts on where and how they acquired these feelings of cultural pride. Not all of their responses were direct comments; however, several spoke of pride indirectly. There is a certain ethnocentric voice when these women share their viewpoints. It also helps to paint a picture of how societal influences had a direct impact on their identity formation. The participants described their cultural pride in various different ways including their ethnocentric beliefs about being Cuban American, which was coined as 'Cuban ego' by a few of the participants.

Even though this theme is a general description of pride, there is some overlapping into other ideals of politics and immigration, and the theme of traditions/rituals. These feelings of pride may be perhaps because for most Cuban Americans, the family struggle to come to the United States for a better life has left them with a nostalgic strain that keeps them connected to their strong cultural roots in Cuba. Regardless whether the participants were first or second generation, all of them felt a connection to Cuba despite the political upheaval the country was facing. For the research participants, there were direct questions about what their favorite thing about being Cuban was and their answers were not surprising when they spoke of food, music, and traditions. It was their responses that were intertwined in subjects of politics, immigration, power, and socioeconomic status where they spoke of cultural pride at a 
deeper level. There was an entwinement of nationalism and pride when discussing these themes; therefore, the discussion of politics and immigration are included in this section.

Many of the participants also had a very good understanding of how their family's past in Cuba and the current political situation in Cuba had an effect on them as individuals. Most were aware of the socioeconomic status and social privilege they were born into or acquired after living in Miami and how they were viewed by others in the community, both Hispanic and non-Hispanic. These women also were able to vocalize the issue of socioeconomic status and discrimination within the Cuban community. It is clear that they understood the idea of social power and the influence it had on who they were becoming. It is hard to discuss this cultural pride without discussing the influences of these social issues as the sense of national pride permeates cultural pride. From a psychosocial developmental perspective, Chickering would suggest that many of the participants are in the developmental vector of "establishing identity," in which a person becomes aware not only of their personal identity but of a sense of one's social and cultural heritage (as cited in Evans, Forney, \& Guido-DiBrito, 1998).

When discussing the perceptions of those Cubans living outside Miami and the experiences of living somewhere else might be like, Luz commented:

I heard some funny anecdote about it. Like some places where some people assume if you are Hispanic, you are Mexican. They think that Cuba is an island and random like that and some have not even heard about it, which is so strange to me because everyone here knows Cubans and we speak Spanish. I have heard that they just assume you are speaking Mexican. It is not even a language. It is just one country 'cause that is all they really hear about. It is very surprising to me, because living in Miami...I just assume the whole world knows where Cuba is. 
Many of the participants grew up in parts of Miami where the majority of residents were Cuban American. Most attended private Catholic schools that were predominantly Cuban but were aware of their cultural heritage as early as elementary school, which was the beginning of the awareness of who they were. Carmen remembered a time early in her education:

In elementary school middle school....I would say $98 \%$ or even more were children of Cubans. When we asked somebody if their parents were Cuban, we were like "What?? What do you mean no!" In high school we had a lot of South American students. So you know you saw Cuban but you also saw... and finally when I came to FIU it was everyone from all over the place.

Carmen, who was born in Miami and was raised with both parents who were very

involved politically and had a cousin who was a political prisoner in Cuba, said:

To be Cuban American. At least the way, when people ask me, "Why do you consider yourself Cuban American?" Well I'm American because I was born in the United States and I am proud to have been but at the same time it's acknowledging that you have those Cuban roots. By identifying yourself as Cuban Americans...those roots have made me who I am. They, they're in the way I talk and the way I speak and what I eat like in everything....I think all Cubans love that island tremendously but at the same time it's you know, I don't know how to put it...but like knowing freedom and loving freedom even more. Like saying okay...I've seen in my family. I've seen in family friends that are Cuban. I've see it everywhere. They left that island physically because of Castro but at the same time they take Cuba wherever they go. Like they'll be in a restaurant...they'll be anywhere and they'll be talking about Cuba. It's taking the island wherever they go. That island has been all over the world because of stories because of their actions, everything...

All of Carmen's experiences had a direct impact on her development growing up. Her pride for being a Cuban American eventually led her to becoming involved in social activism at the university:

Well, I come from a family that has been very involved in politics. My dad he was a Cuban politician, you know and...my mother was also involved in that...so I mean...ever since I was 4 and I wake up in the morning and the radio would be turned on to the local Cuban radio station...talking about how Castro was bad and 
you know all that. So I mean pretty much all throughout my life, I've been hearing it. And at the university level, I had the opportunity to, I mean, yes I was involved through my parents, but at the university level I made a decision to join the organizations that I mentioned earlier...like Free Cuba Foundation and that's when I realized, you know like, and it's not that I was doing it to please my parents or anything, but it was something I found the passion in. Something I loved.

Some of these women knew directly how it felt to have left behind a life they knew for the unknown. Michelle, who was naturalized as U.S. citizen during this research project, said, "I'm proud. I am proud to be Cuban but I am proud to be here at the same time. I would never go back. I wouldn't change this for anything."

Luz understood that all too well. She was one of the participants who left Cuba at a young age and had not visited Cuba for 4 or 5 years. She commented that her maturity level had changed since then and she was wrestling with feelings about Cuba. Unlike her mother, who found it very painful to go back to Cuba to care for her ailing grandfather, she said:

Like I said I grew up so I'm a lot proud of my Cuban (background)...so I don't know how difficult...I have heard lot more stories from my parents and I understood them more. So I definitely would feel very different if I were to go back, but I feel like I do want to go back with this new point of view... with this new maturity and just knowing what it feels like and I think that goes for just about everything. Even though I know that those things happened there and you know...you feel like this is the place where all these horrible things happened but like I'm very much in tune. I know there would be an issue in this certain place...that I would want to go to that place and feel connected to that place and feel the pain from that place. I don't know how to explain it. I want to feel like I'm there. I don't know.

Jacqui and Carolina, neither of who were born in Cuba, when asked about what they

liked about being Cuban American, responded with similar responses. Jacqui said:

I'm unique. I love being unique...I think that's what makes being a Cuban American so unique is that Cuba itself has a unique history. It continues to have a unique history and even today there's all sorts of problems with Cuba and 
everyone I think knows about the issues in Cuba. So being Cuban American it's great because we have this unique history about us and we're continuing a sort of legacy and making something of ourselves and our culture. So that's what I really love about it...I think that's what makes it great. You can meet someone but you never know what they went through or what their family went through. I think being Cuban American, I have that and I love it. It's great.

Carolina's response shared the same sentiment; however, she did comment later about her dislike of the Castro regime because of the messages she heard growing up from both her parents and grandparents:

I think it's that, even though I'm not Cuban in that...I wasn't born in Cuba and I didn't grow up in Cuba. I think that Cubans tend to have pride... have Cuban pride. I guess because it's instilled in us since we were young. I really enjoy my traditions, my culture. I enjoy. I tend to have a lot of friends actually that are Cuban American. I just enjoy the culture... They're very very proud of their background and everything that it stands for. I would say that I've not only seen in my family but in a lot of different Cuban families where they are Cuban but at this point they're very very loyal to the United States and they feel American in a way although they are Cuban just because they like the government here and they feel like it's really been like, something that the government has accepted them.

Blair had an interesting outlook on Cuban cultural pride. She described it in her words:

Very prideful. Cubans are very prideful. Very ambitious. Definitely very loud. Like I would like to think of what was a Cuban back then and what is a Cuban now. It's changed because communism has stripped the land of its culture. Communism will do that. It will strip the land of its culture and its important things...

Natalie, who had a very special relationship with her grandfather, adopted some of his ways in the sense that she would stop and ask someone where they were from, just as he did. Her assumption was that most of the people she met in her neighborhood were Cuban. She believed that being Cuban American will someday benefit her when she begins her life in public office here in Miami. She talked about her cultural pride this way: 
I think a lot...I love my culture. I guess you know with everyone it's that same thing. I guess it's like an insight. You know, to be Cuban I see it as very fun. In the sense that the music and all that culture that comes behind. I love Cuban culture, just learning about it is a very big...I think kind of like the community we're in it helps a lot.

When discussing the occasion when Tiffany brought her first non-Hispanic boyfriend home to meet her family, she comically referenced the movie My Big Fat Greek

Wedding. While she seemed a bit embarrassed by the incident, it spoke of the familial pride that her family had about being Cuban. She recalled:

He comes over and my dad wants to be the most Cuban person knows and he busts out the domino table with the Cuban flag on it. He invites him to play a game of dominos and makes my mom make traditional Cuban foods and wants to induct him... introduce him into the culture. All of a sudden he has all these stories from Cuba that I've never heard and I don't believe. He starts exaggerating so I guess that the time when we're extra Cuban. Because he's so different. Everyone I've brought home has been Hispanic so they already know...My dad gets a little carried away.

It was this intensity that Natalie spoke about as well. She, like a few others in the study, had taken a class or two on Cuban culture. This had heightened their own personal awareness of Cuban nationalism and cultural issues, something to be expected in a developmental way that Chickering speaks of in his work (as cited in Evans, Forney, \& Guido-DiBrito, 1998). Natalie remarked about something she learned in a class:

I've taken a Cuban politics class and one of the first things, the first class we've had and it was talking about how Cuban, and I think it's even of because of our parents and grandparents have gone through...they have a strong nationalism. And we, we're talking about from back then how it was just like... and our professor was saying "Cubans like Cuban coffee, Cuban pastries".... Cuban...the word Cuban is involved somewhere around it...you don't go to places and ask for Peruvian coffee or things like that. So I just feel that there is, even in Miami...I do not understand...I personally do not understand the wet foot/dry foot law. And how the wet foot/dry foot law accepts Cuban Americans and does not accept Haitians. I believe that if they take that journey to come over here, it is for the same that those Cubans are taking it, and you know, I cannot be the expert telling you how Haiti's policies are in all their political aspects but that is a voyage 
you're taking and you know, why is that our because our community accepts or our community is predominantly Cuban American why are we not doing the same thing...especially the leadership of it saying...in these rules we qualify both of these people because the Haitian American leadership has not been able to get at those levels but we should be understanding...we know why our families, our communities are coming

There were two issues that arose from this personal awakening of social issues.

Like Natalie, most of the women were able to articulate the concept of social privilege and power. Others alluded to the fact and some seemed a little embarrassed that they were given privileges as a community that other immigrant populations were not. They were also quite aware of how non-Hispanics in Miami and other Hispanics viewed Cuban Americans in the Miami community. My impression is that they saw themselves in the majority, which has documented societal implications. Additionally, they tended to see themselves in a position of higher socioeconomic status compared to other immigrant and Hispanic groups, including Cubans that came over in the latest waves of immigration.

Earlier in the interview, Jacqui reflected on an experience that happened in high school and left an impression on her. It is clear that these women were influenced early on by the school systems in terms of their understanding of the community issues surrounding them. Jacqui said:

I think it's kind of my perception and it's kind of what I see and sometimes what you hear on the news. When people are just like "Cuban are given this and this and that."...I mean, I think that everybody should have the chance to come here. I mean, I know Cubans have a wet foot/dry foot and other countries don't.... I can understand why someone who is Haitian would be very upset about that

Carolina's thought on how Cubans were viewed by other Hispanics:

A lot of Hispanics across the United States do not like Cubans. I know that they don't like Cubans. Their way of thinking is different. They to not be Republican, they're Democrats. I think that it's different because the people that come from other countries, not always, because now we have people coming from different 
countries, but let's say the people that are from Central American countries. They usually come here because they're poor and they want to leave their country because they're poor. But Cubans didn't come here because they were poor. Cubans came here because of the Revolution, because of the government and most of the people that came to the United States when that happened were not the poor people...so I think that when Cubans got here they were automatically given jobs and things like that and they were more successful maybe than other Hispanics. I think also, for example, if there are Hispanics that come from Central American countries, and I don't want for you to think that like I'm racist or anything like that, cause I lived in Mexico and I have friends that are you know, but for the most part they tend to be more Native American looking and Cubans are very White. So I think that is essence also helped them because I think that although we're getting better there's still a lot of racism in a lot of you know like type of discrimination type of thing in the United States, so I think the fact that they were White, might have helped them get more jobs. And I think that, you know, I think that's a main reason why other Hispanics don't like Cubans.

Sofia, an immigrant herself, when asked about the perceptions of other Hispanics, commented:

When you said that, the first thing that came to mind was that, we may be perceived as privileged in a way because we come here and we get assistance from the government, we are allowed asylum pretty quickly. You know we have all these benefits based on a negative thing which is the political problems that we have in our country, but in a way we are privileged and so a lot of people from outside, some of the comments I've heard is that "oh because you are Cuban you can do this and that and so many things. You are given so many opportunities that we don't have as Venezuelans or someone else." But I think, overall it shouldn't be that negative.

Miette's feeling about Cuban privilege echoed many of the other participants. More specifically, I questioned her beliefs of non-Hispanics and immigrants living in Miami.

Miette's insightful comments about the anti immigrant attitudes were:

I'm sure, well there is anti immigrant feeling in this in this country. A majority of people who are anti immigrant must be so angry about Cubans; I'm guessing they must be angry about Cubans because since we get and we become legal. They are pretty sure there are people that are trying to get those laws abolished. Those laws that allow us to come here and just become legal immediately. I'm sure they are asking why...why is this happening? Why is this still happening? Because they simply don't want any immigrants and Cubans are like a really large group with like power and they must feel that these people have too much power and they're 
just immigrants and we don't want this...and so I'm pretty sure that there are those views out there...but I think it's just mixed with general anti immigrant feeling.

Carolina also alluded to the anti immigrant beliefs she perceived as an issue:

I also think that some Americans dislike Cubans. Not because of them as a people but just because we came in Miami. Now I think there are more Cubans than there are Americans in Miami. And then I see, I think that they get bothered, by example if they go somewhere and the people only know how to speak Spanish. I know that, if that would happen to me and I was American, it would bother me. If I go somewhere and I'm discriminated in my own place because if I don't speak Spanish, I can't get a job or if I go into a random store and I don't speak Spanish, I can't, you know, order what I want to order or you know whatever, things like that.

During the interviews, the participants revealed there were some social power and anti immigrant issues towards the new Cuban immigrants among Cuban Americans. I found this interesting because of the struggles many of them described to me of what their families went through. There was a certain amount of negativity about this new wave of Cubans that were coming to the U.S. On a different note, they did share that there was camaraderie of support when their family members were able to reach the U.S. I tried to understand this stark contradiction based on their responses.

Isabella was one of the participants who had some strong feelings on differences in the Hispanic community. She articulated what several of the participants spoke of when asked about how they perceived social discrimination happening within the Cuban community. It is clear that these societal changes were influencing their thoughts and behaviors as they made decisions about who they were becoming. This was her response:

It is kind of sad because before I never, I wouldn't say I was never prejudiced, obviously I am Cuban-American, but I kind of hold a little bit prejudice now towards the new Cubans that are here. Why? Because they come here not as Cuban-Americans even though they are, they come here as Cubans. They don't have a sense of what America is. They take that for granted. They came here just because they got an easy ride off the island. They don't come here for the 
American dream. The majority of them, even speaking from people that have just come here from my own family, they are here to live off what the government can give them. Old Cuban-Americans that came here were all about America. They were here for America. They were interested in the education and the entrepreneurship opportunities. They were interested in trying to get ahead and making a name for themselves. They wanted to make changes that would be beneficial to other Cuban-Americans.

I guess a lot of these Cubans from my father's and mother's generation that made such a name for themselves influenced the Cubans in their home to think that this is a place where you can make it easy because a lot of Cubans I guess hold pride so when people like my parents are putting a face, oh no it is not difficult to make it here, all their family members come here thinking, "well they did it, we can do it." And it is not like that...I was always very into my culture. I was always about speaking up about Hispanic people and now I am a little bit shyer about it because you start to think, well you know, you can't defend people that are here just to take advantage of what you yourself are, a citizen, an American. So when you see people cheating taxes or taking advantage of food stamps that people really need, that are really on welfare, you kind of get embarrassed.

While her viewpoints seemed strong about current immigration of new Cubans to Miami, they were echoed by other participants. It is important to understanding this because later this chapter discusses biculturalism and for many of these women there is a direct correlation between immigration and ethnic identity.

Tiffany shared her thoughts on this new wave of immigration by saying:

Some of them are coming and they're not coming for the right reasons. They're coming...they are coming and they want to have with the people who came earlier and established themselves have...so they are coming and they are living beyond their means and they're just putting up a false impression. They are just pretending to be something they're not and they feel entitled to things and they're just not the same as the ones who came earlier, worked for what they have...it's taken them time. So these people come only because they see what others have done and they want to be at the same level and they can't be. And they want to go back and take things with them and once you come, either you come and you stay or you stay over there. There is no going back and forth... and I just think they're confused. 
Carolina added to this sentiment by sharing:

Yeah, I see a big difference between the people that came like right when the Revolution started or right after the Revolution and that people that have come here now, you know 50 years after the Revolution. Um, they tend to have different customs and different ways of thinking. They tend to have a different accent, sometimes, different vocabulary, um and they tend to think more like "when I get to the United States all my problems are going to be solved" in a way....But with the people that first got here they just thought as let's go over there because we want to get away from the Revolution because at that point it was a good situation in Cuba, you know. So they saw it as coming somewhere else and restarting the life but not as all of our problems are going to be solved.

Blair shared that when it came to socioeconomic issues that her family who had

been in Miami for over 20 had yet to be on top. She was very aware of the drive to achieve and the effects of immigration on that achievement. Blair also articulated how important the cultural ties to the community were to her and their impact on her:

I mean I don't know if every culture is that nice but I don't want to like overlook the good. Like the good things, the good natured things that other Cubans have done for their people that recently come here, and there is a lot of Cubans support in Miami. I don't know about Kendall, but I know where I'm from in particular Hialeah like there is a lot of like, it's easy to transition. Some Cubans make it really easy for you...there's a lot help. There are a lot of programs. I don't know if every culture that migrates here gets that help. I don't think so because I see the Mexicans really struggle on the west coast so I mean, but at the same time, like in every society I think there are just elitists. There are elitists Cubans that will look down and be like you know, I forgot that's where I came from. You know, I forgot that when I came here I only had like two pair of pants....but there are Cubans who do come here and do acquire and who do put back into their community and who do help those who come...I feel that we've built a nice little support system for ourselves here in Miami.

As stated earlier in this section, this theme is used to describe the pride that these women felt about being Cuban American and thoughts on where and how they acquired these feelings of cultural pride. Many of them spoke of Cuban pride with an understanding that there was a history and struggle endured by their families that came with it. There was a certain ethnocentric voice when these women shared their 
viewpoints. They understood the privilege that came with living in a community that is a majority culture and how societal influences had had a direct impact on their identity formation. The participants described their cultural pride in various different ways including their ethnocentric beliefs about being Cuban American, which was coined as "Cuban ego" by a few of the participants. It was interesting to find that they viewed themselves as different from other immigrants who live in their community. They saw the privileges as something they had earned because of their families' hard work and determination to "make it." They understood the privileges they received being Cuban American in Miami and had a tremendous empathetic view towards other immigrants, but at the same time they developed an elitist mentality that separated themselves from other minority groups and from recent arrivals of other Cubans in Miami.

Traditions and rituals. The third theme is traditions and rituals. This theme is used to describe the familial traditions and rituals experienced or known to these participants. To the participants, traditions and rituals were not just about food and music, but they were about important family rituals that take place at different milestones in the Cuban American household. Cuban American cultural pride does not rest solely on its traditions and rituals, though they are important. The celebrations and the importance of food in family rituals do not define what it means to be Cuban American. It does, however, encumber what it means to value those things that connect family members in different ways. For these women, the meanings behind the rituals were more important than the actual traditional or ritual. It appeared that these traditions and rituals solidified and bonded families together. Traditions and rituals do have direct impact on identity 
development. It is an underlying factor that the importance of family and culture together illustrates the importance of traditions and rituals.

I questioned the participants on various aspects of traditions and rituals in an attempt to find out the following information: what traditions and rituals were celebrated by their family; how important was the value of these rituals, and if they planned on continuing these traditions and rituals with their own future families. It was interesting to find some traditions and rituals such as the etiquette of courtship in the Cuban household emerged in other discussion of gender roles, cultural pride, and family stories, which I interpreted to mean that some traditions and rituals were more commonplace than event based. It should be stated that the interviews were conducted near the Christmas holiday, so these women may have been have been thinking a lot about holidays, but all of them were able to articulate the deeper meaning of the importance of traditions and rituals as a cultural influence.

Some traditions and rituals were more commonly known amongst the participants and other rituals were specifically related to the particular family that created them. Regardless of the experience or how "Americanized" they felt, these women very much valued these experiences as specific and unique to the cultural heritage. I excluded the discussion of religion as a ritual from this section and saved that for the discussion of moral and ethical development. I learned from these women that it was less about the actual tradition that mattered and it was more about the gathering of friends and family that they reminisced about. Food, of course, was a focal point and something most of these women remembered fondly when reflecting about their family. Isabella, who clung 
tightly to her Cuban American roots, yet struggled with becoming more "Americanized"

described family tradition this way:

So Cuban culture is all about the family. There is nothing else and they know religion is important and they know that your traditions like your food, but it is not as important. There is nothing as important as when mom, dad, aunts, uncles, parents and everybody hangs out together. Usually I have been to my fiancée's families. Like one side hangs out together and the other side doesn't hang out together. They never hang out all together. Like the moms in the family would very rarely hang out with her sisters husbands side of the family. My family they are all Cubans so every family member of every person that is married there hangs out together. My aunt who is my blood aunt is married to this man who is my uncle. My uncle's mother hangs out with my mother's mother. It is very strange. It is like all these family members, families from other sides, they have nothing to do but they are bonded by loyalty. They are bonded by that.

Food, I guess that when I told you about food I was not kidding about food. Food is super important. It kind of comforts them. When there is a death in the family there is food. If there is a party there is food. It is always the same food. They always like the same food. They always like the same thing. I mean, pork is essential and it is like if the pork is not there the family is like missing something. They are loyal to whatever tradition they have held on to. My great, great grandfather did pork every single holiday my great grandfather did the same thing, my grandfather did it, my dad does it, my uncle does it now my cousins do it. It is not just the pork it is the way they cook it, the way they pick it. Every year they do it. It is a tradition. Without that pork there is no party. If the party is not there the family is not happy and if the family is not happy you just kind of betrayed the trust of the family. What you have is a bunch of people talking about each other and they finally get together cause they don't ever want to lose that. But it causes problems. They have to be a certain way to be happy. They can't alter what they already know. It is very rare for them to do something different

Carmen echoed similar sentiments about the importance of family being together and how food always played an important part of her adolescence. It is interesting to note that in some of these rituals, a blending was occurring of traditional Cuban cuisine and traditional American cuisine:

Well every Christmas Eve we meet at my aunt's house and we have dinner there with the whole family. Stories are shared, we watch TV, we talk and all that. Christmas Day, I wake up. I exchange gifts with my mom. From there we visit each of our relatives' houses. We go around to all the relatives' houses and 
exchange gifts with them and then we come back to my house. We have food on the table. The family we just visited they come back and visit our house. We spend more time together and also family friends come at that time. So it's one of my favorite traditions right there. For Thanksgiving we also meet at my aunt's house because my aunt is the family hostess. So for Thanksgiving we have a very Cuban American Thanksgiving...turkey and pork.

Carolina also shared this remembrance about gathering with family but about a special

food that was prepared. She described her celebrations to me:

Well I know that for Christmas. Cubans actually celebrate Christmas Eve more than actual day and for Christmas Eve there's a dessert that my family always makes. So then we get together a couple days before Christmas to start preparing it and that's every single year. I know that my parents have what they call a progressive dinner with the rest of my aunts and uncles, they do that every year. We usually go on a trip with a lot of my family for New Years, things like that.... I find them [traditions and rituals] very important actually because I've done them since I was young. If I don't do them it doesn't feel the same and it doesn't feel like its Christmas if I don't get together with them or New Years or Thanksgiving or things like that.

I asked her more specifically about this dessert. While the food was important to the celebration, it was the passing of this tradition from grandmother to granddaughter as significant. This sharing of culture is important in understanding the Cuban American household. Carolina explained this special tradition:

It's called Bunuello. It has different root vegetables in it and it has some sugar and other ingredients. But my grandmother is always there to help us. It's pretty much all of us, my extended cousins as well. It's from dad's side mostly. Mostly the people that I'm close to are them. We just get together and we do them for whole day and we have lunch and we get together and have a good time.

Like Carolina, the passing down of traditions through food was something that she values. Most often when I asked about food, the responses for these women were emotional based on a passing down or sharing of knowledge between generations. Carmen shared this during our meeting: 
Sure. I remember a little cake. I don't know what it is called now. Kind of like a flan. Make of milk and bread and everything and when I went there it was Thanksgiving again so we had turkey but we also had pork. Cubans have pork and salads and stuff you wouldn't see. I remember this little cake, this old lady she was 80 something, she said that was my mom's recipe and you know she started telling us all this story of how her mom taught her to stay quiet all the time. It was very nice.

For some of these women, belonging to a Cuban household, rituals were not always apparent like holiday traditions. When I asked Blair if there was something that she did that she learned from her mother or grandmother, she laughed:

One thing. One thing that I know about my grandma and my mom and I do the same...we're always making something to eat and then when people come over you want to force them to eat it. Whatever we have.. "You need to eat? You want something to eat? You sure you're ok..eat, eat!" You have like this whole, its part of our culture too... when somebody comes to your house you need to make sure you give them something to eat.

For some of the participants, rituals or traditions were not prevalent growing up, but as these women articulated it, they were important in the life of the family. Natalie, who grew up in a small family, with little in the way of traditions reflected about her present and her future. It was clear that the traditions of the holidays and the relationships she had with her family were meaningful to her:

Me and my boyfriend talk about that a lot. We're going to start every tradition in the world...but one of my favorite family things is Christmas Eve. Just because, even more now, like I said before it was just five of us, a lot of my family is here now and we can all get together. Even if it's to embrace each other and especially like the two parts. Because Christmas Day everyone comes to my house and so it's just like we eat the leftovers and just talk and like hang out. A lot of time you know it's...I think my family is very workaholic so everybody's always doing their own thing. It's a time that there's no...it's a sure fire that everyone is going to be there together.

Both Michelle and Sophia, who grew up in Cuba, did not celebrate Christmas. Christmas in Cuba was not celebrated according to both. Traditions and rituals bring different 
meanings to them. Michelle, who did not live at home, commented about the importance of family:

We had a tradition, every year on this time about Christmas, we don't have Christmas in Cuba, but around this time in December, every year, we would go, me and my mom and my dad and my brother we will go to a cute little restaurant that they had, one of a few they still have and it is like a hotel, like a resort in Cuba. It is not for tourists. It is a really nice cute restaurant we used to go. We would go there and eat. It is just this memory I have, like a family thing. The few things that we did as a family.

She later spoke of the importance to her about the value of family and keeping the part of

her value system and as something she would want her future family to hold true:

Twenty years from now when I have my own family, I would try to keep that tradition that the family needs to be together at least in this situation at this time of year we know that in this type of situation in this time of year Christmas do family things together. Like it is not nice to be alone at Christmas. So basically I love all this family gatherings like everybody sitting at the table at the same time. I am very fond of that. I love that. So that would be one thing that I would teach my children and I would teach them how to love people and have compassion for the family. I do have a lot of friends who just don't care about their family, who would rather be playing pool or whatever Christmas night than sitting down at a table with their family. That would be one thing that I would teach. To have that love and passion for family

Similarly, Sophia did not grow up in a traditional laden house, and family tragedy seemed

to bring that to a halt, but she hoped to continue with family traditions in the future:

We didn't have any type of celebrations like that but for some reason the $24^{\text {th }}$ of December (Noche Buena), we would always have a dinner or on the New Year it was kind of like, Hey, happy New Year to each other. We wouldn't really celebrate. When we got there we started getting into that tradition. We never gave gifts to each other in Cuba because that wasn't part of it. But when we got here we do that, but for some reason after my dad and my grandfather passed away we kind of stopped doing that cause my grandmother didn't want to celebrate. She felt it was, I don't know, but she decided that she didn't want to have any parties in the house and things like that. It kind of faded away. I am actually hoping that now that I will have my own place that I can continue with it. 
Isabella who loved the idea of family rituals and gathering was conflicted with

how she would hold onto these if she marries someone who is not Cuban. It was apparent when she spoke about her family that the idea of getting together was important to her cultural value system. She shared from her experience what the differences were between a Cuban family get together and a non Cuban family get together. It is interesting to see her process the importance of the rituals at that time that she was in a relationship with someone not from her cultural background. The conflict with her lied between rejecting her cultural norms and accepting a less traditional way because it was what was expected of her if she marries someone who is not Cuban. She described it as:

Like that's a big deal. Honestly, I love the idea. But the fact that my fiancé is not Cuban he does not hold to those traditions. Actually he is not very thrilled with those traditions. He's not used to in his family so much talking, so much fussing over a pork. He is Hispanic, but he is not Cuban.

\section{Ethical and Moral Development}

The third major topic of ethical and moral development is used to describe those factors that contribute to the identity development formation of the participants in the study as it pertains to their views on spirituality versus religion, decision making, and values clarification. Ethical and moral development has been studied and documented by a few developmental theorists such Chickering, Josselson, Kholberg, and Gilligan (as cited in Evans, Forney, \& Guido-DiBrito, 1996), but understanding cultural and ethnic characteristics in relation to ethical and moral development of students, in particular Cuban American women, is lacking in the research. Gonzalez (2008) addressed the issue of spirituality and ethnicity among Cuban Americans; however, the findings of that study did not address issues of ethical or moral development. This section addresses how these 
women made decisions, how they defined their personal value system, and how they viewed religion/spirituality as a part of their ethical and moral development. Though there are three themes, religion, core values, and decision making, each has an impact upon each other and cannot stand alone.

Religion. This theme of ethical and moral development is used to describe the role of religion in identity development. The complexity of understanding ethical and moral development cannot be viewed as a singular issue. For these women, the issue is what came first, core values or religion? What factors influenced these women most in their own development? While trying to discern their responses, it was evident that what they believed to be their core values system was greatly influenced by their parents, family, and religion. Since religious education typically begins with the family, it was not surprising to learn that core values are tied closely to religion and spirituality. There is also a very fine line of how core values and religion assisted in the decision making process of these participants. It also became evident throughout the individual and group interviews that some of the women struggled with the ideologies of religion. Most of the women agreed that religion was not something that was forced upon them, but it was more of a sense of a part of the fabric of growing up in a Cuban household. Additionally, several of the women attended private, Catholic schools, which appeared to have an impact on how they not only viewed religion but how they incorporated this into their ways of making decisions.

Those born in Cuba shared that religion was suppressed during the Castro regime; therefore, they did not share all of the same views as the others born in the U.S. Some wrestled with the concepts of spirituality versus religion and others questioned their own 
belief systems. Despite individual differences, beliefs, varying degrees of ideology, or family background, the women all shared the common idea that religion and spirituality had been an influencing factor in their ethical and moral development as a part of their overall identity development. In exploring this, it is important to understand a little of their personal backgrounds and where each of the women were in terms of their current development and thoughts on religion in their lives.

Carmen who said, "I have faith in my heart", did not attend Mass every Sunday:

Well, my family is Catholic. So I grew up in a Catholic household where we said prayers every morning, prayers every night. I actually went to Catholic school for 14 years of my life... all the way from pre-K to my senior year of high school. I think religion has played a big role. You see every time we've gone through difficult times, we turn to religion. Right now we've got everything possible. I don't know. It's comforting.

Carolina reiterated this sentiment by sharing that she too thought religion played a big role:

...I'm Catholic. I would say not that I am very religious in that I go to Mass every Sunday or anything like that. But I did go to a Catholic school my whole life, and religion has always been a part of my life in the way that I was raised. I guess the values that my parents have instilled in me have a lot to do with the church and I know that my parents are religious. They go to Mass every Sunday with my brother and things like that. It's always been a very big part of my life.

Natalie who did not go to private schools growing up reflected:

When I was younger it played a big role. My parents went to church every Sunday. I'm Catholic. I've done my Baptism, my Communion, and my Confirmation. What kind of sucks is that I guess the older I get, the more responsibilities they have, so my parents haven't been as continuous but it's kind of something that's always stayed close to me. So I was like, I'll go to church by myself and things like that. I'll go if you don't want to go. So like for me it kind of plays a big role in my life.

Tiffany also attended private Catholic school, as her parents believed it would help her in her upbringing. As a devout and practicing Roman Catholic, she considered religion to be 
very important in her life. As for her parents, she said that they no longer attended

because they did not agree with some of the things anymore, but she said:

I believe it's very important and I attend every Sunday. I go to confession regularly and I have my boyfriend going. I try to bring friends. I think it's very important.

When asked what part of her life religion helped to define, she said:

My entire life. It's a part of everything I do. When you eat, you're thankful. When you go to sleep you're thankful.

Isabella, like Natalie and Tiffany, shared the same issue of having hardworking parents who had stopped practicing, yet used the religion to set the moral fabric of the family unit. I was surprised to see that these women had belief systems that were so strong and intact. It was no longer the family who influenced them. They became the influence on the family. Isabella said:

I think religion, at least in the Cuban household, in general, parents usually use it to kind of set standards. They use it for moral purposes. They want to bring you up a certain way, like stay a virgin until you are married, and since Cubans tend to be very over protective you know it's better for them to say "God says..." than "Daddy says". I don't think my family ever really practiced until I actually found church myself. I went and kind of brought them into it and you know, they have always had their Catholic beliefs but they practice it their own way.

Sophia, in reflection of her life in Cuba, articulated the importance that religion played in her life despite the conditions she was exposed to. She was baptized in the church, but her family was not practicing for fear of persecution. Religion, for her, was something that she felt she was missing. As she matured and immigrated to the U.S., it is interesting to see how her views on religion and spirituality changed. The self reflection of how religion versus spirituality changed was echoed by other participants as well. According to Sophia: 
In my case it's kind of different since I was in Cuba until I was 12. Over there we didn't have Catholic schools, we weren't allowed to go to church and things like that but I did become exposed to it when I was about 6 or 7 years old through a friend. In my house no one was religious even though they believed in God and everything else, and it was the Catholic, not mentality, but followed Catholic beliefs in a way... They never really practiced because you weren't really allowed to practice during that period of time. So basically, I was the first one that started going to school and on Sundays. I was very in, you know, plays that they did at church. I was very involved with the nuns and everything. But it was never something that was encouraged at home because I just did it on my own. I found it on my own, but then when I got here I saw a completely different side of what church was. Completely different from the idea I had about going to church. So I guess my personal relationship with God is just personal. I no longer go to Mass or anything like that because I haven't found a church where I feel comfortable, you know experiencing that...so I just practice myself.

The idea of spirituality versus the role of organized religion was a topic that sparked much conversation during the individual interviews and the group interview. It was not the denouncing of organized religion as much as it was the questioning of it. Michelle was one of those who felt that she was more spiritual that religious.

I was raised as a Catholic. I believe in God, but I never thought of going to church like every week. But I do believe in God but basically if you asked me what religion is, I would not be able to answer. I don't believe in different types of religion. I believe there is only one God.

Miette also felt that she was more spiritual than religious in nature. Growing up, there was some inner turmoil she struggled with when it came to her parents' beliefs versus her beliefs. She discovered she was never baptized and this upset her. She did come to understand her parents' atheist views were in response to what was happening in Cuba. Later after she arrived to the U.S., she eventually chose to be baptized in the church, but she no longer formally attended:

I feel you found the word for me...spiritual, which I just didn't know exactly how to put it. Exactly the same way. My family, we were traditionally Catholic, but my parents became atheists at some point in their youth; and they decided to raise me without any formal religious education. And my parents felt atheists, like they 
felt like they did not believe in anything, but I just didn't feel that way. I feel that there has to be a greater power. I don't like religion per say. I see a lot of negative things associated with it. I don't know, like sometimes I really, it really bothers me. One time this person....I went to like a hair salon, and we always go to the same lady. And her husband, he is usually there because it's her own business... and I never thought about it...nice people whatever...but he gave me this paper which is why I really don't like this. He gave me this paper that was about an Evangelical church, and it had this story about a man that does good work versus a man that has murdered but believed in God and the guy that murdered and believed in God went to Heaven and the guy who only did good work went to Hell. Like no. This is how...I disagree with that. It was horrible. So I don't like, I don't like the way I see some denominations.

Luz is one of the few participants that admitted to struggling with the concept of religion in her life. Like, Michelle and Miette, Luz was born in Cuba. When asked about religion in her life, she said:

It is kind of difficult. I found some questions when growing up. My mom is still very religious but it is a difficult topic for me. I just feel bad about questioning things but I guess it's human nature.

Later in the focus group interview, she went on to explain more:

I'm not that pessimistic about church. I don't really believe in the institution either but I wouldn't call it horrible. I mean at least not generalized, but I do agree that some people just because they go to church they think "I'm going to pray and it will be all forgiven" rather than people who don't necessarily exactly know what they believe in but are just good people like internally just for themselves, and I don't think that's fair. But we used to be very religious when we were in Cuba, when we lived there, and then we came here we were very religious for a while. I got confirmed and everything but then I guess we just got really busy. We stopped going to church and then that's when... and kind of school, just learning about science... you start getting doubt. So I started not being really sure. I'm still pretty spiritual...

Core values. Core values is that set of beliefs and values these women held true to them. This section also gives insights as to where these women believed they acquired their values. As part of exploring their moral and ethical development, understanding what they viewed as personal values is important. Some of their responses varied, but it 
was interesting to note that a few shared the response of "honesty." The questions that were asked included finding out what they believed in and what were some of the core values they believe were instilled in them by their family that helped shape them to who they became. It is plausible to say that having a good set of values or beliefs did not make them ethical or moral, but it led to some insight about how these women were making decisions. Decision making is discussed later in this section. Value systems appeared to have several influences including family, friends, and religion. Many still viewed their value systems the same as their parents.

Jacqui also recalled messages that she received at home that reinforced the messages she was receiving from the church and school. These messages were so strong that she intended to raise her children in a similar manner:

I know like I have the rosary on my bed and my mom put like the Jesus card and the Virgin Mary card under my bed and like every time somebody gets sick you do little Virgin Mary prayer (laughter) you know. Like even though we don't go to church every Sunday, like I really feel like it's something they believe in, but it is true it's a big comfort I think for Cuban families and at least like what you were saying, which I agree, like the Cuban Dads are like "God tells you don't have sex before you're married" like all that stuff, like whatever they did worked on me because (laughter). I really liked going to Catholic school. Jjust like my parents, I was convinced that this was the only way. Like this is it and then I come to college and I'm like "What? What? Like what's going on?" Like honestly whatever they did it worked and as I'm getting older I think "Wow, when I have kids I'm going to use that because it will work on them and if it affects them as it affected me then they'll turn out to be pretty good people (laughter).

Sarah, who was home schooled, felt that her religion based education had an influence on her and on how she was handling challenges:

One of the reasons that my dad put us in a home schooled education environment was that it instilled religious values.... Our education was based on the Bible and we used to memorize bible verses We have a different outlook on life. I don't get as jilted as some people. Usually, some people will freak me out when something bad happens. I just let it play out because I know it happens for a reason. I am one 
of the people who believe that God has a reason for everything so everything happens for a reason

Isabella and Carmen both shared similar thoughts on the role of parental influence on their values and morals. These women just reiterated the important role that the family had in the Cuban household. Carmen also shared similar views that she discussed in the focus group:

I definitely agree. I think my parents like they've played a huge role on the values that I have. I see myself that I make a lot of decisions in a similar manner they would.

Isabella, who reflected on her on morals and values, believed she has had a good

foundation and was able to apply these morals and values while attending the university:

I guess the way that I behave. My morals and my values are all there because of my parents. My family has taught me how to be me....but they have instilled in me, the push. They have instilled that in me. You don't give up. So that part, those morals, those values, they come from them and they have proven helpful in a lot of things.

Several of the women were very clear about the more esoteric humanitarian values that had been instilled in them. These values offer insight to the mind set of these women. As stated earlier, having positive and solid set of values does not necessarily make one moral or ethical; however, it helps to see how these women viewed the world and saw others. When asked what she believed in and how she would describe herself, Blair replied:

Definitely that what you give in, you get back. So I mean. I guess the spiritual side of me or what makes me feel good is that I tried to do good or random acts of kindness here and there. I always felt like that. I give to society. I do charity. What I'm doing as my profession, I'm giving back. Everything I give back to my family. I give back to my relationships. I feel like when I put all that good stuff out there in life. I'm gonna get that back too. So I mean, I'm just somebody who's looking to do good and hoping that everything will be good and I'm as who I am, I'm still really young...so that whole identity has really gotten me together. I 
know I'm going to have a strong professional identity because even now, I'm not even completely there and feel like I'm already a therapist. I guess I'm somebody who always wants more. Who always wants to reach to the next level but at the same time I don't want to step on anybody to do that. I feel it's very important to keep your respect for others and dignity and be a do gooder. I like to, in relationships, to give back to people. I don't know. That's a very hard question. That's a very hard complicated question. I am who I am right now. I don't know.

Carolina was also given the message of respecting herself and being respectful to others and of her family. The most important message she received was the value of being there for her family if it was needed. Michelle, who lived on her own and did not have anyone monitoring her behavior, said:

Yes, there are a lot of core values that I still hold from my family that I don't need to....there is something in me that says that it is the correct way of acting.

During the interview process, she also reflected on the value of her personal integrity:

I believe in honesty. There is not a percentage of me that would be a hypocrite. I could never be that person. I could never be a two faced person. I am the same person everywhere I go and I guess what I believe in. Honesty is a big word for me. Basically, if you can't be honest, I don't think you are worth it...

Honesty, as a personal value, appeared a few times in the interviews. Not only Michelle but both Luz and Natalie commented how important this personal value was for them.

Both, Luz and Natalie attributed this characteristic to their parents. Luz said:

My mom always told me that honesty is very important. She said that one day that I lie to her is going to be pretty bad because she is afraid that she will be unable to trust me again if I am dishonest. So that is one of the biggest things and I guess caring for your family comes first before everyone and those kind of things.

Several of Natalie's lessons on personal integrity were role modeled from her parents' and their hard work ethic. She stated:

Honesty. My parents have been big on hard working. Like that's something they've always always, even though I'm never not in school, I'm pretty much working. I work every Saturday at the business. Justice. I think that's a big one. Humility. Even though I compare to what my parents had before to like now and I 
would say they were well off. Every bone in my parents is very humble, very giving.

Decision making. The theme of decision making is used to describe those factors or influences the women in this study utilized when making decision in their everyday life. It was not unexpected to find there was a strong connection between family, friends, and religion with decision making. At times it was difficult to determine which drove the decision making process more, religious values or risking parental disapproval. Parental approval and disapproval was an area that I explored with these women. Ironically, parental approval was very important to these women and it was their parents they turned to when making tough decisions despite that fact that they risked disapproval. Most did say that their parents were very supportive of the decisions they were making in regards to their life choices.

For some of the participants the significance of the decision was also one factor in whom they turned to for guidance. If it was a simple problem, often times the women would turn to friends. If the problem was serious or troubling, they would turn to their family or religion. As it related to their moral and ethical development, what these women considered to be core values also had an implication on decisions they made. It appears as if it was less about right versus wrong and more about who would be affected by the decision. This is consistent with both Gilligan (1982) and Josselson's (1987) research on women's identity development.

Jacqui said about decision making:

I think what guides me the most is just experience, I really feel. I think that my family and religion. They all accumulate to an experience that I've had. So when I'm looking at certain decisions so of it is just yes or no, I mean there's no question about it. You don't have sex until your married...that's it. But then there 
are other things that you go through your life...like I know I'm in college right now and there's a lot of things like drugs and drinking that flow around here and now. When it comes to what I feel like I should do about these decisions, I really rely on my experiences in what I've been taught and just like people I know. I've been very fortunate to meet a lot of people that have dealt with a lot of different things and so I think that's what kept me grounded and what's kept me on a good path. So I think when you experience it, is when you learn the most and I've really learned from my mistakes. I've made a couple you know. I think that when I make mistakes is when I know what's right and I know what's wrong.

Sometimes I think that's important. Even if you parents tell you what's right it really doesn't mean much until you experience it.

This is what Carmen described as her process for decision making when it was not so critical:

Well it's not like I exclusively just turn to religion. Like for example, when I have to make a decision like my major. When I had to chose my major, I was like ok, I love children, I love Spanish. You know, I opted to do my major in elementary education then going on to get my Master's in Spanish hopefully. When I had to make that decision about what career path I was going to take, first of all, I reflected myself, on my own. Then I turned to my family and they gave me their input and then I was like , 'God, this is the decision I've reached, please like, not like give me a sign but give me the peace of mind that I've made the right decision.

She did, however, feel differently when it came to harder choices:

Everything I do...you see me... every time I have to make a big decision, I pray. So I think that it's not just part of what I am today but it will continue like. It continues forward, like every day. Like everyday there's a new decision to be made... and I feel like God is always there.

Carolina said that she definitely went to friends but when it was tough, she went to her

parents. Below is an example of her thoughts on how she made decisions:

I guess it's a little bit of everything. I think I take what my parents say. I think I take that a lot into consideration because I feel they've lived more than me. Although we disagree in opinion sometimes, maybe in political opinions and things like that, I do trust them a lot and trust their judgment. I would say that...religion also...my friends as well... but I would say my family more. 
Michelle, who was very comfortable making decisions, felt that whenever she thought about doing something she reflected on whether or not it was something her mom or dad would accept. In general, however, she said:

It would be a combination. Most of the times, I find myself when I have to make a huge decision that could affect other people, I would think of what other people might be involved if I make that decision. Who am I going to hurt? Basically because I might hurt myself or others 'cause sometimes we make a decision and don't think about how I am affecting other people. So yes, I do think about my family. What they would think and my friends and what would they be thinking of me if I make that decision. So I take that into consideration.

\section{Gender}

The fourth major topic of gender is used to describe the importance of understanding what it means to be a woman in their identity development. The findings in this section describe how these participants became aware of their gender roles and expectations as a part of their identity development. This section addresses several themes that form a picture of gender through the complicated connectedness of culture and family. The themes include how these women became aware of gender differences growing up; the roles and expectations involving gender; defining what it means to be a woman and how that differs from defining what it means to be a Cuban American woman; and value these women placed on being independent. Gender is one of the four findings that intersect with family, culture, and ethnicity in this study and is seen as a significant part of identity formation. Developmental theorists have done little in the way of understanding and appreciating those factors that influence a woman's development with the exception of pioneers such as Gilligan (1982) and Josselson $(1986,1997)$. In the present study, Josselson's theory of women's identity development lays the foundation of understanding gender (1986). This section provides an insight to the journey of 
awareness these participants went through. It became obvious that there was some struggle for these women as they were bound between cultural traditions and familial generational gaps. There is some cognitive dissonance occurring as they were obligated to hold onto family values and traditions, yet they yearned for future independence. When they spoke of themselves as independent, it is as if they did not recognize the hold that their families and culture had on them. Much to their chagrin, messages about gender began early and had a lasting impression on most of the participants.

Gender differences. Nine of the women came from homes where there were siblings or step siblings. While there were differences in the birth order of the siblings, the participants who had male siblings, older or younger, noted that treatment based on gender was obvious when they were growing up. The participants who had younger, same sex siblings, noted they were treated differently as well because the older had more familial obligations. Oftentimes it was the father or male head of household who created these discrepancies in treatment between the siblings. The women described their mothers as understanding, but the mothers supported the fathers' decisions. This is one irony which is discussed later as part of the examination of how these women defined being a Cuban American woman. These messages of gender bias, as conveyed by the women, were evident when they were growing up and continued on for those that were living at home. The messages were seldom overt, which led to some rebellious behavior. It became obvious through their interviews that they felt diminished and frustrated by the unequal treatment. The impacts of these messages of inequality had an active part in choices they were making later in their lives. For some, there were conscious choices 
about future rearing of children. For others, there was a strengthening in conviction of rejection of cultural values of how women were treated.

Sarah, who grew up with six brothers and sisters, said although her dad was a Cuban American male, he did not behave in a sexist manner. He professed that everyone in the family was responsible for helping out with chores. However, she recalled two incidents in her childhood that had helped her shape the way she was raising her own daughter. The first one she recalled was the time that she wanted to work on the car and do repairs, and he would not let her, stating that girls did not work on cars. The second incident involved backyard camping. She said:

...I love the outdoors. I love nature, but my dad bought a tent. It was a two or four person tent. I think I was about 11. He bought a tent at Walmart and we set the tent up in the back; and I was super excited because I thought we were going to have a miniature camp. So at night, he only let Charlie and Steven sleep outside. So I got really mad. I think it was three times that I got really upset with my dad because he would not let me sleep outside with Charlie and Steven. I really couldn't figure out why he would do that and the reason for it....we did everything together and then like all of a sudden, I can't sleep with them.

Later after the incident she asked if it was because she was a girl and he said yes.

Michelle says her father was not that rigid with expectations, but shared that she was treated differently from her brother while they were growing up. She said the following about her father:

He wouldn't say it, but I guess I have always been his little girl so he expects me to act that way I guess... also when living at home if we wanted to go to a club, they would allow me to stay to a certain hour. To her brother, they would just say "oh whenever you come back, that is fine."

She described how she felt about the negatives messages she received about playing nontraditional women's sports in Cuba (hockey and riding a bike) and the impact these messages had on her: 
I have always been against that. I really thought that women and men should be treated equally. We have the same brain cells, so we should know better. I have always been a rebel 'cause when they tell me no 'women should do this, men should do that', I feel like why? I always questioned life. I am a female but I like to do those things. I do them because I like to do them and that is it. I don't care if they are gender role biased. If I don't like doing it, I won't do it. I don't care about what other people think.

Natalie and Tiffany both described similar stories of gender bias and preferential treatment for male siblings because of it. Natalie, also shared her thoughts on the differences between her and her brother:

My brother had it the easy way but I guess that's my good easy way of saying it. I know when I was younger there was a lot of I guess you could say issues between my parents and my brother. Like they would let him be more free. Like he could be able to do different things. With me, my parents are always very like old school...women do this and men do this. Not as much as in what I want to do in the future and things like that but in just, everyday things. Like I never had a boyfriend before until 2 years ago and then like I remember before that, we date guys that everything was like going with my cousins to the movies and then meet up and because my parents didn't understand the whole dating or talking or anything like that. Then with my boyfriend, he had to come to my house. It was the worst experience ever because when he came to my house there was my Grandparents who were here from Cuba and a couple of family members were over and Dad decided to get up from his seat. I could not go out with him, us together, until my Dad met him. But in my head I could not understand how you could meet someone, and then go up to bed, to go to sleep. So just things like that. I remember my brother going out every weekend like it was his job. Just in things like that it's always been hard of what I should do and I what shouldn't do. I think a lot of times. I think it's affected me more just because of the lack of rebellion.

Tiffany's frustrations appeared to have a significant impact on her as she described the mixed messages at home. At times emotional in the interview process, Tiffany said the "word is the same, the action is different" when describing how she and her brother were treated. In regards to curfew, while they both shared the same one, only she was held accountable. Her brother was not. Tiffany was not allowed to drive until she was 18 , while her brother was given a brand new car at 16 . She told of how she was given a hand 
me down, used car and explained that her brother needed a nice truck to pick up girls for dates. As for helping out at home, Tiffany shared how she viewed the expectations of chores at home:

We're both expected... our only job is supposed to be keeping our grades up because it's the most important thing. We live at home. We're fed. We both have cars. So our only real job is to get good grades. My brother did not get good grades so he does not have scholarship so they paid for his school... where I got scholarship and it's paid for. And what's not paid for, I got a job to pay for. I pay for my gas at times. His gets paid. He does not have a job and does not need one but I do to pay for my outings but my dad gives him money for his outings... because it's different. He's taking a girl out and I get taken out. So I shouldn't have to spend money, but I do. I help with the laundry. I help with the dishes. I help with the cooking. But he's a boy so he doesn't do those things. He's supposed to mow the lawn, but he's tired because he's focusing on school, so my mom and I mow the lawn at times. We cut the trees outside. He takes the garbage out occasionally. I pick up the mail. I sweep the house. I take care of the animals. I feed the animals with my mom. He claims none of the pets so he doesn't have to take care of them.

Luz, the only participant who was an only child, recognized that being female was the reason that she was not allowed to do a lot of things that she saw other people doing. She recalled:

Being able to go out with friends. To get involved. Just because I was female, they would worry about what could happen, although my cousin being here....even now, when we go out together, she is very happy that I go with him because she feels that I am protected. She still warns us to be careful of this, be careful of that. So even though he is male, he still gets a lot of her protection.... I think it is unfair, but I haven't had so much of a problem with it at my house because I feel like it's my mom being overprotective whether I was a guy or a girl. Maybe a little more because I am a girl...

Gender roles/expectations. The theme of gender roles and expectations is used to elaborate more on the messages about gender that these women received growing up. It became clear as discussions continued about gender that either by observation at home or 
by direct verbal messages, these participants were expected to adhere to prescribed gender roles, usually dictated by the family and supported by social and cultural norms. What I found was that many of the women participated in these roles and met the expectations and found it very stressful as full time college students. They received mixed messages from their family about the importance of school and helping out at home. They were expected to be successful in school and still help out at home, unlike their male siblings. They clearly stated that there were traditional female roles and male roles in the household, but they did not necessarily feel they would continue these later in their lives.

What was interesting to note is many of these women possessed some very progressive feminist ideals of equality but when asked about the roles of women, most shared that the task of raising a family was the woman's primary responsibility. These women articulated that roles and expectations were not necessarily equal, yet most fulfilled these obligations as to not disappoint their family. Many of them struggled with this idea of raising a family and having a career. Most did not want to be like their mothers in the sense that they did want to stay at home, yet they felt family was as important as a career. There appeared to be some generational changes occurring as not all of the participants' mothers were stay at home moms. The women in this study were able to see how things had changed from their grandmother to their mothers to them. This shift had had an influence on their future aspirations and on their own identity development. This is discussed later in the section.

Jacqui, who had a profound streak of independence, attributed this to the women in her life who served as role models. Her mother was nearly killed as a baby when 
assassins tried to kill her grandfather. This story was something that Jacqui held near to

her and she equated the story with the strength of the women she was surrounded by. She said:

Even though there's a big stereotype around Hispanic women that says you're supposed to cook, you're supposed to clean, you're supposed to do...I'm not going to lie my grandmas are great cooks, they're amazing...they love having clean houses and everything but what I feel they taught me the most was to be independent. Even though you have a husband that's taking care of you...you need to learn how to take care of yourself. And actually I think all the women in my family have jobs. I don't think there was one of them one that was just a housewife that stayed at home. And that's ok if that's what you want but they really stressed that...yes, you take care of your family because family is number one and yes, if you become a mother like your kids are your priority but you need to become an independent person.

That if the man would leave you one day, you need to be able to stand on your own. And they really stressed that. I really think that just comes from the struggles they had in Cuba in coming to America. I know that at least on my mom's side, my grandmother spent years apart from her husband. So she was literally a single mom without being single. That was tough. She didn't know where her husband was and she had two kids she had to take care of. And I mean, she is definitely a very strong women and my great-grandmother still around and she's kind of like the "head honcho" because she started the family tree and right now she's 92.

Even though Natalie's parents were incredibly supportive of her extracurricular and academic achievements, there was still an expectation that she adopt traditional female roles. Natalie, who was very much aware of these gender roles, was pressured to meet these expectations and had already given thought to what it would be like if she married her current boyfriend. She said:

Well I guess for me a lot of it is just to complete my degree and everything that I want to do before anything else. I think that's why a lot of the emphasis always been like "no boyfriend, no boyfriend, no boyfriend" because both of my parents got married and had a child by the age of 18, so sometimes I'm much more advanced, and it's not in my plans to do this. I feel like I'm set on what I want to do, however, my Mom's a big person of like women need to be the woman of the house. Sometimes my room, is not the cleanest room ever...not 
gonna lie...it's clean for me! Not for my Mom. So like there'll be times where I'll have like my pile over here because that's what I have to take to the dry cleaners and I wasn't able to take it today. She'll come into my room and she's like, 'I just can't wait until Jorge sees this room. He won't marry you. How can you be a woman? Look at this house.' I'm like, 'Well mom, I just got home from school and I need to study for my test and probably not going to sleep all night.' There's some of my priorities go more than others...so a lot of times it's just you know like...even though they do accept the new age of me going to school and getting all these degrees, doing all of this, at the end the day, even though I want to become a lawyer.

I want to become whatever I want to be. They're like you need to know to cook and you need to know how to clean. You need to do all of this. In my head and kind of what my boyfriend and I talk about a lot, 'I'll cook but you do the dishes.' Because he doesn't like to cook, I'm like well 'you gotta do one of the two.' Like, I guess it's more new age. We talk about a lot of things that for both of us, there's gonna be responsibilities, and I don't know if because my mom took a lot of the responsibility on and my mom is very like, she won't accept help so she would do everything in the house like finance, like everything. My boyfriend is a finance major so he can do that, because I need to take care of other things. So even though I think they do see the light of you know the new era, of woman graduating and all that, at the same time she expects me to have all then 'woman chores' done that I need to get done all the time.

Like Natalie, Isabella also felt the stress of trying to be a full time student, yet balancing all the responsibilities she had at home. She described her father as a traditional Cuban, meaning that he expected that the house was clean, there was someone to clean up after him, and the dinner was on the table when he came home from work. It is interesting to listen to her describe her recognition that she was living between a generation of tradition and a new generation of thought on the role of women. She described what it was like for her on a daily basis:

For example you go home and if you are a girl you have to cook. If your mom hasn't cooked and if your mom is not home to clean, you are supposed to clean because you are another girl and if you are the only daughter or have a sibling that is a sister it doesn't make a difference to your father because with Cuban men the tradition is women clean, women cook...this is a new generation but you still have the responsibility as a woman whether you are 12 or you are a 100 . You have to do it. It makes it difficult to live with Cuban parents because, yes, 
education is a priority with them. They have a lot of priorities. They really do not prioritize. Everything is on the same level. You have to be organized. You have to work, and you have to go to school, and you have to be home by a certain time. They don't care if you are 25 or 30, if you are not married; you get home by the time they say. It is a lot of stress because they want it one way and you are trying to please them but sometimes it doesn't work out that way. It is just go to do things that are not very good for you but you do it to cope with the fact that you have so much stress coming from your family unit.

It is evident that there was a cultural shift occurring. Carolina, who for years was

observing these traditional roles in her own family, starting with her grandmother said:

I know for example when we get together at family gatherings before the woman sits down and eats she always serves the plate for her husband. That always happens. I know that my grandmother was saying how a guy should never ever wash the dishes, she should always do it. How it's not the man's place to clean the house. Things like that.

Her reaction was similar to Natalie's and Jacqui's, and while there was movement for her toward a changing time, she still understood the cultural value:

...I think those times have changed. I think that right now the friends of mine that have been involved with their boyfriends, they completely share all responsibilities. So it's different, and they're Hispanic and they're Cuban. I think very much now it's sharing responsibility, and it's not about it all being on one person. I think traditionally it's a very big thing. In Cuban families and other Hispanics also, it is important for the man to feel that he can support his family financially. It's very important...I guess for the husband to do that for his family.

When I questioned her about generational changes from her grandmother to her mother to her in regards to gender expectations, she said that she felt that there was a movement of being more liberal. I found this to be true of most of the participants, as they struggled with balancing decisions about family and career choices, different from the ones their mothers made. Carolina shared this about her family:

I guess, an example can be my mom's grandmother. She never got divorced and she was in a bad marriage. And then I know that now as times have passed, if that would happen to maybe my mother's age, she would get a divorce. So it's kind of 
like they become more liberal more independent, and I think that comes from generation to generation. They tend not to be as subservient to their husband.

When I questioned Carmen on gender roles, she recognized that because she was a

female, that she had certain expectations from her family. She said:

There are many things that are expected from me as a female. You know, for example, the whole chaperone thing...like when I go out with my boyfriend or... when I go out with guy friends that I'm attracted to or whatever, I go with a chaperone. Whereas with my male cousins they can go out with their girlfriends no problems... with the gender comes expectations and norms....Well, I mean I even see it with female friends that are also Cuban. The chaperone thing is a big thing. I've seen that. They're expected to care for the family. Not that the males are not expected also. The males are also expected but even more so from the female. I don't like to associate this only with Cubans because I think women regardless of their ethnicity, they're expected to be nurturing and caring and all that...but it's even more so in Cubans.

Sofia found herself often floating between the dutiful daughter and head of household.

Since she lived with her mother, she recognized the dual roles she played since her father and grandfather passed. When we spoke of generational changes, it was clear that she recognized the impact that living in the U.S. had had on her evolving self. She said:

I think it is looser now. I don't know if that is the word, like there is more freedom now. Like with my grandmother, I mean she didn't go to school. First of all they didn't have the means for her to go to school. She stopped going to school when she was in third grade and she pretty much taught herself at home and with her other sisters. It was pretty much all about the house, taking care of the house, being prepared to find a husband and have kids and that was it. With my mother it was also strict in the house. She wasn't allowed to go out by herself and stuff like that, but she went to school. She didn't go far enough because like you were expected to get married early. For my grandmother, if you didn't get married by the time you were 22 you were going to stay by yourself. With my mom it was a little bit higher, like 25 or 26 . You had a boyfriend, and you were expected to get married with that boyfriend because it had to be the first boyfriend you had. With me, it is different. Like now I get to choose what I want to do. I want to go to school. No one can tell me yes or no or what I should study so I guess it is different. 
Regardless of how she viewed these differences, there was still evidence of gender

expectations. It is interesting to note that she accepted it for what it was and did little to

change the culture. She said:

....We would all sit at the table but until my grandfather would sit, we would not start eating. My mom would serve everyone and then she would sit down to eat or if my dad was in the bathroom or the bedroom we would wait for him to sit at the table because we would always eat together. Now my grandmother serves to my uncle and if he eats, he leaves the plate there. He doesn't even pick it up. He expects her to do it. It is not something rude or something bad. It is just something that happens. But if I do that like that, I am expected to pick it up because I am a women and that is what I am supposed to do. It has never been an issue leading to arguments. It is just the way it is.

Tiffany shared that she made a decision to live at home and save money in order for her to move away when she attends law school later. However, she felt an enormous amount of stress trying to live at home, meet numerous familial obligations, and do well in school. When asked about messages about gender expectations, her passionate response echoed many of the participants:

I still get them every day. According to my mother the woman cleans; the woman cooks, the woman is the crutch for the man, and the woman puts up appearances and keeps them up. The house is always clean. They're always happy. There are no fights in their marriage. Their marriage is falling apart but it's perfect. So mom is all about the appearances. My dad is more behind the scenes. My dad is more the woman keeps her legs crossed; the woman wears skirts below the knee; the woman doesn't speak unless spoken too; the woman rides in the back seat if there are two men in the car; the woman can hold her husband's hand and walk next to him but if not why would she need to be next to him; the boy can have a girl over in the room and close the door and be under the sheets; the girl have a boy visit and sit with three relatives between them on the couch. The woman is nothing. To my mother the woman is nothing. And I don't feel that way.

\section{Defining what it means to be female/woman versus being a Cuban American}

woman. This theme is used to describe the thoughts of the participants on their personal views of what it means to be a woman versus what it means to be a Cuban American 
woman. Based on the conversations about their gender and gender roles, I wanted to know how they defined being female. I was then curious to know if there were differences then about being a Cuban American woman. Based on their thoughts about gender roles and expectations and listening to them define the struggle of following cultural norms versus a more feminist ideology, I sensed there was a change in thought in how they defined being a woman. Because of this shift in mentality, I expected to find that most of the women would have similar strong feelings about being a woman and also about being a Cuban American woman. I did not expect to find there was a disconnect between the two. There were similar beliefs on what it means to be a woman in general but very mixed feelings about what it means to be a Cuban American woman. Some participants viewed Cuban women still as a subservient and oppressed group, and others felt they were the strength in the Cuban American household.

These participants, based on what they shared in the interviews and despite where they were born, articulated very clearly there was a cultural shift in mentality, supported by their mothers. Behind the scenes, the mothers of these women appeared to be the reason for the shift, encouraging them to be strong and independent. They were encouraging their daughters to adopt new ways of thinking about success and family, but not to the point where they sacrificed all cultural values. What some of these women shared was that the struggles of immigrating to the U.S. were the impetus of the grandmothers' and mothers' message to them. They did not want their daughters and granddaughters to have to live like they did. The biggest irony is that the mothers, some, not all, did not always act in the manner that they were portraying to their daughters. Not surprising, most of the women looked to their mothers and their grandmothers as role 
models and sources of strength. I attribute this increased value of being a strong independent woman as a positive factor in their identity development.

I specifically asked most of the women what it meant to be female. I expected that they would have very positive feelings based on their perceptions and thoughts on gender. What I discovered that was unexpected was their thoughts on how society views women that were much more negative in their eyes. Natalie, who was in a prominent leadership position at the university, faced challenges as a young female leader. She had been in situations where she felt treated differently because she was a woman. About being female, she said:

Wow. I think it means a lot of things...To me, I think female is some or I guess I don't even...I guess sometime I consider myself a stronger female, and I think it's being about to overcome your challenges. Just because I feel a lot of the time like even nowadays like there's a lot of challenges that you know you go through....

Later, as she reflected on this more, it became evident that the role of her mother was the source of her influence. She, like many of the participants, recognized that the messages about being a woman came clearly from the women role models in their lives, including the grandmothers. Natalie said:

But I think a lot of times it's felt to be like that strong woman trait, and we probably learned a lot of that from like our mothers who kind of told us "you need to be strong" and maybe they're not the strongest person in the household you know, but they kind of influence and my mom has always been like, "You need to be strong woman, you need to be an independent woman." Even though, like my parents love my boyfriend...my mom is like, "You need to do everything for yourself first. You need to love yourself before you love anyone else, and you need to keep that strong trait." So I think, not even in that I just think you know... it goes along with women but I think a lot of times with my specific mother's influence on me that's been one of her biggest things...you need to have all the weaknesses that you could be given and counteract them with strength that you are going to have later on. 
Miette also shared her appreciation for the women in her family, despite the fact that there was lack of presence of these women for a while as she grew up. As she matured, she recognized the sacrifices that her grandmother made for her mom and that her mother has made for her. These bonds were strong but the messages about strength were undeniable factors in what was influencing these women as they were developing themselves. Miette reflected back on her life and shared this thought:

About this strong woman role. I agree because a lot of the women in my family beginning with my Grandmother who I really admire and we haven't been in contact as much as guess I would like but when she came, she came here for almost a year. Then after 11 months, she decided to go back to Cuba. During that time we were very very close. She's coming back now..we're getting her..now it's definitely forever...but we very close when she was here. I got to know her more and more about her history and her husband died when my mom was a few months old, so she became a single mom and that was when she lost her servants. She had to become a single mom with far less help than she had been used to [in Cuba]. So that made her a really strong person and she really brought up her daughters up in a way that I really admire. Like my mom and my aunt, they learned English. My mom came here knowing and speaking English and French also, she really cared for their education. She was educated herself and then my mom well she when she got the opportunity to come here, she did it. She did it for me. So that's the way that I see the women in my family. Women that have the drive, have kind of like survived through hardships, and accomplished what they set out what they set out to accomplish.

This was a pattern that was repeating for one participant. The drive to make things better for the next generation continued. Sarah, who was joining the army as a reservist to make a better life for her and her daughter said:

Being female? I still think that there is a double standard in society. You just have to work harder. There are the same goals but you have to work harder than the male.

In a succinct voice, Tiffany's response was simple when asked about what it meant to be female. There was a sound in her voice as she said these words as if she wanted to believe them. It was as if she was looking to the future and not reflecting what she was 
experiencing in her current situation at home. She said simply, "Power. Possibility.

Potential."

This feminist perspective is what is separating this generation from the prior one.

These women appreciated their past histories, respected the traditions that guided their

lives culturally, but yet they were seeking to explore new areas of their womanhood.

Jacqui, Luz, and Isabella spoke to this new movement of women yet it is clear that

culture still bounded them to the past. Jacqui said:

Being female is wonderful. I love it. I mean I love being girly girl. I love being the girl that does her nails and gets dressed up and things like that. But then there's this completely other side of me that I think a lot of people are shocked by and that is that I'm very strong and very independent. Even though I'm currently in a relationship, I'm very much independent of myself. I know that if anytime I were to be left, I would be ok. I think that that's extremely important. So being female to me is very empowering and I think the fact that we are the care givers and that yes we are the mother figures, we are independent. We don't have to be that stereotypical woman that cooks all day and has to clean and just stays home waiting for the husband. Matter of fact, a lot of women chose nowadays not to get married and not to have kids. Which is completely their decision but I think that's what being female is to me. I think we can do anything a man can do. I love that this generation is embracing that. During my parents generation it was kind of like men ran anything.

Luz was receiving this message of being independent from her mom, despite the fact that her mom appeared to be overprotective at times. Luz was the first to recognize that her mother had a tug of war in regards to holding on and letting go. Luz shared:

Yeah, my mom she was educated in Cuba, we still had a really difficult life and she had a really difficult, a very difficult childhood...But when coming here, she definitely worked hard, and she always told me, "I don't want you to go through anything that I went through...I want you to be so successful that you don't have to stand for anything." So she definitely has given me the strength. She has a lot of strength and she's definitely given me the strength and encouragement to better myself to have something that she has not been able to have. 
Isabella shared her thoughts on what being a female meant to her:

Female, it is hard to say because everything we base ourselves on is society's way of thinking. Female is supposed to be delicate and strong at the same time. They are supposed to be smart but not too smart. You are supposed to be a lot of things. I feel personally for me what it means to be a female is to kind of grow independent. To grow on my own. Not to identify myself through a man but still remain feminine I guess... To be female to me, what I think would be the best thing is to be able to define yourself in terms that are not necessarily scripted by gender rules of society....

All of this discussion about being a female led me to probe further with these women about their cultural and ethnic identities and what it meant to them to be Cuban American women. I wanted to know if they defined themselves differently as Cuban American women versus defining themselves as women. I was curious to know if their responses would be positive, negative, or indifferent to this notion. My line of questioning came as a result of the women referring back to phrase "stereotypical Hispanic family" that came up a few times in the interviews. As they talked about their own independence and strength, they shared what it was like to be a Cuban American woman. They also spoke of the women in their families and their thoughts on how this had shaped their own identities. It is clear that what appeared to be mixed messages at times about gender were not always mixed. There were family dynamics that showcased and exemplified the Cuban American females' role in the family. All of these messages about cultural treatment of women, both implicit and explicit, had an impact on these women's self development. Isabella said:

You know we were talking about female, I was thinking, people have this conception that women, female the gender, they're soft spoken, they're delicate, and you know when you're talking about Cuban American women...not only the fact that they're strong but you know the fact that they're very independent and that's something you don't see every day or you talk about. Even though the woman's right and everything that happened, you people still see us women as 
being dependent on men. Cuban American women, yes, they have men that they look after and men that look after them... They're very competitive. Cuban America women you know, they're very determined. They want to be equals.

Even though now in the U.S. you have equality. Women want to be equal but you don't see these women like going out there and laying tile with their husbands. I have seen so many Cuban households where the women out there shoveling in the dirt, laying tile, putting up the roof. You don't see that in every household. Yet there's a lot of Hispanic households that you have the woman who is working but she's not equal to the man. Cuban women make themselves equal to the man.... And Cuban American women, you know, they see themselves as it's not just what they want to be, it's who they want to be...they're going to do it no matter what and it's the very big difference between you say we are but we don't do it, than we do it and that's who we are.

Carmen, whose father passed away and who was living with her mother, had similar views as Isabella. She said:

I think, personally being a Cuban American woman sometimes it's like playing two roles. Like you know, you have the nurturing side, you know, the caring Cuban mother, overprotective all of that. You also have the strong side to the Cuban woman; you know that she's very determined. This is shaped by my mom. My mom has her values; you know she's a very good woman, hard working.... She's been through a lot and you know, she vulnerable at times so it's like two roles in one. It's hard to explain but...that's how I see it.

She went on to clarify this more by examining the evolution of thought between generations. She planned on living at home until she was married, but her thoughts on the progressiveness of Cuban American women living in the United States were on her mind.

She talked about the changes:

Yes, because I think many times you know I've heard "Cuban women oh they stay home, they cook for their husbands"...there are some of us that are actually out there getting an education, not just confined to the home. I think it goes back to how things were in the past. I think you can't judge situation because "oh, years ago it was like that"...because cultures evolve with times. Just like every culture. Cuba has evolved too.... Well first of all I hope it will change, that's the first thing. I mean I still see girls from my generation that still want to be a housewife. If that's what makes you happy, then more power to you, but as long as you're doing it to please your husband or because you think that's what is expected from you. I think it will change because the fact that yes we have all 
these Cuban roots but we're living in the states. We're exposed to a world that my grandmother was exposed to when she was my age. I think that will play a huge role.

Isabella, challenged by living in a traditional Cuban house until she was able to leave, understood the conflict and what it meant to her personally. She articulated what many of the participants felt about living in both worlds:

Cuban American female. As much as people don't want to admit this it would be to be a successful mother and wife. You want to be educated almost what you would consider an American stereotype of a Hispanic household. You want to live a life where you could call yourself a doctor, where you could drive a nice car, and be considered what everybody wants, an American dream. But at the same time you still want to remain traditional. You want to hold onto to your household roles. You still want to remain, I guess, as much as Cuban as possible. You don't want to lose it because that defines who you are. To be a Cuban American woman would be an educated version of an uneducated Cuban woman. Instead of doing everything for a man, you do it for you.

In summary, this section described how the participants became aware of their gender roles and expectations as a part of their identity development. Gender role awareness for many of these women came at an early age. It is evident that there is a struggle with old ways of traditional thinking that is dictated by cultural and familial expectations. Many of these participants' value these traditions; however, they strive for a sense of independence and feeling valued as women capable of doing more than expected. There is an underlying message between the generations of women that is often shared only between women. While the mothers and grandmothers were expecting these participants to remain close to their cultural roots, they were also encouraging them to be strong and independent. 


\section{Education}

The fifth major topic of education is used to describe how education was an influencing factor in the identity development of the women in this study. The subject of education has more of a direct relationship to family than to the other themes in this study. It was not required or mandatory; however, for most it was a familial expectation that each of these women attend college. There are three themes in this section. There were some interesting findings in the discussion with these participants about how education was viewed within their families and what obtaining a degree meant to the families. The second theme was the influences that attending an HSI had on their identity development. While only one participant attended a PWI, I will include the thoughts and views of the other participants as to what they valued about an HSI versus a PWI. This theme lends insight to what degree the influence of attending one type of institution over the other had on them. A third and related theme to attending an HSI is their involvement in campus activities and relationships formed on campus during their college experience. In sum, the decision to attend college, where and why they attended college and those experiences that occurred during their time in college influenced these women in many ways. For some, this provided growth and challenges as evolving young women as to decisions about their futures, their values, and their identity.

The value of education. It was very clear after interviewing these women that one thing was consistent with each of them; education was very important to them and to their families. While degrees of educational attainments within the families differed, this value that education was a way to succeed in life was ingrained in each of the participants. For many of the women, a family member or two received an education in 
Cuba that did not translate in the United States. The women shared that many of their family members were at least high school educated. Some parents received college degrees in the U.S., but this was not the majority. Many of the participants' parents owned their own businesses because after arriving in the U.S., they found that more lucrative than working menial labor jobs. Regardless of the educational levels, whether college educated or not, all these women shared that education was a valued trait when they were growing up. Five of the participants graduated from private, all girls, and Catholic schools as mentioned earlier in this chapter. For the women, the value of education appeared to be a way to make a better life for them and their future families. For the parents and the grandparents, the meaning and a value of an education was to ensure and solidify this. For these women it was something that they enjoyed doing; however, their families did not want their children, daughters in this case, to have to struggle as they did. Therefore, there was this added pressure to do well and succeed. Anything less would be a disappointment to the family. This was a message that was reiterated to these participants again and again as they were growing up. For most of these women, they were a first to go to college and graduate. Not only did they feel a sense of accomplishment, but it was as if their families were living vicariously through them in this achievement. Also, the women appreciated the value of education they received and how it positively impacted them despite all the additional responsibilities they had at home. They all realized the importance of education in their future. Miette, whose mom supported her academics by encouraging her not to work, said:

Well definitely the strongest message, the one that I have felt all my life, for as long as I can remember, education is important. Education is very important. You have to go to the university. You have to be educated. You have to have a high 
education. That has been the overriding value because it's the strongest. That has really fell onto me from every member of my family....

Michelle said the following:

He (dad) would love to see me graduate and a degree in my hands and to do something with that degree. So that would be success. For me to become a successful woman would be to get a degree and get a nice job and make a living for myself.

Sophia added:

I think I have been in school now for like 14 to 16 years. It has been a very important part of my life. I think I put it on my statement, my letter of intent that education was something that was always encouraged at home and that is something that I find interesting with my mother and grandmother it was never so. Maybe that is one of the reasons why they encouraged it..... Whenever I talk about getting married or something like that, you have to finish school first and then think about that and that is something that I tell myself. School is everything to me.

During the focus group, Sofia shared that her value of education was based on her experiences in Cuba. Her destiny was in the fate of the government to decide what she would do career wise. Her parents decided to bring the family to the United States in order to provide her better opportunities. She knew the sacrifices that were made for her. For her it was never a question if she would go to school; it was always a passion for her and something her family supported.

Carmen said the following about the messages she heard about succeeding:

Education. If you want to succeed in life you have to get an education. If you want to excel academically you have to try hard. You can't expect it to happen. You have to work hard to get it. Definitely working hard, getting an education were the recipe for success and something that I believe in.

Tiffany, Sarah, Luz, and Natalie were the first to graduate from college. Luz said:

I'll be the first person in my family to graduate from college. On my dad's side of the family I don't know anything about my great grandparents being that we're not close to them and I just know that they all passed away. My grandmother was 
raised in the country and I don't think she finished high school. I think she went only up to middle school. My grandfather finished school, did to high school and he started studying pharmacy. I believe he was a pharmacy tech, either someone in the family owned it. I don't think his father owned it but he worked in a family owned pharmacy and he had to stop when Castro took over and he never finished his degree or I guess his studies.

Tiffany also shared:

The first to go into...my parents always thought that education was number one. Without a degree unfortunately you can get anywhere in life. They feel like everyone else is ahead being that we had to come to this country and start over. There's the pressure of not failing because you're the first. So you're the example and it's almost like you're the stepping stone for those behind you. So you have think of those coming behind you all the time.

The message about education that Luz received from her parents was that without education it would be very difficult to be successful and that all her parents wanted for her was to be comfortable and successful. She said:

Well my parents haven't gone and definitely not my grandparents have not...so I am the first one in the family and I'm an only child. So this is definitely a big deal and I think it's $10 \%$ of our conversations every time we have a conversation on the phone and I am calling her. Like she mentions it somehow, "so how's school?" and she brags about it all the time.

Natalie knew how important this degree was to her parents. Her parents came to the United States with nothing and had built a business from the ground up. She said they would rather have nothing and give the world to her. Ultimately, she would like to go to law school, which her parents embraced fully. When asked about education and her family, she said:

To them it's a big deal. Like I remember my high school graduation. It was a very very big deal. I just think a lot because they haven't been able to obtain.

The experiences and influences of attending a Hispanic Serving Institution. The second theme is used to describe the experiences and the influences these women 
articulated about the effects these experiences had on their identity development while being in school. There has been research examining the experiences of Latina females from Hispanic descents, such as Mexican American, Puerto Rican, and Dominican attending, an HSI and a PWI; however, there has been little exploration of Cuban American women attending a 4-year public HSI and what this experience means (Hernandez, 2002; Rodriquez, Guido-DiBrito, \& Torres, 2000). I was curious to understand a few things in regards to their experience. First, I wanted to know if attending FIU was their first choice and why (see Table 2).

Much of the literature states that while there is great support for their educational attainments, Latina women are expected to stay at home. I wanted to know about the decision making process as a way to understand if that premise was true for these participants. I also wanted to explore their attitudes towards attending an HSI to understand their overall experience and if that was any influence on their identity development. This included their participation, if any, in campus activities. Table 2 lends some insight as to the decision making process about attending FIU and what types of activities these women were involved in on campus.

It is interesting to note that of the 12 participants in this study, for six of the women FIU was their first choice because they wanted to, not because they were told to or expected to go. Most of these women decided to stay at FIU because they wanted to be close to their families or they were planning on transferring. Two participants stayed because they felt that their parents were not emotionally or psychologically ready or that they were the best caretakers of their family. Ironically, both of these women were living on campus and were within minutes from home. Of the remaining six participants, only 
Table 2

Summary of Participant Determining Factors About Attending FIU and Types of Campus Involvement Activities

\begin{tabular}{|c|c|c|c|}
\hline Name & FIU: First Choice? & Determining Factors & Campus Involvement \\
\hline Blair & $\begin{array}{l}\text { Yes, but thought } \\
\text { about transferring }\end{array}$ & taking care of mom & sorority \\
\hline Carmen & $\begin{array}{l}\text { Yes, even though } \\
\text { she received scholar- } \\
\text { ships from other schools }\end{array}$ & being close to family & religious \& cultural clubs \\
\hline Carolina & No, but chose FIU & $\begin{array}{l}\text { applied to other } \\
\text { schools, but FIU } \\
\text { offered better scholarship }\end{array}$ & $\begin{array}{l}\text { sorority } \\
\text { ps }\end{array}$ \\
\hline Isabella & No, but chose FIU & $\begin{array}{l}\text { parents said no } \\
\text { to her leaving }\end{array}$ & club involvement \\
\hline Jacqui & No, attended PWI & $\begin{array}{l}\text { transferred to FIU } \\
\text { after a semester }\end{array}$ & peer advising, fundraising, \\
\hline Luz & $\begin{array}{l}\text { Yes, with the } \\
\text { intent of transferring }\end{array}$ & $\begin{array}{l}\text { she said her parents } \\
\text { were not ready yet } \\
\text { for her to leave }\end{array}$ & resident assistant, clubs \\
\hline Michelle & Yes & $\begin{array}{l}\text { transferred from } \\
\text { Miami Dade, financial }\end{array}$ & no involvement \\
\hline Miette & No, but chose FIU & $\begin{array}{l}\text { was accepted into } \\
\text { art school but } \\
\text { changed her mind }\end{array}$ & Honors College, clubs \\
\hline Natalie & Yes & being close to home & sorority, SGA, peer advising \\
\hline Sarah & No, but chose FIU & $\begin{array}{l}\text { was considering a } \\
\text { school in north FL, } \\
\text { but financial reasons, } \\
\text { and family stayed here }\end{array}$ & no involvement \\
\hline Sofia & Yes & not ready to leave home & clubs \\
\hline Tiffany & No, but chose FIU & $\begin{array}{l}\text { wanted to leave but } \\
\text { but was offered } \\
\text { better scholarships at FIU }\end{array}$ & $\begin{array}{l}\text { sorority, clubs } \\
\text { J }\end{array}$ \\
\hline
\end{tabular}


one applied to out of state schools with the intent on leaving and was told "no" by her parents. The other five applied to other schools, but due to family ties, financial aid packages, or change of heart decided that FIU was the best option for them. There were two transfer students in this group, one from a local community college and one from another state school in Florida. One transferred to FIU because she was able to meet the entry requirements, and the other was considerably unhappy at her first choice school. Whether or not FIU was the first, second, or the only choice, none of these women articulated that they chose FIU because it was an HSI. Luz said that she originally wanted to leave the state, so her intention was to transfer after a semester. She said:

I wanted to go to a different school. Somewhere far away, somewhere I wasn't like on the majority. I just wanted a different experience. I decided I was going to stay at FIU for about a semester; maybe a year at the most, because I didn't think my mom was quite ready to let me go yet. So I came to FIU, and then I ended up really enjoying it. I guess I just got used to it and I just didn't want to leave.

Luz did make a decision to live on campus, which was still very hard for her family. She said that she decided to live on campus to help her mother let go a little bit and because she wanted the "whole college life experience." That led her to apply for a Resident Assistant position, which helped shape her in her time at FIU.

Like Luz, Blair also made a decision to live on campus after deciding to spend her first 2 years at FIU before transferring. She said:

I wanted to stay local, just because it was really weird for me to leave my family and they really didn't want me to leave. I wanted to stay local and just knew that UM [University of Miami] was not where I wanted to go....So I know that FIU seemed like a good school; so you know I liked it. I've always liked FIU. I still love it. I love living here.

Tiffany shared that she was not sure where she wanted to go but had been offered athletic scholarships to attend a school in Alabama. The message that she heard from her family 
was a push for her to stay local. Her mom, in particular, was the major contributor to these messages. Quoting her mom, Tiffany said, "You're not leaving anywhere, you're not leaving home, why would you want to cook for yourself, do laundry for yourself....stay home, stay home." So she made the decision to stay home and save money in order for her to be able to move out when she attends law school.

Carmen, who graduated third in her high school graduation class, was offered a scholarship to attend a school in New York. For her, the decision was about family and finances. She said:

...the main factor that I considered when choosing a university was location. Being as family oriented that I am, I wanted to be as close as possible to my family. I looked at it from the point of view, like ok, they are offering me all of these scholarships... There's already been a financial burden placed on my family for attending private school, all those 14 years. I want to be able to say, "Now it's your turn to lay back and relax and not have to worry about my education in a financial sense." So that's why I selected FIU. So it was location and also just when I came here I felt at home at FIU. Like I walked around, I fit you know.

Carolina also explored her options and considered going to other schools, which her parents supported, but ultimately she said that the scholarship she received from FIU was the reason she came to this school. However, Isabella had no choice. She had worked very hard in high school that afforded her to achieve an Associate degree by the time she graduated. In her mind, she assumed her parents would see that she worked very hard and would let her attend the school of her choice.

Without consulting them, she applied and was accepted to Georgetown University in Washington, DC. This was not the only school in which she was accepted. Ironically, a bad break in her father's business was the ultimate reason she stayed, even though she knew her parents would have never supported a move away from home. She recalled: 
I knew Georgetown was out of the question. There was no way around that one. That was too far away. But I thought maybe UF [University of Florida] in Tampa or maybe UCF [University of Central Florida] in Orlando. That would be great. It was close but not too close. So I kind of mentioned it to them. At that time, I had just started dating my boyfriend and I would have thought they would want me to leave because they didn't like him. Even then they didn't want it. They didn't accept it. I told my parents I really want to go here. I got the scholarship. All you guys would have to do is help me with my apartment or my dorm. I am not the only one that is going there. Some of my friends are going and they went like yea, yea, we will think about it. Think about it was the summer. Fall came around, no actually I graduated in May and summer was going to be my break period so I would have had enough time to still get into school.

It just so happened that in June or July my dad had his second downfall in the business and there was no way I was going to leave. Now they couldn't hire a secretary and I was the one doing all the paper work. If I would have left it would have meant they wouldn't have enough money and I wasn't just the secretary I was doing everything for them. You are not just a secretary. You did the delivery then you did the cleaning and lock up and you open up and you manage the employees and you do everything. They don't see you as an employee. They see you as an owner and you are trained to think like an owner and one day you will take over. Obviously right. I did this for you. How are you going to sell it and break it up in pieces if it is for you. They don't think any other way.

While Isabella's choice was made by family obligation, Sofia recalled her decision as her only choice. She said:

When I was going to graduate from high school, I think that was my only choice. I wanted something that was close to home. I didn't want to move away and I was not also encouraged to do that so, I made a decision. My first and only choice I guess. I applied and got in. I didn't bother to look anywhere else.

It was Jacqui's experience that opened the door for conversations about the difference of being a Hispanic woman at a PWI. Her experiences were challenging not only because she was a Cuban American but, as she recalled, her decision to come to FIU was life changing. She shared:

Ok, well um, straight out of high school, I like many other 18 year olds wanted to get away from home and get my own place and far far away. I decided to attend the University of Central Florida, up in Orlando, Florida and I stayed there for a semester, and my experiences there were not exactly what I wanted. I found, 
strangely enough, I felt extremely out of place. And it's just something I never realized living in Miami and living around people who are like me, that look like me and that act like me. I really didn't think there'd be such a cultural shock in just four hours away... but there really was. I remember sitting in a 300 person auditorium and me being possibly the only Hispanic.

Maybe there was few that I did not notice, but I remember I sat next to Americans, I sat next to an African American, but it was so hard to find Hispanics. I also found that whenever I'd go to Publix or anywhere for that matter, that some people looked at me and were kind of like, 'Oh, you speak English' and it was kind of strange for me because a lot of these people were actually in shock that I actually spoke English. I think that maybe has to do, I know I was told I'm Cuban but people would say, “Oh, are you Puerto Rican?” I know that there is a big Puerto Rican, I think, population in Orlando. And although they weren't exactly roaming around where I lived, I think when they saw me they were kind of like, "oh, are you Puerto Rican?" and "I'm like no, I'm Cuban and I speak English don't worry." I guess you could say, some people discriminated me for that. They kind of looked at me and some people would not even look twice at me for that matter. It was hard to get help if I was at a store or anything like that... which was very odd. Of course, there were a lot of people that were excited to meet someone like me... they were like, "wow, you have such a cute accent and I can't believe that you're from Miami." You know some people embraced it. Others were really kind of cold about it and because of that I found it really hard to get involved at the university.

It was really hard for me to just find an organization that I was comfortable with and was just hard for me to connect with people even if it was rushing a sorority or what not. I mean you look and $99 \%$ percent of them are all blonde and blue eyes and for me, I was just like this isn't for me...this isn't where I belong. I just think there is something to say about Hispanic hospitality. I feel it a lot at FIU, in particular and in Miami. I mean I remember the first day I walked into this school. I probably met more friends than I did my whole semester at UCF. And even people that I never met, even though a lot of my friends did come to FIU, I never see them and because of that I got extremely involved at FIU. It feels like so much more like a family, so much more like a home. I really feel like that has to do with being Hispanic because my friends family are always like, 'oh, you're family, you're always here.'.... not to say anything bad about UCF. I'm sure it great. I have two that actually went up with me that are Cuban, and they did stay, and they loved it. They're having a great time, but for me I didn't want to feel out of place. And then I thought of, well what if I stay here and I get a job here, this is definitely not where I want to live. I want to be with my people. I want to be in Miami with people I know. 
It became evident during the interview process that these participants were very positive about their individual experiences at an HSI, regardless of their involvement or reasons for attending FIU The participants were asked specific questions about attending an HSI but were unable to articulate how that influenced them in terms of their identity development. From their reactions, emotionally and otherwise, it became clear that this was one of the first times they had reflected on their own personal growth since attending the university. It is important to note that since all but one of the participants had never attended a different type of university (i.e. a PWI), they may not have been aware of the influences the university setting had on their identity development. If attending an HSI was transformative, these women were not aware of that, therefore the focus remained on their articulation of the salient experiences. An implication for practice would be to dialogue with women as they progress through a university to gather information about transformation, perhaps from a longitudinal study examining a first year student through graduation from the university.

Their sense of cultural awareness was also something they spoke positively about, including the impact that it had on them and their awareness of who they were as maturing women. They were very much aware they were a part of something even though they had a hard time explaining what was occurring around them.

Most of the participants, when asked, commented on their appreciation of the diversity of the institution as one of their favorite things about FIU. Many of them grew up in predominantly Cuban neighborhoods or went to schools where the population was mostly Cuban, so attending FIU was very diverse to them. They encountered people who were like them, as they spoke the same language, but were from other parts of the world. 
They were introduced to new and different ideals, cultures, and religions. As Cuban Americans, they embraced this diversity in an environment they described as comforting. I found this to be interesting as they, themselves, are considered a minority by broad American societal standards. Though they recognized that in Miami they were the majority and perhaps unknowingly, they had social clout. They spoke of this diversity almost as if it were outside their core, not for what they brought to it. However, as they continued to reflect on their part of this diversity, they realized that this environment allowed them to be proud of whom they were.

This idea that they were racially unaware is something that the participants did speak about. However as they spoke about the diversity of FIU, they became more aware that this was not a back yard university. Many of them grew up in Miami and saw FIU potentially as a "fall back or default" school. Many of them spoke about not worrying about knowing people because their friends from high school were close. It appears they had a greater appreciation for that diversity as for many of them it was the first time they recognized differences in populations other than themselves as Cuban Americans.

As Jacqui described it earlier, there was a sense for most of these women that they found a "fit" at FIU. Other factors that they spoke about included appreciating being in a academic setting where the language was not a hindrance and where businesses in the student center celebrated the Hispanic culture by serving food and drinks. One of the participants, Miette, commented that:

Well I thought it was diverse and now I'm kind of like, I think it is diverse now. I mean, I guess it's diverse because people come here from other places really. At first, I didn't really, I was not aware. I was not really thinking of people as...I kind of thought of the people at FIU as reflecting the Miami population which now because of what I have heard like throughout the years is like no...it's 
doesn't reflect the Miami population. It is actually many people from different places coming here outside from the south Miami population. But at first, I actually thought that it did and that it reflected because it was my world I guess. My Miami. It's Florida International University. So for example, I never really noticed whether a Black person was either a Haitian or a African American, to me there were just all Black, like they were all African Americans to me...but the African Americans draw a distinction. There are Haitians and there are African Americans. I'm like ok, I never thought about it that way. Then I also had this idea that being Hispanic, that Hispanics are very diverse which I still think so, however there are other people that don't think so. They think of Hispanics as a group and you know, if like they think of Miami as not so diverse because there's just Hispanics there, so it's not so diverse after all. But I always thought about it as Hispanics being diverse, because we have people from different countries. But anyhow, FIU diversity I see. I can notice from looking at the people that they are from different places. We have upstaters and we have people from Central America and South America that come here to study and I hear them speaking Spanish... so yeah, I do enjoy the diversity.

Sarah commented about her first day of the semester, which she remembers sharing with

her mom and dad. She said:

....I met someone who was Persian and someone from Jamaica. On the first day, I had a conversation with each of these individuals. I am happy that I have that opportunity because somewhere in the middle of Oklahoma you might not have that opportunity in your local college or university setting. Because this is such a diverse college, I do have the opportunity which is really really good because you get to see a lot of different points of views, different opinions, and such.

Jacqui said about the diversity on campus:

What I love about FIU is its diversity. I know that when I was coming to apply to colleges, I was kinda like "I don't want to go to FIU, everybody goes to FIU. All my friends go away to all the same old same old," but like I said earlier, I walk through these hallways and I do not see one person I went to high school with. They're all new friends I've made and that's incredible that even though a good percentage of my high school class came to FIU, I never see them. But what I love is just is diversity, and it's not just with Hispanics. I mean I know in the Graham Center they have all those flags that represent all the different countries that are here, and I think that's wonderful. And before when I used to frown upon people that were like, "I just got my citizenship," I was like "my gosh," "you're such a ref...how did you just get your citizenship without signing?" And now it just fascinates me that these are people that really are international students and their home is not even in America.... This university is giving people who are different, people who are diverse an opportunity and to me that's great. I would 
love to be a part of that percentage of Hispanics they give degrees to, which to me is fabulous. I thought it was incredible.

Carmen shared that she did come to FIU with a lot of people from her high school and slowly she began taking classes that they were not in. With this sense of independence, she found herself approaching other students who were like her, not only in the ethnic sense but in those that did not share same values as her. Two of the women made comparisons between FIU and other PWIs in the state of Florida after visiting the campus. Though Jacqui had a semester long experience at a PWI and could talk more thoroughly about it, Michelle and Blair made the following observations. Michelle said:

I love FIU. I love the culture. I love the environment basically. There is really a high energy environment. I just went to University X [located in Florida] this weekend and it was so boring. I'm sorry, but it was boring. Like, I just love Latin people. They are always laughing. I went to University $\mathrm{X}$ and it was a different atmosphere. It didn't feel the same. It was like I don't know. I can't explain it but it was a different environment surrounding me. I just love this place.

Blair reflected about her trip to another state school in northern Florida, which is considered a PWI, and a conversation with a friend of hers who attends that school. She said:

....You know what, I love FIU so much more, because it's so much homier, it's homier. People are just, you know, it's different. People are willing to get to know each and she's said, 'at University $Y$ is just not like that...you know it's really, everybody is out for their own.' So, I guess that's an advantage because FIU is really...I mean I look at it...well FIU is big and it has a lot of students but not really like compared to other states schools... so it's a little bit homier. I felt it when I've gone to visit other schools but at the same time, it's not...it's just average...it's just not the average college experience.

Sophia said:

Well, it's been great obviously I feel more comfortable sometimes speaking in Spanish, so I can get to see other people and like we speak in Spanish most of the 
time and it's good because I can go back and forth between languages....I know my professors are pretty much bilingual, most of them. In that sense, it's good because it feels more like I can...fit in more. I don't feel so isolated.

Natalie, who went to a public high school in Miami, was glad that she attended FIU and realized that her experiences at FIU afforded her more opportunities for personal growth. Participants who did engage in campus activities reported an elevated level of recognizable personal growth and change while reflecting on their experiences. I asked each of them questions to begin to explore just how their campus experience besides attending an HSI had influenced them in terms of their identity development. I asked them about what they considered to be the most meaningful experience or an experience that had an impact on them.

Not surprising, most of the women spoke of extracurricular activities or academic achievements such as study abroad that helped change them or influenced them. The supportive environment of attending FIU was evident and this allowed the women to begin to appreciate who they were as Cuban American students. With support from family, friends, and FIU faculty and staff, these women articulated that their successes and positive developmental changes were due in part to the environment. To what degree did participating in campus activities have an impact on these women? The findings show that not only could these women discuss the experiences, but they could identify those personal attributes that they gained from the experiences. More importantly, even though only one participant actually attended a PWI before transferring, based on observations or conversations with friends who attended other institutions, these women understood that a combination of environment and involvement had a significant impact on their personal development. 
Sophia, who admitted that she got involved in things that she would have never thought about, was then introduced to women's group through a women's studies course. From there she said she got involved with other psychology organizations, events, and an honor society. She said:

....At first I didn't talk to anyone, I was very shy. I just came to class, went home and that was it. Then I got more involved in my classes. I actually would speak with my professors and stuff. After class I would go to the office hours. Then I got involved with some of the organizations on campus and then I got a job on campus, and it grew from there. So, I see not only as a student that I changed because I learned so much at FIU that my personality has also changed.

During the focus group she shared this:

....like the experiences I've had in school, what I've learned, what I've been exposed to. Being my major is psychology, I've seen a lot. I've heard a lot....so I think each of those experiences have shaped me in a different way I guess.

Luz, who started her involvement journey with the College Democrats, describes being a Resident Assistant (RA) as one her most meaningful experiences. She said since she started getting involved, she became more open and less shy. She felt her confidence level increased and the more activities she tried the more she wanted to do. She reflected on her RA experience:

Definitely, being a Resident Assistant at the dorms. Meeting all the different kids and being an impact on their life. Having them, now they're doing applications for new Resident Assistants for next year and just having other people tell you that when they receive an application, your own residents told them, 'oh, I was so inspired by Luz' and things like that. And that's why I want to be the first person to say hi to someone, like when they first come to school.

Carmen sought out other students who shared her passion about Cuba. By joining the

Free Cuba Foundation, she found a connection. However, it was her involvement with the Catholic Student Union that had a significant meaning for her. She too commented on how she had changed since her freshman year. With an increased sense of self 
confidence, she said she was more open to other people and new friendships with those that she did not go to high school. Also, she said that early in her academic career, she would often sit quietly and say nothing. She noted this changed:

.....it was interesting, I got the opportunity to meet other students, who like myself were at the university level and were passionate about Cuba, so that was exciting. Then with the Catholic Student Union, it kinda made me feel at home, because I've gone to Catholic school all my life, and it was my first time attending an institution what wasn't Catholic...so it was...it was a continuation of that.

Some of the most profound changes were those noted by the women who joined a sorority as a part of their experiences. Blair, Natalie, Tiffany, and Carolina all had similar responses to their sorority experiences, which lead to other questions about the sorority experience and identity development. They all joined because they were looking for an experience that would add to their college experience but none anticipated the deeper outcomes of the experience. It is probably that they joined hoping that they would form friendships, a natural part of the sorority experience. Most of them responded they gained a sense of confidence, reported increased self esteem, and acquired new skills involving leadership in the organization. Tiffany's main reason for joining was to find other women with similar interests and to play intramural sports. What she gained was a connection with the women in the organization that was more than she hoped for, according to her. As for changes in herself, she said that she was always outspoken and that she had not changed much but she felt she had contributed to the group. She said:

....I say things only when they need to be said. A lot of girls go and they talk and talk and talk and talk and you can't take them seriously because they are always talking. But I just wait and say things when they are appropriate and when they are needed. Just because you are not speaking all the time doesn't mean you are not leading all the time. So I feel that I've brought that to my chapter. 
Carolina joined a sorority immediately after entering FIU. From this she became involved in other activities, which is not uncommon. Because she went to a Catholic school growing up, she sought out a group that was different than what she grew up with in her life. She described it as:

Well, they've given me a support system and a place I know where I have things in common with people. I guess a way of feeling more a part of a community, like I came from a small school and coming to such a big school, it gave me a smaller type of group within such a big group of people. So that helped me. It's helped me open the doors to getting more involved....

Blair found that getting involved in campus, after 2 years of not doing much on campus, was something she loved. She found herself taking on leadership roles within her sorority, which appeared to be stressful but not from her perspective. When I asked what she gained from being in the sorority, she said:

Oh! So much confidence! Like, I wish that I had joined a sorority my freshman year. That's like the, maybe if anything, I don't generally regret things, but I wish I would have like anticipated that it would have been so beneficial for me. I mean, the connections that I've made with...the type of women that join sororities are usually women that want to be involved if they're leaders and you know, if they're not. I've seen people grow and I'm one of those of people. Like I've always had leadership qualities but you know, they kind of like refine it a little bit. So, I mean I've gained so much confidence about what I'm doing and just the way that I interact with different types of people, just like there are different types of women in my sorority, like it's taught me so much socially and it also teaches me how to like balance different things out in my life. Like I don't spend all this time on one thing and just you know time management is also good with that.

While Natalie was involved in several leadership groups on campus, including serving as a Peer Advisor and an executive member in the Student Government Association, it was her sorority experience that was the most meaningful and had the greatest impact. As a senior at the moment of the interview, she reflected on this experience:

I think one of the biggest things that to me that had the most impact in my 4 years here, and it's funny because I think I don't vocalize it as much sometimes, 
because to me it's a very significant part of my life was joining my sorority. I think that just that has given me so much, you know, boost in courage and self esteem and just everything that I possibly kind of maybe felt missing before that would not have led me to do everything that I did....I knew what I wanted to get out of it but I never expected how much I've gotten out it. And how much it's benefited me and how I've met people that I look up to and people that I know that I probably wouldn't have gotten everywhere that I did afterwards if it wasn't because of them.

Jacqui's experience at a PWI was very telling of how the HSI offers an environment of support that all of the women spoke about. Jacqui commented that she did meet more people in one day than she met in her semester at the PWI. She immersed herself in several campus activities, but it was Dance Marathon (charity fundraiser) that had the most impact on her. From that experience, Jacqui went on to participant in Peer Advising.

When I asked her how she had changed since being involved at FIU, she reflected:

I think it's made me more of a leader, and it's given me more independence, which is strange because people think that if you go away to college and you're living on your own you become independent. But I was actually very scared in Orlando, and I found that I depended a lot on the few people that I did know. And if they weren't there for me, I kind of just shut down and would just stay in my room and sleep all day. And here, I'm living at home, but I'm practically never home. So I'm here and I'm just building relationships, and the positions I've taken have really made me an independent person. So strangely enough it has worked in the opposite way. I never thought that staying in the city I was born in with my family would make me so responsible and independent like I am now.

\section{Ethnic Identity}

Jacqui's experience at the PWI opened the door to understanding a complicated

yet fascinating aspect about these women, ethnic identity. Ethnic identity is a complicated aspect of how these women identify themselves because it includes issues of race and culture. Often times, I found that how these women identified themselves was complicated, confusing, and emotional as they struggled with complex concepts of who they were in terms of their ethnic backgrounds and how this related to their overall 
identity development. There were two themes in this section including the idea of biculturalism and what being a Cuban American/American meant. I found that having an understanding of what it meant to them to be Cuban American/American was important to understanding how they placed themselves in terms of their ethnic identity. For the majority of women, (see Table 3) they self assessed and identified themselves as bicultural. What impact on their surroundings influenced their decision to choose or relate to a bicultural ethnic identity?

On being American. During the interviews, I noted the number of times that the participants referred to non-Cuban friends or family as "American." I found this interesting as all of the women with the exception of four were born in the United States, making them native born American citizens. There appeared to be some cognitive disconnect when I asked them directly if they were American. The responses were positive as they recognized that they were born in the U.S. but did not necessarily feel that they were American. For example, Carolina, born in the U.S., did not consider herself American. She said, “I mean, I don't know, I guess I don't feel like I'm American, like a typical American." This prompted me to ask the participants what being American meant to them. I learned that it had less to do with race and culture but was more philosophical in nature. It was an ideology that appeared too had influenced by family primarily, but also by being a first or second generation American born.

This concept of ethnic identity is strongly attached to valuing American ways and staying true to Cuban culture and tradition. Isabella, who was appreciative of her Cuban heritage and, at the same time, was very much trying to live the American lifestyle, shared her insights on her hesitancy to call herself American. She said: 
Table 3

Summary of Participant Self Identification on the Torres Bicultural Model of Orientation and Country of Birth

\begin{tabular}{lll}
\hline Participant Name & $\begin{array}{l}\text { Self Identification on Torres } \\
\text { Bicultural Model of Orientation }\end{array}$ & Country of Birth \\
Blair & Bicultural & United States \\
Carmen & Bicultural & United States \\
Carolina & Bicultural & United States \\
Isabella & Bicultural & United States \\
Jacqui & Bicultural & United States \\
Luz & Bicultural & Cuba \\
Michelle & Bicultural & Cuba \\
Miette & Bicultural/Marginal & Cuba \\
Natalie & Bicultural & United States \\
Sarah & Bicultural (Multiracial) & United States \\
Sofia & Bicultural & Cuba \\
\hline
\end{tabular}

I have the problem...They'll all ask you 'where are you from?" and you don't want to say, 'oh yeah, I'm American' because you kind of feel like you are letting go of your family, and you want to make sure you bring them with everything you do. So then you don't want to say you're Cuban because you actually weren't born there. It's kind of like taking credit for something that you really aren't. I usually start off the sentence by saying, 'Well I was born in Miami but my family is from Cuba so I'm Cuban American.' That's how I end it (laughter).

This becomes important as we discuss the notion of biculturalism in the following section. Michelle, who was sworn in as a United States citizen during the interview 
process, said:

I would say spirit. Americans have a lot of spirit for freedom. I guess like anything. They are like into whatever they believe in...I don't know how to describe it. The American spirit, I don't know; people are proud to be American.

During the focus group interview, Isabella shared her thoughts on what it meant to be American. She saw it as a lifestyle and about choices, but she also mentioned the notion about not reliving the past struggles of her family. This too was a reoccurring theme with many of the participants who acknowledged that what they had was a direct result from the struggles their family endured coming to the United States. She said:

I mean, American to me is a lifestyle. I mean, we're always taught like, you know, what an American is. You know, not just the person, you know, the tall, White guy. It's also like the cars you drive, the clothes you wear, the schools you attend or the way you think is very Americanized. Living the American dream, which like you said is freedom. A lot of it has to do with freedom but you know, even more than that it's the choices you make. You could have freedom and make the wrong choices. Being an American, they believe that there is a certain lifestyle that you live, you know. There's a, you have a certain belief in the government, a certain faith in a religion, and you have you know, you just kind of....it's a mentality you have to hold onto the freedom. So, I guess being a Cuban American, you're associating all your past struggles or your family's past struggles or your family's past struggles with being free. So you want to make sure that it doesn't happen again so making the right choices as an American is what an American is.

There is also a sense that these women understood that being one of the first generations born in the United States was something very important. It became clear they recognized that while they sat between two cultures, they appreciated the value of both. There appeared to be a looking forward to the future, while looking back to their roots. Jacqui said:

And I know my Dad's always 'when I was in Cuba we couldn't do this and we couldn't do that.' You hear it. When I was younger I was rolling my eyes like 'oh God, he's bringing Cuba up again.' Like, 'I get it already.' You know as you get older and you start... you connect more with your family and you connect more 
with the elders in your family. I started to really listen to their stories and I start to really understand what they went through and you're like 'wow' you know, I'm so lucky to be here and I'm so lucky to have these rights and to have these freedoms that they didn't have. Then it kind of puts a lot of things in perspective. I guess that's why they push me. I guess that's why they do this and they do that and I just know that when I get older and it's my turn to have a family, even though I was not born in Cuba, I was born in Miami, I'm as American as they get, but I'll be like you know what? This is where you're from and yeah you were born here and you weren't born in Cuba but you have Cuban American running in your blood. It's in your blood. It's who you are...overall you're born in America but you are Cuban. No matter what.

Tiffany believed that being American was someone who was defined as:

....being anyone, no matter where you're from or where you come from who pours their blood, sweat and tears into this country and making of it what they want and what they need. That's what I defined as American. So I see everyone as American.

Natalie, whose parents are Cuban business owners, agreed with her. She said:

I like your definition, because I couldn't think where to put myself. I was talking to someone the other day and was like, 'what's American?" because everyone is from somewhere. So I think a lot of time American is a like a vision... like dad he doesn't even speak English, well he's learning with my 4 year old niece now, but like life, liberty and the pursuit of happiness.... So I don't think you can find any one exact American that's why I think it something so difficult to answer sometimes but I think as a Cuban American. Then I think that's the spin that gives it a little more flavor. I'm thinking of a Cuban politics class now and we talk about being Cuban and the nationalism that Cubans feel that has been going since the $17^{\text {th }}$ century. I think when you say Cuban American it's so much easier for us to answer because we're actually answering that Cuban part and then living here in the United States...but a lot of times it just not...being American so hard because... a lot of it is the liberties and the freedoms that we have for being in this country...but it's in the land that we're in...

Luz, born in Cuba and raised in Miami, considered herself an American, but as she met others, she said that she realized that she was still very much Cuban. Although she and her family came over legally, she used to be embarrassed by this fact; however, as she matured, her family history became a source of pride for her. Luz was also naturalized as a U.S. citizen. She reflected in her interview: 
When I was younger and people would ask me, 'oh where are you from or where you were born?' or things like that and I would say Cuba. You know they always had the image that I was refugee and that I came in a boat and things like that. And in the beginning, it was kind of a little embarrassing because everybody expected you to be a refugee. Not that there is anything wrong with it but just kind of like they had a bad connotation and they kind of like made fun of you a little bit. So it was kind of hard for me to tell them, so I mean when I was younger, I would make sure to tell them, 'oh, I was born in Cuba but I came legally and I came by a plane.' Like I would tell them things like that and it was back to back. And now that I'm older, whenever they ask and they tell me, 'oh are you a refugee?' 'No, I'm sorry I don't have any cool stories about being on a boat or anything like that.' I wish I did, but I don't. So it's definitely changed a lot. I used to be a little more embarrassed about it but....

Biculturalism. The second theme of biculturalism is used to describe the component of identity development of the participants as it relates to their acculturation level to the dominant U.S. White culture and their ethnic identity together. Torres's (1999) Bicultural Model of Orientation is probably to date the most commonly used model that helps to explain how Hispanic students identify themselves and the factors that influence them. Torres et al. (2003) found three factors influencing student identity during the first year of college: (a) environment in which the student grew up, (b) familial influences, and (c) self perception of status in society.

Torres's (1999) concept of the Bicultural Model of Orientation for Hispanic Students was based on the student responses in her research. She discovered students could be categorized into one of four cultural orientation quadrants: bicultural orientation, Latino orientation, Anglo orientation, or marginal orientation (Torres, 1999; Torres et al., 2003). Her study findings indicated that there are students who do not find themselves advantaged to be in one quadrant over another; however, they do seem to maintain their ethnic identity even when they are more Anglo oriented. I was curious to know if Torres's model was applicable to the Cuban American women attending an HSI. After 
presenting each of the participants with a chart that defined each of the quadrants as defined by Torres, I asked each woman to self identify where she felt she fit on that chart (see Appendix E).

At first, for a few there was discussion of the term Latina/o. Some of the participants felt that the terms Hispanic and Latina were interchangeable yet preferred the term Hispanic over Latina. A few rejected the term Latina as they felt that it did not recognize their familial heritage or roots. They vocalized that their families were not from Latin American origins but from Spain and other European countries. As shown in Table 3 , all of the participants self identified themselves as bicultural, with the exception of Miette and Sarah. One interesting thing to note was that all participants chose bicultural despite where they were born, either in the U.S. or in Cuba. I wanted to explore why they chose bicultural. Based on the previous themes of what it meant to be American, I sensed that the reason they identified as bicultural was more complex than simply addressing acculturation. For these women, it was more about what defined them as Cuban Americans, which seemed to be easier to articulate. Acculturation appeared to be more about comfort level and performance in society; however, it is very important to recognize that this study was done in Miami, a predominantly Hispanic city. Acculturation as Torres (1999) defines it was about a Hispanic student in a majority Anglo culture. As discussed earlier in what it meant to be an American, I am interpreting that what the women in this study viewed as acculturation was not acculturation in a majority Anglo city, but in a majority minority city in which the American culture was valued. For a few of the women, early memories of school were the beginning of the journey of developing ethnic identity. There was an early recognition of the difference 
between race and ethnicity, which was often a source of confusion. This happened in two forms, in the school system and demographic choice boxes. Carmen remembered a time when she was younger coming home from school perplexed by issues of race and ethnicity; however, this only strengthened her own self identity. She recalled:

Well, the thing is, like I have a kind of a problem with the White/Hispanic thing. Because when the first time when I encountered that, though not the first time, but the question was during the SATs and on those tests, you know we had the guidance counselor in my high school would tell us, 'if your parents are Hispanic, you have to check that Hispanic box, you can't check the White box.' I started to question myself. Ok, White is a race, you know and Hispanics they can be White, they could be Black, they could... So I kind of like I was like, 'What's going on You know if I look at the color of my skin, I could obviously check that White box. So, granted I was going to check the Hispanic box anyways, but I felt like ok Hispanic is not really a race per se, it's an ethnicity.

This only strengthened her identity as she matured. She said:

To be Cuban American. At least the way, when people ask me 'why do you consider yourself to be Cuban American?' Well, I'm American because I was born the United States and I am proud to have been but at the same time it's acknowledging that you have those Cuban roots. By identifying yourself as Cuban American, those roots have made me who I am. They, they're in the way I talk and the way I speak and what I eat, like in everything.

Sofia, who was often accused by her family as being too Americanized because of the way she carried herself and the way she spoke, identified herself as bicultural. However, during the interview process she said:

I think I have never thought otherwise. Like since I came here, I have always thought of myself as Cuban. Like even now, I don't call myself Cuban American. I call myself Cuban and even as time passes by I think I am Cuban and not American. I was just having a conversation a couple of days back. Oh my God, I have spent almost half of my life here and half back there, but I still think of myself as Cuban but my children will be more Cuban American.

When I asked her more specifically about why her family felt that she was more American despite the fact that she considered herself more Cuban than Cuban American, 
she replied:

I guess I don't want to speak Spanish or you don't want to be like every other Cuban or you don't want to talk loud when everyone else is talking loud...I don't know, like dance and be all wild and stuff when everyone is doing it just for the purpose of having fun. But I think it also has more to do with my personality, so I guess I say more American, it's more refined, more in line with this here, like speaking the language, being more educated.

Michelle's appreciation for living in the U.S. was tempered with her pride of coming from Cuba. Despite the hardships of life in Cuba, Michelle felt more complete having had that experience. Her identity as she described it was a combination of holding to her Cuban roots and appreciating what she had acquired from her life in the United States.

She said:

Being Cuban in this society has been a great experience. I guess it has been better. I don't think it would be the same if I was born here because I wouldn't have had those roots like the way I was raised in Cuba. I don't mean to offend anybody but the way females are raised in this country is not the same. There is a huge difference. I thank God for me being born there because I have a choice of both cultures and I guess I have that feeling of what it is to not be American. The feeling of coming here and of being a Cuban. Being able to have the two experiences. It helps me a lot to be bilingual and it helps me a lot to be Cuban in Miami. I think if I was American all together I wouldn't speak Spanish. I wouldn't know what it is like to be someone else too, you know, to have some of that background I guess and when I came to this country I found a lot of different things...I thought it was really amazing like, if I wasn't Cuban American I wouldn't have the things I have now. I am bilingual. I have the two perspectives so I am more like a full person.

Carolina discovered while taking a Cuban cinema class, her identification with her Cuban roots was stronger than she realized. She said that she was bicultural because she still felt Cuban and connected to her Hispanic background while at the same time felt comfortable with the American culture. She said:

I actually took a Cuban cinema class this semester because I'm a Spanish major. So it was Cuban culture through Cuban cinema. And as I was watching all those films and what they thought and about the way they spoke and all that stuff. I just 
said, 'I am definitely a Cuban American.' Because a lot of the things that I saw in those movies and the stories is a lot like the things I would see my family either speak that way or think that way. So I guess when I came to that, I was definitely a Cuban American.

Like Carolina, Luz said that as she matured, she became more proud to be Cuban despite the fact that she had difficulty when she was young explaining that she was a refugee from Cuba. She said:

But you're also proud of where you are now. You appreciate a lot of what America has given you. You know because you love Cuba and you love where you're from but you love the country not necessarily the situation that it's in and so you're really appreciate of calling this your home and that your homeland.

Tiffany replied that she was bicultural. As she described her thoughts, it appeared to be less about acculturation and more about pride and connections to her family roots. She said that she would love her future children to respect, understand, and never forget where their culture came from, not just Cuba but from Spain as well.

.....We came and we don't have the intentions of going back, we just broke with that and we want to make a different living. We're Cuban and we don't deny it, but we're not. We're here, we're in America. We're American.

Isabella, raised in a very traditional house, stated that she self identified as bicultural but there appeared to be some conflicts as she explained how she identified herself. She stated that she felt that she was a "little past her culture closer to the Anglo culture" because she was raised in the U.S. and even though her parents were Cuban and had passed on traditions to her:

I have studied in an American environment....I really feel that I don't speak Spanish that well. I don't read Spanish that well. I don't know anything in Cuba except Havana. I really don't know it that well. I know what my parents have taught me in regards to traditions. The food we eat, the music we listen to, the way we act, the people we talk to, how we converse, how we dance, what we read, how we say certain words, that is what I have learned. The basics but not necessarily have I experienced the true Cuban culture. I have never really been 
there. To actually say that I am so Hispanic, so Cuban is what I am. I know what America is about. I could tell you every state, every capital. I could speak English better than I could speak Spanish. I associate myself better with people who were born here, raised here. It is very hard for me to associate myself with people who have Hispanic origins. I take it offensively when we are sitting down and start to speak Spanish in front of people who don't understand....

However, later as she was discussing a situation that happened on a family vacation in New York, in which a woman made some disparaging remarks about Hispanics, which elicited a strong response from her, she said:

....I would never necessarily like just completely remove myself from Hispanics....you kind of overlook it but you still know who you are. So yea, I am an American but if you really need to pull out the Cuban, you pull it out. You have it there. Why not use it if you need it. I, on the other hand, kind of respect both my heritages, both of my cultures. I don't really like what I see now from Cuba, from my parent's generation. I respect what they did and that they came because they were Cuban. So you can't take that away. I am Cuban American.

Unlike Isabella who identified herself towards Anglo orientation, Miette originally identified herself as bicultural but later said she felt that perhaps she was Marginal. Miette, who was born in Cuba, raised by her father in Nicaragua, and was eventually, reunited with her mother in the U.S., questioned her ethnicity. She said:

I picked bicultural orientation but I kind of feel that I reject both my ethnicity identity and even acculturation to the American community. Like I really, I don't feel well here. I don't feel at home and as for ethnic identity, I have all these kind of awareness of that, as people thinking of us as refugees and looking at us down and so I kind of don't feel comfortable then.

Later she said she spoke of the resistance of labeling, which is why I believe she had a difficult time with identifying herself on any quadrant. She did say:

.....and then there is my culture, I do resist the labeling of me as...I would never say I'm American without mentioning that I am Cuban but I might fail to mention it sometimes if I feel that I am going to be discriminated against. 
Jacqui's experience outside of Miami was very telling of how ethnic identity is contextual based on experience outside of one's comfort zone. Jacqui self selected as bicultural and describes herself as "very Americanized and I'm not someone who is $100 \%$ Cuban all of the time." Growing up there appeared to be some lack of real identity with her ethnicity. But after further conversation with Jacqui, it became clear that her appreciation for her ethnic identity had grown. Despite her lack of cultural awareness, she remembered having to check the demographic boxes on the SAT. She said:

I mean I'm just like, my name is Jacqui, my last name is a very Hispanic last name so it doesn't matter if I put White, they're going to be like..I've never had a doubt. For me it's like I put Hispanic. I remember, I think possibly the first time I ever had to check those boxes, I kind of asked my mom, 'mom, when the box, the little box comes on the SATs and stuff, I put I'm Hispanic right??' and she's like "yeah, your Hispanic' and I'm like, 'ok, was just checking cause I know I was born here but I want to make sure I'm Hispanic.' She's like, 'no no no, you check the Hispanic box, that's where you belong.'

The paradoxical part of Jacqui stating that she felt "Americanized" and bicultural is that she described during her time in Orlando as very confusing for her and that she felt more comfortable in Miami. Once her ethnicity was challenged in an environment where she was no longer the majority, her self esteem and self worth were all questioned:

....because in high school, I was the kind of person that was just like whatever I'm American. I don't want to talk Spanish, I don't want to do this, I don't want do that, like I really don't care. My dad is always like, 'look, you can run away from it but this is who you are. It doesn't matter what you think, you're American and I'm not taking that away from you, but you're also a Cuban American and your family is Cuban and this is where your family is from. You need to know this.' I don't think it was until I went to UCF that I started to appreciate that and I started to understand. So I think that a lot of people that are like, 'I'm American, who cares about being Hispanic,' are just people that really haven't had an experience like I've had. I think they're just kind of in a city that's full of Hispanics and you know at one point it can get a little annoying. You're kind of like 'oh gosh, everywhere I go it's people that are just Hispanic and they just look like me,' but you kind of appreciate it when you go away and you realize that no one looks like you and nobody has the same ideas or morals that you have and 
then you come back and you're like, “wow, thank God, I'm home...people like me"

\section{Summary}

This chapter provided a description of the setting of the study, a personal introduction of the participants, and a presentation of the data collected. The setting for the study was FIU, a 4-year, public HSI located in Miami, Florida. The participants included 12 self identified Cuban American undergraduate and graduate women who were attending FIU at the time of the interviews. Each participant was between the ages of 18-24 and had attended FIU for at least 1 year. Six major topics were explored and themes emerged from the data including family, cultural influences, gender, ethical/moral development, education, and ethnicity. Many of the themes were complex and overlapped or were tied closely to other themes. Data were used to help explain these topics, and select quotations were chosen to serve as descriptive examples. Several themes also emerged and were represented in the presentation of data.

The family topic was used to describe the significance family plays in the life of the participants in this study. It included two themes (a) the importance of family and (b) the influence of familial support. It is not surprising the family theme is significant in the findings.

The topic of cultural influences described the impact that culture plays in the formation of identity development of Cuban American women college students. It included several themes such as (a) family history/story (b) pride in being Cuban, including issues of politics and immigration, and (c) traditions and rituals. The study examined cultural influences from an anthropological and sociological perspective as it related to the psychosocial development of the women in the study. Cultural influences, 
different from issues of ethnicity, examined the unique characteristics, values, and beliefs that are shared amongst these Cuban Americans. This theme provided an overview to the experiences of being a Cuban American.

The third major topic of ethical and moral development was used to describe those factors that contributed to the identity development formation of the participants in the study as it pertained to their views on spirituality and religion, decision making, and values clarification. This section addressed how these women made decisions, how they defined their personal value system, and how they viewed religion/spirituality as a part of their ethical and moral development. There were three themes, religion, core values, and decision making, each had an impact upon each other and did not stand alone.

The fourth major topic of gender was used to describe the importance of understanding what it meant to be a woman in their identity development. The findings in this section described how these participants became aware of their expected gender roles and expectations as a part of their identity development. This section addressed several themes that form a picture of gender through the complicated connectedness of culture and family. The themes included how these women became aware of gender differences growing up, the roles and expectations involving gender they learned, defining what it means to be a woman and how that differs from defining what it means to be a Cuban American woman, and value these women placed on being independent.

The fifth major topic of education was used to describe how education had been an influencing factor in the identity development of these women in this study. The theme of education did have a direct relation to other major themes in this study, as a college education was something that these women chose to do but ultimately is was an 
expectation the family placed on these women. It was not required or mandatory;

however, for most it was an expectation. There were three themes in this section: (a) value of education, (b) the experiences and influences of attending an HSI, and (c) the importance of campus involvement on identity development.

The sixth topic was used to describe ethnic identity or how these women viewed themselves in terms of race and ethnicity. There were two themes in this section including the idea of biculturalism and what being a Cuban American/American meant. Several findings and recommendations are presented in chapter 5 based on the data provided this chapter. 


\section{CHAPTER V}

\section{FINDINGS AND RECOMMENDATIONS}

This chapter provides a summary of the study and outlines the major findings and conclusions. Included is a section that briefly summarizes the purpose, methods, and themes examined in this study. A review of the research question provides a basis for the second section that examines the findings based on the data. The final section covers conclusions and recommendations for further research, applicable to both university administrators and members of the academy.

\section{Summary of the Study}

This study examined the experiences of Cuban American women attending an HSI and the cultural influences and personal factors that affected their identity development. This study was conducted with 12 Cuban American women who attended Florida International University (FIU) and were classified as juniors, seniors, or graduate students. By utilizing a three interview process (two semi-structured and one focus group), each participant was able to describe her experiences growing up as a Cuban female in a predominantly Hispanic city and being a full time college student at an HSI. I sought to gain an understanding of these experiences as it pertained to their personal growth and identity formation, not only as women, but as Cuban American women. By utilizing both purposive and snowball sampling techniques, I was able to find candidates for interviewing who provided much diversity within this homogeneous group. This included factors such as being first or second generation, living at home versus not living at home, age, and various levels of academic achievement. 
The interviews were transcribed, coded, and analyzed to understand the experiences of these participants. The cross case comparison method was utilized to help analyze and code the data into themes. Triangulation of the data occurred in several ways. There were two focus groups conducted in order for group responses to be compared to each other and to challenge or confirm themes that emerged from the individual interviews. After the interviews were conducted, the member checking process allowed for participant feedback. Finally, a peer reviewer examined the narratives and offered suggestions and feedback during the data analysis process.

As a result of the data analysis, six major topic areas were explored and seventeen themes emerged. The major topics were: (a) family (b) cultural influences, (c) gender, (d) ethical and moral development, (e) education, and (f) ethnic identity (see Figure 1).

The family topic was used to describe the significance family played in the lives of the participants in this study. It included two themes (a) the importance of family of origin and (b) the influence of familial support.

Cultural influences described the impact that Cuban culture played in the formation of identity development of Cuban American women college students. It included several themes such as (a) family history or story; (b) pride in being Cuban; including issues of politics and immigration; and (c) traditions and rituals. The findings examined cultural influences from an anthropological and sociological perspective as they relate to the psychosocial development of the women in the study.

Ethical and moral development described those factors that contributed to the identity development formation of the participants in the study as it pertains to their 
views on spirituality versus religion, decision making, and values clarification. Three themes emerged from this theme including, religion, core values, and decision making.

Gender was also important to their identity development. The findings in this theme helped to understand how these participants became aware of their gender roles and expectations as a part of their identity development. This theme addressed several themes that form a picture of gender through the complicated connectedness of culture and family. The themes included how these women became aware of gender differences growing up, the roles and expectations involving gender, defining what it means to be a woman and how that differs from defining what it means to be a Cuban American woman, and value these women placed on being independent.

The fifth major topic of education described how higher education was an influencing factor in the identity development of these women in this study. There were two themes examined in this section including how education was viewed within their families and what obtaining a degree meant to them and the influences that attending an HSI had on their identity development.

Ethnic identity, the final topic, was a complicated aspect of how these women identified themselves because it included issues of race and culture. There were two themes in this section including the idea of biculturalism and what being a Cuban American/American meant.

\section{Research Questions}

Three broad questions guided this study. I revisit the questions here to summarize the themes. 
What are the personal narratives of Cuban American women as they describe their identity development while attending a 4-year Hispanic Serving Institution? Do the women speak of cultural influences or personal factors as important to their identity development?

While contemplating a response for these research questions, I found it very challenging to separate these two questions. An answer to the question of "do the women speak of cultural influences or personal factors as important to their identity development?" is simple. The answer as they shared is that both cultural and personal influences are important to how they define themselves. However, it is through their narratives that they explained the complexities of this simple answer. Their narratives demonstrated that there was a deep and meaningful connectedness of cultural and personal factors that helped to explain just how growing up in a Cuban American household influenced the personal identity development of these women.

The findings were presented by theme in chapter 4; the following is a synopsis of those findings that address the overall question of how these women described their personal growth and identity development while attending an HSI. As mentioned the six major topics that emerged were: (a) family, (b) cultural influences, (c) gender, (d) ethical and moral development, (e) education, and (f) ethnic identity. Individually, each of these offered a small glimpse and compartmentalized view into the personal development of these women, but it is when all these themes are intertwined, a clearer picture of their identity development begins to emerge. As demonstrated in Figure 2 in chapter 4, there is an interconnectedness of these themes (family, gender, cultural influences, education, and 
ethnicity). If one aspect were not represented, the picture of these participants would be incomplete.

There were two exceptions, ethical and moral development and education. These two major themes were connected in more indirect ways. Ethical and moral development had less to do with culture and ethnicity and was more influenced by family and gender, though there was an indirect connection. Education was the theme that was more indirectly related to the other themes, but determined to have a direct connection to the theme of family. The choice to attend college is just that, a choice, however, family was a strong influence on that choice. The personal development and growth of these women was enhanced by this experience. The participants all stated they had acquired more personal growth and development by their academic achievements and/or involvement in student activities at FIU. Another area to explore further in research would be Cuban American women who choose not to attend a university.

Additionally, as seen in Figure 3, there was also a connectedness with their personal narratives as they spoke about their identity from three viewpoints, psychosocial, sociological, and anthropological. Up to this point, researchers have tended to look at identity through a single developmental lens, whether that was psychosocial, sociological, or anthropological. Developmental theories that fail to examine all three are missing the comprehensive picture of identity development. As these women shared information about themselves, it was clear that each theme, or "lens", was important in understanding their identity. By looking at personal growth and development from a wider lens and a personal narrative, a more complete understanding of who these women considered themselves to be was portrayed. By not solely examining individual 
components that make up traditional ways of looking at identity development, the complexities of each of the women could be examined and connectedness to other components could be compared. Identity from a multidimensional lens allows for a better understanding that identity development is complex, diverse, and fluid, yet interconnected. For example, most of the ethnic identity models spend little time examining gender, and for these women, their ethnic identity as Cuban was intertwined with their identity as Cuban woman and with all the expectations and stories of strength that went with that cultural tradition. This is supported by Portes and Rumbaut (2006) as they describe this as selective acculturation, the ability to acculturate to American ways without abandoning the parents' language and culture Similarly, psychosocial identity models that ignore the cultural context of development can be inappropriate for students. Family was seen as integral to the emotional and psychological well being of the women who participated in this study. Many of these women, despite the varying degrees of closeness to their families, all credited the importance of family in their identity development. The women clearly articulated that they were in part who they were because of their relationships with their families and the important role their families played their lives. It should be noted that there is literature that discusses the role of family and identity development and the role of the family as a support system while in college (Hernandez, 2002; Torres, 2003, 2004a, 2004b), but little is shared about the value that family plays in the formation of identity development of the Hispanic female. For these women the connectedness of family with their gender, ethnicity, and cultural influences was hard to separate, but the influence of family was undeniably present in each of the other themes. 
All of the women in this study were first- or second-generation Cuban Americans, and a majority of them were first-generation college students. With the struggles that many of their families had endured either in the immigration process or in the process of settling in Miami, all of the women had a very deep appreciation for those family members' sacrifice. This sacrifice allowed the students opportunities that would have never been there. The four participants who were born in Cuba and moved to Miami when they were young stated how fortunate they were to have the opportunities afforded to them. It was interesting to note the impact that family history had on the ones who were not born here. From their narratives, it was clear that their family struggles impacted these women. Most of them had never been to Cuba but described their emotional attachments as if they, themselves, had immigrated.

The secondary impact on their development was a direct result of their parents and grandparents instilling in them the traditions and values associated with being Cuban. The messages of cultural pride these women received were more than about food and music; it was about the strength of family, being there for each other, and carrying on the core value of family to future generations because the family had helped them survive the struggles of the past. Who they were culturally and ethnically was not just about being part of a family, but being part of a Cuban American family and all that they attached to sociologically, anthropologically, emotionally, and psychologically. Carmen said it best:

...I'm a firm believer that where we've been has a huge impact on who you are today and who you'll be tomorrow. That is something that I keep on repeating because I feel very strongly about it. You know, I think given my experiences with my family, given my educational...it has shaped me more today. It has formed my mentality. Very family oriented and the lessons they've taught me are lessons that I will carry with me every step of the way... wherever I find myself. 
Gender identity, like the recognition of cultural influences and ethnic identity, for these women started from a very early age. These women were very cognizant of the messages they received as young girls about the roles of women in the household and the difference in treatment because of their gender. For these women, cultural influences and ethnic identity were very closely related to the gender roles and identity. Questions regarding being female resulted in very different responses than those about what it meant to be a Cuban American female. As stated in chapter 4, these messages of gender bias, as conveyed by the women, were evident throughout childhood and continued on for those that still lived at home. It became obvious through their interviews that they felt diminished and frustrated by the unequal treatment occurring at home. Most intellectually reject the traditional division of labor and service roles for women of traditional Cuban culture, even if they continued some of those practices out of respect for their parents. These messages of inequality affected the choices they were making now about how to raise their future children. Others participants disagreed and wanted to reject the traditional treatment of women.

It became clear as discussions about gender continued that either by observation at home or by direct verbal messages, these participants were expected to adhere to prescribed gender roles, usually dictated by the family and supported by social and cultural norms of the extended families and local community. They found it very stressful to be a full time college student and meet these family expectations. They received mixed messages from their family about the importance of school and helping out at home. They clearly stated that there were traditional female expectations and male roles in the household, but they did not necessarily feel these would continue later in their lives. 
Many of these women expressed some very progressive feminist ideals of equality, yet not completely. When asked about the roles of women, most shared that the task of raising a family was the woman's primary responsibility. These women articulated that roles and expectations were not equal, yet most fulfilled these obligations so as to not disappoint their family. Many of them struggled with this idea of raising a family and having a career. Most did not want to be stay at home mothers like their mothers, yet they felt family was as important as a career. There appeared to be some generational changes occurring, as not all of the participants' mothers were stay at home moms. The women in this study were able to see how things had changed from their grandmothers to their mothers to them. This shift had influenced their future aspirations and their own identity development. The women held similar beliefs on what it meant to be a woman in general but very mixed feelings about what it meant to be a Cuban American woman. Some participants viewed Cuban woman as a subservient and oppressed group, yet there was a contradictory narrative of feminine strength.

Many spoke of the strength of their mothers and grandmothers in their immigration stories and the message of female strength and independence their mothers instilled in them. These participants, based on what they shared in the interviews and despite where they were born, articulated very clearly there was a cultural shift in mentality, supported by their mothers. Behind the scenes, the mothers of these women appeared to be the reason for the shift, encouraging them to be strong and independent. They were encouraging their daughters to adopt new ways of thinking about success and family, but not to the point where they sacrificed all cultural values. What some of these women shared was that the struggles of immigrating to the U.S. were the impetus for the 
grandmother's and mother's message to them. They did not want their daughters and granddaughters to live as they did. The biggest irony was that the mothers, some, not all, did not always act in the manner that they were portraying to their daughters. The mothers portrayed a message of subservience, but acted a message of self-sufficiency. Not surprising, most of the women looked to their mothers and their grandmothers as role models and sources of strength. I attribute this increased value of being a strong independent woman as a positive factor in their identity development. It appears from an outsider's perspective that there was a conflict for these women between the movement towards independence and an acceptance of more traditional values that place women in a subservient role. These women viewed their mothers, grandmothers, as well as other female family members as the cornerstone of strength in the family; therefore, they did not reject these notions that a women's place was to value family first. This generation of women not only wanted to place their family first but they wanted to work and have a life outside of the home as well.

A major theme that was more closely related to family and cultural influences was that of moral and ethical development. This theme addressed how these women made decisions, defined their personal value system, and viewed religion/spirituality as a part of their ethical and moral development. Though there were three themes, core values, decision making, and religion, each had an impact upon each other and cannot stand alone. The participants noted that the factors that influenced them the most in their own ethical and moral development were their parents, family, and religious beliefs. Because religious education typically begins with the family, it was not surprising to learn that core values were tied closely to religion and spirituality. 
There was also a very fine line of how core values and religion assisted in the decision making process of these participants. Some attributed their moral and ethical code to their upbringing. Although religion was evident in their life, it was their moral and ethical code instilled in them by their families that bore most of the weight on their decision making process. It also became evident throughout the individual and group interviews that some of the women struggled with the doctrines of their religion. Most of the women agreed that religion was not something that was forced upon them, but it was more of a sense of a part of the fabric of growing up in a Cuban household. Additionally, several of the women attended private, Catholic schools that appeared to have an impact on how they not only viewed religion but how they incorporated Catholic teachings into their ways of making decisions.

Education as noted was the only theme that that was not connected directly to the other main themes; however it was tied very closely to family. Attending a university is not a compulsory act but a voluntary act; however for these women it could have been considered an expectation. For these women, education was something that was not only seen as valued, but it was seen as a way to succeed, and this was very important to the family unit. Much has been written about the support of parents in a Latina (Hispanic) household, but I was more curious about the experiences of these participants at an HSI and the influences on their identity development.

Their sense of cultural awareness at an HSI was something they spoke about positively, including the impact that it had on them and their awareness of who they were as maturing women. They were very much aware they were a part of something unique, even though they had a hard time explaining what was occurring around them. Most of 
the participants, when asked, commented on their appreciation of the diversity of the institution as one of their favorite things about FIU. They were introduced to new and different ideals, cultures, and religions. As Cuban Americans, they embraced this diversity in an environment they described as comforting and homey. I found this to be interesting as they, themselves, were often considered a minority by societal standards. As noted, it is widely accepted that a social support network is especially important to racially diverse student populations on majority campuses (Kenny \& Stryker, 1996).

Though they recognized that in Miami they were the majority and perhaps unknowingly, they had social clout. They spoke of this diversity almost as if it were outside their core, not for what they brought to it. In other words, they found themselves living between two cultural worlds, White and Hispanic. Carolina reflected by adding: ....because here at FIU I feel like I belong. You know I look around and I see women like myself, not only Cuban but Hispanic, and we are all working towards one goal which is the college degree.

Even though Jacqui was a transfer student, she spoke for several of the participants about the sense of independence that she gained attending this institution. She said:

I think it's made me more of a leader, and it's given me more independence, which is strange because people think that if you go away to college and you're living on your own you become independent.

The participants who did engage in campus activities reported a higher level of recognizable personal growth and change, as compared to those who did not participate in extracurricular activities. I asked them about what they considered to be the most meaningful experience they have had or an experience that had an impact on them. Not surprising, most of the women spoke of extracurricular activities or academic achievements such as study abroad as experiences that changed or influenced them. The 
supportive environment of FIU was evident, and the women began to appreciate who they were as Cuban American students. With support from family, friends, and FIU faculty and staff, these women articulated that their successes and positive developmental changes were due in part to the environment. And while this study did not clearly find that there was significance in the HSI setting; the setting was a factor in personal development of these women as supported by the Astin, Pascarella, and Terezini, Kuh and DeSousa (1996) research that sustains the idea that Black students reported higher educational and extracurricular achievement at an HBCU than their counterparts at a PWI, thus the environment is important at some level.

To what degree did participating in campus activities have an impact on these women? The findings showed that not only could these women discuss the experiences, but they identified those personal attributes that they gained from them. More importantly, even though only one participant actually attended a PWI before transferring, based on observations or conversations with friends who attended other institutions, these women understood that a combination of the cultural environment at FIU and Miami and campus involvement had a significant impact on their personal development. Because this was a study about the experiences of Cuban American women attending an HSI, not necessarily a study about the HSI and the influences on identity development, it was hard to discern if the process of attending an HSI was transformative in terms of who they were as women. There are arguments that their identity is established prior to the arrival at the university, but what I found was that while that may be true, their perceived personal growth was enhanced by the experience. And while, I asked several questions about FIU as a Hispanic Serving Institution, for many of the 
women, this was the first experience they had to actually reflect on the changes that occurred in their time at the university. The participants spoke of friendships, extracurricular activities, leadership opportunities, social situations with others that were different from them, and academic influences as experiences that positively influenced them. It can be concluded then that these positive experiences enhanced their personal identity and they were not aware of the setting as influential; possibly because they have no experience with different types of institutions other than FIU. Only one participant who transferred, was actually able to speak of attending a different type of institution and her experiences at the other institution were not positive and did have an effect. Further research in this area would be necessary to measure the impact the setting has on personal identity. For this study, the HSI was the setting and not the object being studied. A comparative study would be necessary to discern those differences.

Do Torres's (1999) bicultural or Josselon's (1987) gender identity models adequately summarize the complexity of these women's experiences or is a multidimensional model more appropriate? While Torres's bicultural model has led the way in higher education research for a better understanding of the Hispanic student experience, it has not fully articulated the experience of Cuban American college students. It can be said that, a small percentage of students included in her work on understanding biculturalism were of Cuban American descent, and as with most other research the sample of students included in that study were of mixed Hispanic backgrounds. Granted, my study was a bounded case study examining Cuban American women college students in Miami and due to sociopolitical movements and immigration issues in Miami, Torres's work may not be as applicable. Hispanics in the United States, 
as it has been noted, share many similar cultural values, including language and value of family; however, when examining the influences that impact identity, it is important to separate out Cuban Americans because of the differences in social issues impacting this community of Hispanics and possibly because of the general socioeconomic and ethnic differences. Torres's Bicultural Model of Orientation is very useful when examining issues of ethnicity and acculturation; however, when utilizing this model with this particular group of students, it became obvious that acculturation had a different meaning. Since Torres's research work was primarily conducted in the northeast at a PWI, acculturation for the Hispanic students in her research was to the dominant White community. The students in this study felt that they were "acculturated" in the Miami community; however, due to the make up of the city being a majority Hispanic and substantial immigrant community, the participants all felt that they were bicultural because they were able to fit into the American culture as experienced in Miami and keep true to their Cuban roots. My conclusion is the Torres's Bicultural Model of Orientation is sufficient for understanding ethnic aspects of identity when examining issues that affect Hispanic students overall; however, the model is not sufficient when examining issues of Cuban American women students at an HSI. Identity development is a malleable construct, which should not just be limited to a definition of quadrants that only define one aspect of identity. Additionally, this model, like other identity development models, tends to examine identity by racial and ethnic characteristics disregarding other social, psychosocial, and gender related aspects.

Gender is a facet of identity development that receives very limited attention in student development research, especially when investigating issues of race and ethnicity. 
Josselson's (1987) research on gender identity development is the most commonly used in the understanding of the identity development of women. While her research is one of the most beneficial in understanding the female experience, it is incomplete. It excludes the conversation on race, culture, and ethnicity. Her model of identity development was based on a longitudinal study of 60 college-aged women grounded in Erikson's work and object-relations theory. Josselson, herself, sought to explain how a woman goes about the developmental task of forming her identity, including how a woman incorporates choices she makes for herself, her priorities, and the guiding principles that help with those decisions. Josselson states that unlike other developmental theorists, such as Erikson, who looked at identity as content, it is important to look at identity as a process (Josselson, 1987). Josselson's theory is more relevant to the Cuban American women in my study because it addresses issues that occur during late adolescence of college-aged women. However, it still does not address issues of culture or ethnicity and their influence on identity development primarily because Josselson's research is based on examining women from a psychological perspective. And while Josselon's research has been integral to understanding gender identity, it does not examine other dimensions such racial and ethnic identity issues that are important when looking at a comprehensive identity development model.

A multi dimensional perspective is more appropriate in helping to understand the complexities of Cuban American woman college students' experiences as it relates to identity development. Jones' (1997) Multidimensional Model of Identity attempted to examine the multiple dimensions of identity development based on the premise that theories of identity development are often contextualized by race and/or gender but the 
two have not been brought together. Jones (1997) argues that theories of racial and gender development have failed to include other identity dimensions and is critical of other developmental researchers. This is supported by the work of Tanaka (2002) whose theory of interculturalism is important to the discussion of identity development, in that it is a reminder that current student development and identity development theories can be enhanced by adding a social theory component to them. She believes that most research has "frequently considered differences according to gender, age, or other particular social conditions, the models and research have generally not addressed intersecting social identities" (Jones, 2000, p. 405). As with the findings in this research study examining Cuban American college women, her findings suggest that categories themselves are not independent of each other and that there is a connectedness and a relationship between them. For example Jones (2000) found the "influence of family" was prevalent throughout the data and influenced other key categories. Her categories were (a) relative salience of identity dimensions in relation to difference, (b) the multiple ways in which race matters, (c) multiple layers of identity, (d) the braiding of gender with other dimensions, (e) the importance of cultural identifications and cultural values, (f) the influence of family and background experiences, (g) current experiences and situational factors, (h) relational, inclusive values and guiding personal beliefs, (i) career decisions and future planning, and (j) the search for identity. Jones' (2000) participants articulated the concept of identity as an evolving concept that blended fluidly "meaningful contexts of race, culture, gender, sexual orientation, family, relationships, religion, experience, and personal attributes" (p. 9). 
While there were many similarities with my findings and those of Jones (2000) such as family, values, current experiences, and gender, I believe some of the differences can be attributed to the sample of participants in the Jones' study. Her study was comprised of 10 women from various backgrounds, including sexual orientation. What legitimized the findings in the Jones' study as compared to my findings were that her work was the first to look at the multiple layers of identity as it concerns women's identity development. It is clear now that despite the differences with the make ups of the groups in regards to the diversity issues, there are more commonalities among women than differences.

Unlike Jones' (2000) study, which suggests the experience of difference shaped identity, the women who participated in my study embraced their cultural identity because they were from a majority minority context. Additionally, the women in my study were from an HSI, which places a different slant on cultural difference. Nevertheless, both Jones and I suggest the importance of outside influences such as family, society, and peers on identity development and that a multidimensional approach incorporating both gender and culture is essential to understanding the identity development of women.

\section{Conclusions}

Several conclusions were formed based on the examination of the findings from the data collected and analyzed in this study. The major conclusions of this study are:

\section{Identity development is fluid and an on-going process based on relationships and}

life experiences. The Cuban American women who participated in this study demonstrated that their sense of who they were was a fluid and evolving process. 
These participants were a product of their experiences, both social and psychological. Josselson (1997) defined identity as the "stable, consistent, and reliable sense of who one is and what one stands for in the world..." (p. 10); however, she states that identity is "always bound to one's sense of connection to others" and that "identity is neither a sum of roles nor an intra-psychic process alone." These women spoke of family, culture, education, and religion as important to who they were.

This is supported by the work on Cuban American college students done by Geertz González (2008) in which he found that in addition to what was reported by the women in my study, students in his study stated that celebration and food, cultural conflict, language, and racism were also how students defined their ethnicity. They had a good sense of who they were based on where they came from; however, there was a sense of disconnect or tension between the influences, mostly cultural and gender related, that kept them from declaring their independence against those values that they did not necessarily agree with from their families. Behind the scenes, the women who they consider role models, their mothers, supported this independence and achievement yet sent mixed messages about family and gender roles. Who these young women were, as supported by Josselson (1997), was more about the connections they formed.

2. Understanding immigration issues. Because this was a bounded case study done in a majority Hispanic city, it soon became evident during the interviews that immigration issues had an impact on identity development. This is supported by the research conducted regarding immigration and social power and the influences 
that social power carries with regards to identity development (Portes \& Rumbaut, 2006; Portes \& Stepick, 1994; Stepick et al., 2003). Only four of the participants were actually born in Cuba; the remaining participants were born in the United States. Most women who were U.S. citizens from birth bore the struggles of their families "making it" in the United States. This particular group of women was raised with and was dealing with the political situation in Cuba. This message of struggle was reiterated over and over and was an integral part of their selfdescription of their identity. There was much pride when discussing Cuba despite the current situation. The participants agreed that being Cuban was just as important as being American regardless of where they were born and that separating the two terms would be impossible.

3. Understanding generational differences. Understanding generational differences were important as well to understanding the impact being a first or second generation daughter had on them. The notion of biculturalism is typically applicable in dominant White cultures. However, the women felt that the longer their families were in the United States, the more American they (meaning future children) would become. Despite their attempts to become more American, it was important to keep Cuban tradition and culture alive in future generations. I sensed this group of women embraced the past and looked to the future, which was something their mothers and grandmothers felt they were not allowed to do but encouraged their daughters to do. This is supported by the research findings by Portes and Rumbaut (2006) who discuss the many unique characteristics of second generation immigrants. 
4. Understanding difference is contextual. Perhaps, this is the conclusion that lends itself to further research on ethnic groups in the United States. As it has been stated, Miami is a majority Hispanic community with cultural influences from other immigrant populations. Unlike immigrants who arrive in Miami for economic reasons, Cubans are granted special privileges legally that other immigrants are not. This growth of Hispanics in Miami has led to a socioeconomic and political status not granted to other members of the immigrant community (Portes \& Stepick, 1994; Stepick et al., 2003). Because most of these participants in this study grew up in a city that is diverse, understanding difference is contextual. Meaning, difference to them lies within seeing other differences within the Hispanic populations and immigrant populations. Many of these participants because they grew up in a predominant Hispanic community, only started to recognize difference when they left Miami. This is particularly true for some of them that grew up and went to schools in large Cuban enclaves of Miami. Attending FIU was the first time many of them interacted with a diverse population, something they all said added to their sense of self. Many of them had been unaware of other minority or immigrant populations in Miami. Attending FIU broadened their awareness of differences, not only within the Hispanic community but within international and other immigrant populations. This heightened awareness led to sensitivity about privilege and social issues within Miami. Researchers that have studied the unique pattern of social privilege and acculturation issues have found similar patterns of behavior in other studies (Portes \& Rumbaut, 2006; Portes \& Stepick, 1994; Stepick et al., 2003) For some 
of the women, there was no self recognition that they were considered to be a "minority" by larger social status due to the uniqueness of living in a majority Hispanic community. It was not until they started dialoging with other students that this recognition occurred or if they left Miami to visit other places outside of this community.

\section{A universal connection to other immigrant or diasporic communities. Not to} contradict the previous conclusion that difference is contextual; however throughout the process of exploring what it meant to be a Cuban American woman, it can be concluded that there was some common, universal connection to other immigrant populations. While there are differences in the sociopolitical and immigration patterns of Cuban Americans versus other immigrants to the United States, peer reviewers reflected that though the voices of the women participants, a universal sense of understanding the immigrant family experience became apparent. The peer reviewers' own journey of identity development that crosses the boundaries of gender, race, ethnicity, and even religion from the Cuban American women emerged as they read the oral histories and stories of these women. I consider this an unintentional finding, but believe this understanding strengthens the importance of learning about groups different from one's own. This research allows the reader to engage in their own personal journey and discover that perceived differences and sometimes "otherness" are often those things that unite us.

6. Redefining the term bicultural in a majority minority environment. When the discussions of biculturalism emerged in the interviews, all of the participants self 
reported as bicultural. Bicultural as it was defined in the interviews was a person with a high level of acculturation to the dominant culture and a high level of ethnic identity and who indicated a preference to function competently in both the Hispanic and Anglo cultures. Most work with diverse populations has occurred in predominantly Anglo cultures, not in environments where the majority of people were of "minority" status (Torres, 1999, 2003, 2004a, 2004b). These women all claimed to be bicultural because they felt that they could function in an Anglo culture while holding true to their Cuban ethnic identity. What was interesting and a slight disconnect to what they said was when these women described interactions outside of Miami. Though they claimed to be and were American, often they felt "different" when they were in an Anglo dominant community. By self report, all of them felt competent in the Anglo communities, but their sense of self was challenged by the actions of others in those situations. For most, it was the first time that they had faced some type of discrimination. So bicultural as it is defined currently in the research may not be applicable to all Hispanics in all situations.

\section{A multi lens approach to understanding identity development is more beneficial} than singular lens. As the data from the interviews were sorted and coded, it became apparent that understanding the experiences of the Cuban American woman college student was more complete when examined from multiple perspectives simultaneously. Research in identity development historically uses a psychosocial approach, which is important to understanding the intra psychic processes that occur in identity development. Studies on ethnic identity have examined identity development from a sociological and/or anthropological 
approach (Geertz González, 2008; Portes \& Stepick, 2003; Stepick et al., 2003), often not considering the psychosocial development issues that are occurring. Through this qualitative study of the experiences of Cuban American women attending an HSI, it can be said that examining through a sociological, psychological, and an anthropological lens completes a picture of how these women view themselves.

\section{Recommendations}

\section{Recommendations for Research}

The following are recommendations for further research and practice based on the findings and conclusions. The recommendations are specific to this study and offer suggestion for further research in the area of Cuban American students in higher education as well as general research recommendations about students attending Hispanic serving or minority serving institutions.

1. Conduct more studies on Cuban American women and student involvement at HSIs. Since there is a lack of research on Cuban American students, in particular women at HSIs, it is recommended that further studies on leadership development, student involvement, and identity developed factors specifically for Cuban American women be considered.

2. Take a comparative look at Cuban American women attending an HSI versus a PWI. Based on the findings of this study completed at an HSI and the input of the one transfer student who attended a PWI, it would be important to examine the experiences of Cuban American women attending a PWI in Florida or a comparison study at both. Based on the interviews, each of the women had friends 
or acquaintances and shared third party testimony of what it was like to be a minority student in a White dominant university setting. Examining the experiences of Cuban American women attending both types of universities would add to the existing research and give further insight to the identity development of Cuban American women attending college.

3. Study gender identity development of Cuban American male and Cuban American female students attending an HSI. An exploration of gender differences would be an interesting area to investigate. It is clear that gender roles and expectations in the Cuban American household do have an influence on self worth and value in development. A comparative examination would give some insight as to how those differences affect identity development. Alternatively, the current study could be replicated with males. Although it was beyond the scope of this dissertation, the lack of literature on Cuban American males is also problematic.

4. Continue the examination of the changing HSI. Much of the literature about the Hispanic student population attending HSIs is based on the 2-year community college. A comparative look at the changing HSI at the community college and at 4-year public research university (Florida to Texas) would be an important addition to the existing research on Hispanic students in higher education.

5. Conduct and examination of experiences of Cuban American women versus other Hispanic women of different descent and experience at an HSI. After the completion of this study, it became apparent that due to the diverse nature of Hispanic women at FIU, a study looking at those differences would be interesting to examine. There are some distinct and similar differences and commonalities 
between Cuban American women and women of different Hispanic or Latin American decent including the relationship with family, religion, and cultural pride. A study investigating those differences and similarities would add to the existing literature about Hispanic women attending an HSI.

\section{Recommendations for Practice}

1. Conduct focus groups for Cuban American women. During focus groups, the women had an opportunity to meet each other briefly. It was clear that upon introduction, each of the women felt a camaraderie as a participant in this study. A few of the women recognized each other and a cultural bonding was evident. For many of the participants, there was a sadness that the process of interviewing was over. Many of them expressed that this was the first time that anyone had asked them such thought provoking and personal questions about their life as a Cuban American woman. Most found it to be an emotional and reflective exercise about their lives. A recommendation for future practice would include continuing this dialogue, possibly informally through the Women's Center or the Office of Multicultural Programs and Services, giving these women an outlet to speak about their experiences. This reflective experience is important to helping the women articulate their educational process and how it has benefited them. Focus groups are an excellent way for these women to embrace their cultural and ethnic heritage which can be empowering, as noted throughout the interview process.

2. Offer more courses with content focus on the experience of Cuban American women. Due to the uniqueness of the social immigration issues in Miami, 
offering a course or courses about the Cuban American experience with a focus on women would be an excellent opportunity to bridge the understanding between the groups of students on the campus. Integration of this material about being a first or second generation immigrant could also be a component, as this is an issue with many of students, not just Cuban American students.

3. Support the implementation of student clubs and organizations. While there are currently students clubs and organizations on campus with the focus being a Cuban American student at FIU, there is no club solely for the Cuban American women. While some Cuban American women may not feel comfortable with discussion groups, some may feel empowered by speaking with other women who share some of the same issues. This group could provide and outlet for them to discuss social, emotional, and/or familial issues that are relevant to them.

\section{Summary}

The purpose of this study was to gain an understanding and gather insights into the experiences of Cuban American women attending a 4-year public HSI and how those experiences influenced their identity development. This was accomplished by conducting in-depth interviews and focus groups with 12 self-identified Cuban American women who were classified as sophomores, juniors, seniors, or graduate students. All of the participants had attended FIU for at least 1 year. The women had varying degrees of involvement in on and off campus academic and campus activities. Based on the coding of the data provided by the participants, six themes were formed: (a) family, (b) cultural influences, (c) gender, (d) ethical and moral development, (e) education, and (f) ethnicity. 
The themes were all found to be interconnected and related to each other as they related to the idea of identity development including education. Education, it can be concluded, was a major factor in personal growth for these women. It can be concluded from this study that identity development for first and second generation Cuban American women attending college is complex. It was not easy to identify if there was one factor that was more important than another in terms of identity development. Gender is a factor that other factors had direct relationship to as part of the findings. The notion of biculturalism as it has been presented in the literature was also challenged in such that the idea that culture is contextual and this was important in this bounded case study.

It can also be said that by looking at identity through a multidimensional lens is essential. Looking at personal growth and development from an anthropological, sociological, and psychosocial lens gave greater insight to the exploration of a population of students who have been largely underrepresented in the literature. It also suggests that one-dimensional theories, though useful, are incomplete.

The findings and recommendations from this study have been summarized and presented in this chapter for members of the academy, both academic faculty and members of the university who work with minority student populations, in the hopes that it will enable those who work with diverse populations to understand a growing population within the Hispanic community. It was my intention as well to do a gender specific study to also lend more insight into the differences and uniqueness of Hispanic women who are oftentimes misunderstood in the literature. 


\section{REFERENCES}

Akens, C. A. (2001). Students' recollections of participating in a first year residential learning community experience. Unpublished Dissertation, Florida International University, 2001, Florida International University.

Alverez, C., Bliss, L. A., \& Vigil, P. (2001). Cuban identity: A preliminary study (No. ED 454 316) Retrieved from ERIC database.

Arana, M. (2001). The elusive Hispanic/Latino identity. Nieman Reports, 55(2), 8.

Astin, A.W. (1977). Four critical years: Effects of college on beliefs, attitudes, and knowledge. San Francisco, CA: Jossey-Bass.

Bliss, L., \& Sandiford, J. (2003). The effects of institutional culture on study strategies of Hispanic students as measured by the inventario de comportamiento de estudio, the spanish version of the study behavior inventory. Journal of Hispanics in Higher Education, 2, 203-220.

Bogdan, R.C., \& Bilken, S. (2003). Qualitative research for education: An introduction to theories and methods. Boston, MA: Allen and Bacon.

Bohr, L., Pascarella, E., \& Nora, A (1995). Do Black students learn more at historically Black or predominantly White colleges? Journal of College Student Development, 36(January/February), 75-85.

Castellanos, J., \& Jones, L. (2003). The majority in the minority expanding the representation of Latinalo faculty, administrators, and students in higher education. Sterling, VA: Stylus Publications.

Creswell, J. W. (1998). Qualitative inquiry and research design: Choosing among five traditions. Thousand Oaks, CA: Sage Publications.

Dayton, B., Gonzalez-Vasquez, N., \& Martinez, C. R. (2004). Hispanic serving institutions through the eyes of students and administrators. New Directions for Student Services, (105), 29-40.

Denzin, N. K., \& Lincoln, Y. S. (Eds.). (1998). Strategies of qualitative inquiry. Thousand Oaks, CA: Sage Publications.

DeSousa, D. J., \& Kuh, G. D. (1996). Does institutional racial composition make a difference in what Black students gain from college? Journal of College Student Development, 37, 257-267. 
Evans, N. J., Forney, D., \& Guido-DiBrito, F. (1996). Student development in college: Theory, research, and practice. San Francisco, CA: Jossey-Bass.

Ferdman, B. M. \& Gallegos, P. I. (2001). Latinos and racial identity development. In C. L. Wijeyesinghe \& B. W. Jackson III (Eds.), New perspectives on racial identity development: A theoretical and practical anthology (pp. 32-66). New York: New York University Press.

Florida International University. (2008). Retrieved September 23, 2008, from http://www.fiu.edu

Gardner, S. (2003). ACE minorities in higher education 2001-2002 report: Generate enlightened comments; experts size up realities and propose solutions. The Hispanic Outlook in Higher Education, 13(16), 10.

Geertz Gonzalez, R. (2007a). College student spirituality at a Hispanic serving institution. Journal of College and Character, 9(4), 2-26.

Geertz Gonzalez, R. (2007b). Ethnic identity at a majority Hispanic serving institution. Unpublished manuscript.

Geertz Gonzalez, R. (2008).College student civic development and engagement at a Hispanic serving institution. Journal of Hispanic Higher Education, 7, 287-300.

Gilligan, C. (1982). In a different voice: Psychological theory and women's development. Cambridge, MA: Harvard University Press.

Gonzalez, K. P., Jovel, J. E., \& Stoner, C. (2004). Latinas: The new Latino majority in college. New Directions for Student Services, (105), 17-27.

Hamrick, F., Evans, N. J., \& Schuh, J. H. (2002). Foundations of student affairs practice: How philosophy, theory, and research strengthen educational outcomes. San Francisco, CA: Jossey Bass.

Hatch, A. J. (2002). Doing qualitative research in education settings. Albany, NY: State University of New York Press.

Hernandez, J. C. (2002). A qualitative exploration of the first-year experience of Latino college students. NASPA Journal, 46(1), 69-84. Retrieved from Wilson Web database.

Huberman, M. A., \& Miles, M. B. (1994). Qualitative data analysis ( $2^{\text {nd }}$ ed.). Thousand Oaks, CA: Sage Publications. 
Hurtado, S., Milem, J., Clayton-Pederson, A., \& Allen, W. (1999). Enacting diverse learning environments: Improving the climate for racial/ethnic diversity in higher education (ASHE-ERIC Higher Education Report No. 8, 1-116) Retrieved from Wilson Web database.

Johnson, B., \& Christensen, L. (2004). Educational research: Quantitative, qualitative, and mixed approaches (2nd). Boston, MA: Pearson.

Jones, S. R. (1997). Voices of identity: A qualitative exploration of the multiple dimensions of identity development in women college students. Journal of College Student Development, 1-11.

Josselson, R. (1987). Finding herself: Pathways to identity development in women. San Francisco, CA: Jossey-Bass.

Josselson, R. (1996). Revising herself: The story of women's identity from college to midlife. New York, NY: Oxford University Press.

Keefe, S. E. \& Padilla, A. M. (1987). Chicano ethnicity [electronic resource]. Albuquerque, NM: University of New Mexico Press.

Kenny, M. E., \& Stryker, S. (1996), Social network characteristics and college adjustment among racially and ethnically diverse first-year students. Journal of College Student Development, 37, 649-658.

Kirsch, G. (1999). Ethical dilemmas in feminist research: The politics of location, interpretation, and publication. Albany, NY: State University of New York.

Komives, S. R., \& Woodward, D. B. (Eds.). (2003). Student services: A handbook for the profession ( $4^{\text {th }}$ ed.). San Francisco, CA: Jossey Bass.

Laden, B. V. (1998). An organizational response to welcoming students of color. New Directions for Community Colleges, (102), 31-41.

Lincoln, Y. S., \& Guba, E. G. (1985). Naturalistic inquiry. Beverly Hills, CA: Sage.

Madriz, E. (2003). Using focus groups with lower socioeconomic status Latina women. Qualitative Inquiry, 4(1), 114.

Merton, R. K., Fiske, M., \& Kendall, P. L. (1990). The focused interview: A manual of problems and procedures. ( $2^{\text {nd }}$ ed.). London: Collier MacMillan.

McGlynn, A. P. (2004). Nurturing Hispanics to four-year degrees. The Education Digest, $69(5), 51-56$. 
Miles, M. B., \& Huberman, A. M. (1994). Qualitative data analysis ( $2^{\text {nd }}$ ed.). Thousand Oaks: CA: Sage.

Montell, F. (1999). Focus group interviews: A new feminist method. NWSA Journal, 11(1), June 24, 2005.

National Center for Educational Statistics. (2006). Retrieved June 7, 2006, from http://nces.ed.gov/index.asp.

Newman, I., \& Benz, C. R. (1998). Qualitative-quantitative research methodology: Exploring the interactive continuum. Carbondale, IL: University Press.

Pew Hispanic Center. (2008). Retrieved June 2006, 2007, from http://pewhispanic.org/.

Poindexter-Cameron, J. M., \& Robinson, T. L. (1997). Relationships among racial identity attitudes womanist identity attitudes, and self-esteem in African American college woman. Journal of College Student Development, 38, 288-296.

Portes, A., \& Rumbaut, R.G. (2006). Immigrant America: A portrait ( $3^{\text {rd }}$ ed.). Berkley, CA, University of California Press

Portes, A., \& Stepick, A. (1994). City on the edge: The transformation of Miami (2 ${ }^{\text {nd }}$ ed.). Berkeley, CA: University of California Press.

Rendón, L., \& Hope, R. (1996). Educating a new majority. San Francisco,CA: Jossey Bass.

Rodriguez, A. L., Guido-DiBrito, F., \& Torres, V. (2000). Latina college students: Issues and challenges for the 21st century. NASPA Journal, 37(3), 511-527.

Santos, M. (2004). The motivations of first-semester Hispanic two-year college students. Community College Review, 32(3), 18-34.

Seidman, I. (1991). Interviewing as qualitative research: A guide for researchers in education and the social sciences. New York, NY: Teacher College Press.

Stepick, A., Grenier, G., Castro, M., \& Dunn, M. (2003). This land is our land: Immigrants and power in Miami. Berkley, CA: University of California Press.

Szapocznik, J., and Kurtines, W. Acculturation, biculturalism, and adjustment among Cuban Americans. In A.M. Padilla (Ed.), Psychological Dimensions on the Acculturation Process: Theory, Models, and Some New Findings. Boulder, CO: Westview. 
Tanaka, G. K. (2002). Higher education's self-reflexive turn: Toward an intercultural theory of student development. The Journal of Higher Education, 73(2), 263-296.

Torres, V. (1999). Validation of a bicultural orientation model for Hispanic college students. Journal of College Student Development, 40(3), 285-299.

Torres, V. (2003). Influences on ethnic identity development of Latino college students in the first two years of college. Journal of College Student Development, 44(4), 532.

Torres, V. (2004a). Familial influences on the identity development of Latino first-year students. Journal of College Student Development, 45(4), 457-469. Retrieved from http://muse.jhu.edu/journals/journal_of_college_student_development/v045/45.4torr es.html.

Torres, V. (Spring 2004b). The diversity among us: Puerto Ricans, Cuban Americans, Carrribean Americans, and Central and South Americans. New Directions for Student Services, (105), 5-16.

Torres, V., \& Baxter Magolda, Marcia B. (2004). Reconstructing Latino identity: The influence of cognitive development on the ethnic identity process of Latino students. Journal of College Student Development, 45(3), 333-347. Retrieved from http://muse.jhu.edu/journals/journal_of_college_student_development/v045/45.3torr es.html.

Torres, V., Howard-Hamilton, M., \& Cooper, D. (2003). Identity development of diverse populations: Implications for teaching and administration in higher education (ASHE-ERIC Higher Education Report No. 29 (6). San Francisco, CA: Jossey-Bass.

Tweed, T. A. (1997). Our lady of the exile: Diasporic religion at a Cuban Catholic shrine in Miami. New York, New York: Oxford University Press.

Walker, R.L., Wingate, L.R., Obasi, E.M., \& Joiner Jr., T.E. (2008), An empirical investigation of acculturative stress and ethnic identity as moderators for depression and suicidal ideation in college students. Cultural Diversity and Ethnic Minority Psychology. 14(1), Jan 2008, 75-82.

Wijeyesinghe, C. L., \& Jackson, Baily W. III (Eds.). (2001). New perspectives on racial identity development: A theoretical and practical anthology. New York, NY: New York University Press.

Wolcott, H. F. (2001). Writing up qualitative research $\left(2^{\text {nd }}\right.$ ed.). Thousand Oaks, California: Sage. 
Wolf-Wendel, L. E. (1998). Models of excellence: The baccalaureate origins of successful European American women, African American women, and Latinas. Journal of Higher Education, 69, 141-86. Retrieved from Wilson Web database.

Wood, A.G. (2008). Borderlands: an encyclopedia of culture and politics on U.S. Mexico divide. Westport, Connecticut: Greenwood Publishing Group. 
Appendix A

Sample Recruitment Advertisement

Research Study Being Conducted at FIU

\section{Wanted: Cuban American women college students}

Looking for approximately ten students to participate in interviews about the experiences of Cuban American women college students attending FIU and the influences of these experiences on identity development.

Participants must meet the following criteria: Must be Cuban American

Must be female

Must be 18-25 years old

Must have attended FIU for at least one year

All participants will be asked to meet with the researcher on three (3) occasions for approximately $1-2$ hours each time. Participants will be minimally compensated for their time in the study.

If interested or would like more information, please contact Vicky Owles at 786-208-4859 or via email at owlesv@fiu.edu 
Appendix B

Letter to Potential Participants

August 31, 2007

Name

Address

Dear:

I am writing to request your participation in a study. I am currently a doctoral candidate in the College of Education here at FIU. Some of you may also know me in my role as the Associate Director of Campus Life and Orientation. For my dissertation, I am planning to conduct a study about the experiences of Cuban American female college students. The purpose of my study is to examine the experiences of being a Cuban American female college student attending a Hispanic Serving Institution (FIU) and how those experiences influence identity development of these women.

Your participation in this study is requested because of you have been identified as a participant who fits the necessary requirements for this study (Cuban American female, age $18-25$, and with at least one year of college). Participating in the study would require approximately two occasions for $1-2$ hours (individually) and one occasion for 1-2 hours (group interview), as well as time either in person or electronically for 1-2 hours to review summary information compiled from my interview(s). The interviews will, with your permission, be tape recorded and/or videotaped and transcribed. To maintain confidentiality, you will not be identified by your name on the tape, nor will your name be used in my writing. You will be minimally compensated for your time in the study if you are selected.

So that you have a better understanding of what would be required of you, I have attached a sample of a consent form that outlines your rights and that any participants would be asked to sign. I am not asking you to sign this now. Rather, my intention is to follow up with you by phone in the coming week to talk with you individually about your interest and to answer any questions that you may have. I will select approximately 10 students as participants. I appreciate your thoughtful consideration of my request.

I look forward to talking to you soon.

Vicky Owles

owlesv@fiu.edu

(786)208-485 


\section{Appendix C \\ Participant Consent Form}

\section{AN EXAMINATION OF THE EXPERIENCES OF CUBAN AMERICAN FEMALES ATTENDING A HISPANIC SERVING INSTITUTION AND THE INFLUENCES ON INDENTITY DEVELOPMENT}

I freely and voluntarily consent to be a participant in the research project listed above to be conducted at Florida International University during the fall 2007 and spring 2008 semesters with Vicky Owles, as principal investigator. I have been told that my involvement will require approximately 3-6 hours total of my time.

I understand that the purpose of this research is to examine the experiences of Cuban American female college students attending a Hispanic Serving Institution and how that has influenced identity development of the participants.

I understand that the research procedures will be as follows: I will be interviewed on two occasions for 1-2 hours (individually) and for one occasion for approximately 1-2 hours (group interview). I will be asked to talk about my experiences as a Cuban American female college student and about my family and college experiences. I will determine how much information I wish to share with the researcher. I may also be asked to meet with the researcher or contacted via electronically to review summary information collected from my interview(s).

I understand that there are no known risks or benefits involved in this project. I further understand that my identity will be considered strictly confidential. I understand that a pseudonym will be used in place of my actual name in the research. I understand that there are approximately ten students participating in this study.

I understand that I may withdraw my consent and discontinue participation in this research project at any time with no negative consequences. I have been given the right to ask questions concerning the procedure and any questions have been answered to my satisfaction. I understand that if any new findings are developed during the time I am in the study, which affect my willingness to continue to be in the student, I will be informed as soon as possible.

I understand that if I desire further information about this research, I should contact Dr. Glenda Droogsma Musoba, Department of Educational Leadership and Policy Studies, at 305-348-2450. I also understand that if I have any questions concerning the rights of human subjects, I may contact Dr. Patricia Price at 305348-2618 or 305-348-2494. If you have questions, need to contact me, or would like additional information, you may contact me at any time at (786) 208-4859 or via email at owlesv@ @iu.edu.

Your signature below indicates that you have read this document, that all of your questions have been answered, that you are aware of your rights and that you would like to participate in the study.

Signature of Participant

Printed Name

Date

I have explained the research procedure, subject rights and answered questions asked by the participant. I have offered her a copy of this consent form.

Signature of Witness

Date 


\section{Appendix D \\ Sample Interview Questions}

1. Tell me about yourself.

2. Tell me about your family.

3. Do you live on campus or at home?

4. (if home) How is the experience of living at home versus living off campus?

5. Did you ever consider moving away for school or was FIU your only option.

6. How important is your family to you?

7. What are some of the values that you hold that you feel your family contributed to?

8. What does being female mean to you?

9. Tell me what being Cuban American means to you.

10. What about being a Cuban American female?

11. Can you recall a time when you consciously remember being Cuban American?

12. (if yes) What were the circumstances involved and how did it make you feel?

13. Was this at FIU or somewhere else?

14. What influenced your decision to attend FIU versus another school?

15. Tell me about your general experiences of being an FIU student?

16. Has being here at FIU changed you since you started?

17. Is there any experience that you can remember that had an impact on you?

18. Tell me your thoughts on the diverse nature of FIU.

19. What does it mean to be Cuban American at FIU?

20. What are some of you aspirations or dreams for the future?

21. Do you think you will stay in Miami or move away?

22 . What do you think your family desires for you in the future?

23. Was there ever a time that you felt that being a Cuban American was a hindrance?

24. Was there ever a time that you felt different for either being female or Cuban American or both?

25. What are your thoughts on Cuban students who identify themselves as being "White" and not Cuban?

26. How does that make you feel?

27. How do you think other racial or ethnic groups perceive Cubans living in Miami/at FIU?

28. What about people that live outside of Miami... what do you think their perceptions are of Cubans living in Miami? 
Appendix E

Description of the Torres Bicultural Model of Orientation used by the participants to self place into a quadrant based on definition

\begin{tabular}{|c|c|}
\hline Bicultural Orientation & Latino/a Orientation \\
\begin{tabular}{|c|} 
high level of acculturation and a \\
high level of ethnic identity
\end{tabular} & $\begin{array}{r}\text { low level of acculturation and high } \\
\text { level of ethnic identity }\end{array}$ \\
\hline $\begin{array}{c}\text { Anglo Orientation } \\
\text { high level of acculturation and low } \\
\text { level of ethnic identity }\end{array}$ & $\begin{array}{r}\text { Marginal Orientation } \\
\text { low level of acculturation and a } \\
\text { low level of ethnic identity }\end{array}$ \\
\hline
\end{tabular}

The Bicultural Orientation Model (BOM) was introduced in a pilot study (Torres \& Phelps,1997). The model is composed of four quadrants, created by intersecting acculturation and ethnic identity. A person with a high level of acculturation and a high level of ethnic identity has a Bicultural Orientation, indicating a preference to function competently in both the Hispanic and Anglo cultures. A person with a high level of acculturation and low level of ethnic identity has an Anglo Orientation, indicating a preference to function within the Anglo culture. A person with a low level of acculturation and high level of ethnic identity has a Hispanic Orientation, indicating a preference to function with the Hispanic culture. A person with a low level of acculturation and a low level of ethnic identity is considered Marginal, indicating that he or she is not able to function adequately within the Hispanic or Anglo cultures. 
VITA

\section{VERONICA OWLES}

December 21, 1966

1989

1993

$1991-1993$

$1993-1996$

$1996-1999$

$1999-2001$

$2001-2005$

2002 - present

2005 - present

2008 - present
Born, Ft. Dix, New Jersey

B.S., Psychology

Longwood University

Farmville, Virginia

M.Ed., Counseling and Development, Higher Education

George Mason University

Fairfax, Virginia

Graduate Hall Coordinator

George Mason University

Fairfax, Virginia

Residence Director

College of New Jersey

Trenton, New Jersey

Area Coordinator

Georgetown University

Washington, District of Columbia

Dean of Students

Miami Country Day School

Miami, Florida

Assistant Director for Campus Life, UP

Florida International University

Miami, Florida

Adjunct Instructor

Freshman Seminar, SLS 1501

Florida International University

Associate Director for Campus Life \& Orientation, BBC

Florida International University

Miami, Florida

Adjunct Instructor

Gay and Lesbian in America, WST 3641

Miami, Florida 
